\title{
KRAKOW CLEAN FOSSIL FUELS AND ENERGY EFFICIENCY PROGRAM
}

\section{INTERIM REPORT}

\author{
T. Butcher, B. Pierce, and C.R. Krishna \\ Energy Efficiency and Conservation Division \\ Department of Applied Science \\ Brookhaven National Laboratory \\ Upton, NY 11973
}

\section{SEPTEMBER 1992}

\section{DISCLAIMER}

\begin{abstract}
This report was prepared as an account of work sponsored by an agency of the United States Government. Neither the United States Government nor any agency thereof, nor any of their employees, makes any warranty, express or implied, or assumes any legal liability or responsibility for the accuracy, completeness, or usefulness of any information, apparatus, product, or process disclosed, or represents that its use would not infringe privately owried rights. Reference herein to any specific commercial product, process, or service by trade name, trademark, manufacturer, or otherwise does not necessarily constitute or imply its endirsement, recommendation, or favoring by the United States Government or any agency thereof. The views and opinions of authors expressed herein do not necessarily state sir reflect those of the United States Government or any agency thereof.
\end{abstract}

This work was performed under the auspices of the U.S. Department of Energy Vashington, D.C. Under Contract No. DE-AC02-76CH00016 


\section{TABLE OF CONTENTS}

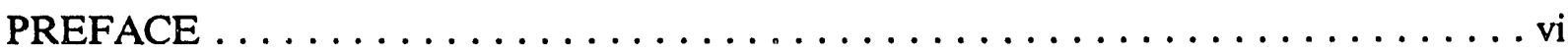

1. PROJECT OVERVIEW $\ldots \ldots \ldots \ldots \ldots \ldots \ldots \ldots \ldots \ldots \ldots \ldots \ldots \ldots \ldots$

BACKGROUND ........................... 1-1

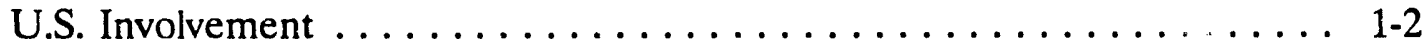

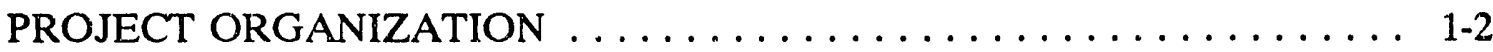

District Heating ......................... 1-3

Converting Old Town Solid Fuel-Fired Boilerhouses

to Natural Gas . . . . . . . . . . . . . . . . . . . . . 1-4

Selected Conversion of Home Stoves to Electric Heat . . . . . . . . . . . 1-4

Modernization of Boilerhouses . . . . . . . . . . . . . . . . . . 1-4

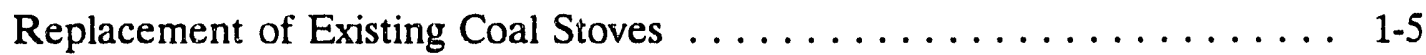

References .......................... 1-5

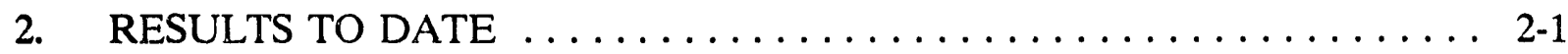

CHARACTERISTICS OF KRAKOW'S LOW EMISSION SOURCES . . . . . 2-1

References .......................... 2-3

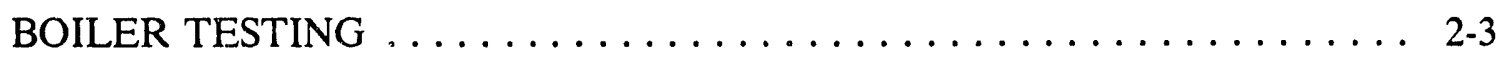

Results of Tests at the Balicka Boiler House $\ldots \ldots \ldots \ldots \ldots \ldots$ 2-3

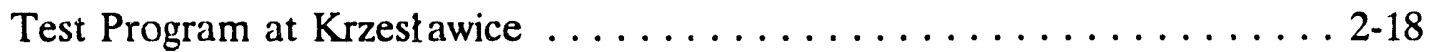

References . . . . . . . . . . . . . . . . . . . . . . . . . 2-19

COAL STOVE TECHNOLOGY REVIEW . . . . . . . . . . . . . . . 2-19

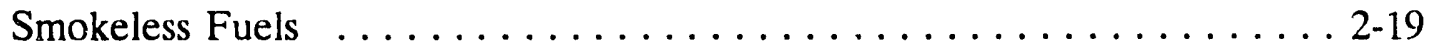

Smoke-Reducing Heaters . . . . . . . . . . . . . . . . . . 2-21

Discussion . . . . . . . . . . . . . . . . . . . . 2-24

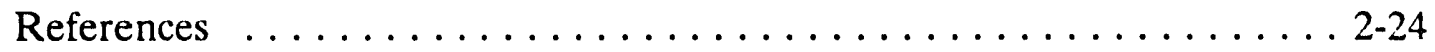

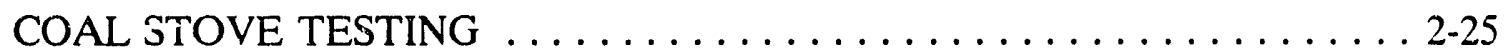

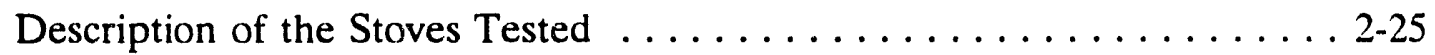

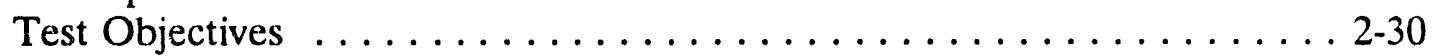

Test Fuels . . . . . . . . . . . . . . . . . . . . . . . . 2-30

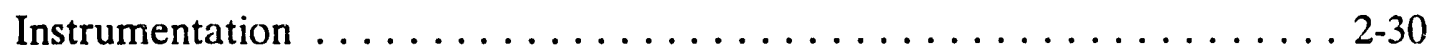

Test Plan .............................

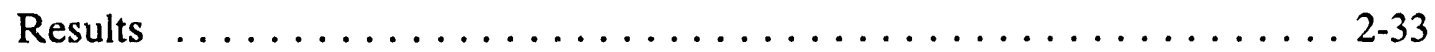

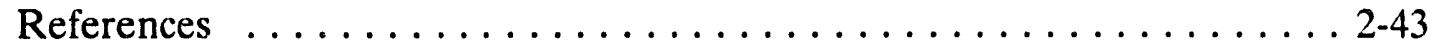




\section{TABLE OF CONTENTS (Continued)}

FUEL PRICE PROJECTIONS $\ldots \ldots \ldots \ldots \ldots \ldots \ldots \ldots \ldots \ldots \ldots \ldots \ldots . \ldots \ldots$

Natural Gas . . . . . . . . . . . . . . . . . . . . . 2 243

Electricity ............................. 2-44

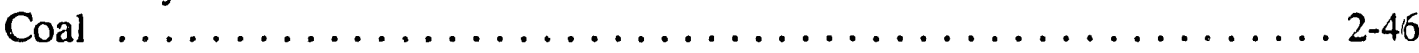

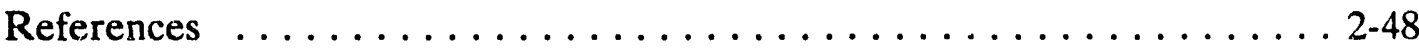

COSTS OF GAS CONVERSION $\ldots \ldots \ldots \ldots \ldots \ldots \ldots \ldots \ldots \ldots \ldots \ldots . \ldots \ldots$

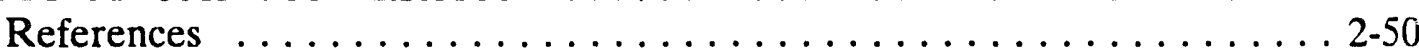

AIR POLLUTION FEES AND PENALTIES . . . . . . . . . . . 2-50

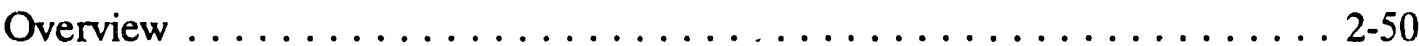

Impact on Gas Conversions in Old Town .............. 2-53

References ............................ 2-57

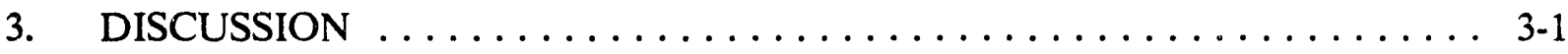

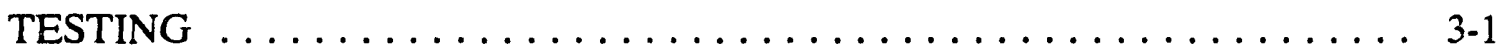

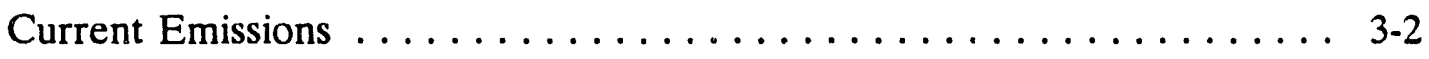

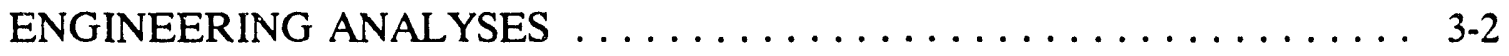

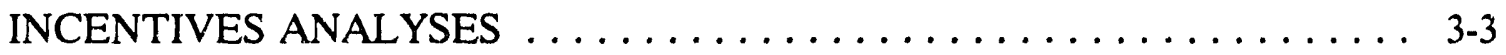




\section{LIST OF FIGURES}

Figure 2-1 Comparison of the Size Distribution of the Tested Fuels with Limits Recommended by the American Boiler Manufacturers

Association . . . . . . . . . . . . . . .

Figure 2-2 Test Boiler at the Balicka Site and Arrangement of Flue Gas

Sampling Equipment $\ldots \ldots \ldots \ldots \ldots \ldots \ldots \ldots \ldots \ldots \ldots \ldots \ldots$

Figure 2-3 Fuel Effects: Comparison of Emissions for Three Fuels Tested at Balicka. With Main Air Damper 100\% Open and No Overfire Air ........................... 2-16

Figure 2-4 Overfire Air Effects: Comparison of Emissions With and Without Overfire Air: Washed and Unwashed Staszic Coal. Main Air

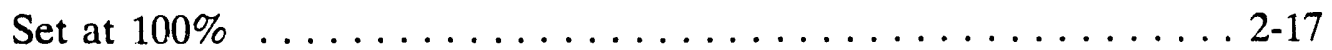

Figure 2-5 Example of a Smoke-Reducing Heater for Bituminous Coal . . . . . 2-22

Figure 2-6 Example of a Smoke-Reducing Heater for Bituminous Coal . . . . . 2-23

Figure 2-7 Vertical Cross-Section of Polish Tile Stove Showing

First and Second Passes .................. 2-26

Figure 2-8 Vertical Cross-Section of Polish Tile Stove Showing

First and Third Passes ................... 2-27

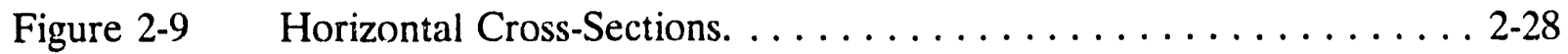

Figure 2-10 Location of Internal Thermocouples . . . . . . . . . . . . . . . 2-29

Figure 2-11 Illustration of Dilution Tunnel System for Emissions and

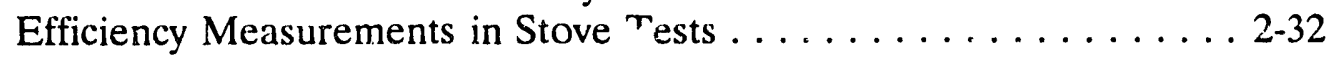

Figure 2-12 Emission of $\mathrm{CO}_{2}$ and $\mathrm{CO}$ trom Tile Stove During a Typical

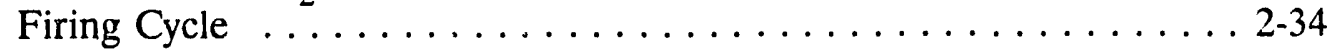

Figure 2-13 Emission of $\mathrm{SO}_{2}$ and $\mathrm{NO}_{\mathrm{x}}$ from Tile Stove During a Typical

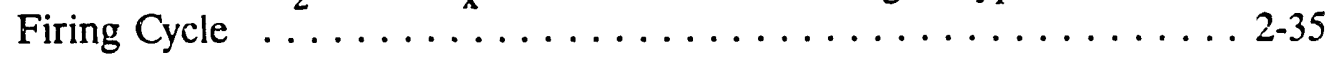

Figure 2-14 Tile Stove - Stove Exit Temperature and Thermal Energy Loss Rate During a Typical Firing Cycle $\ldots \ldots \ldots \ldots \ldots \ldots . \ldots 2-36$ 


\section{LIST OF FIGURES (Continued)}

Figure 2-15 Tile Stove - Stove and Dilution Tunnel Flow Parameters

During a Typical Firing Cycle .................. 2-37

Figure 2-16 Tile Stove - Trends in Internal Temperature During a Typical 20 Hour Cycle . . . . . . . . . . . . . . . . . . . 29

Figure 2-17 Tile Stove - Trends in Internal Temperatures During the Firing Part of a Cycle ....................... 2-40

Figure 2-18 Forecast Range of Natural Gas Prices for Individual

Consumers ............................ 2-45

Figure 2-19 Forecast Natural Gas Prices Based on World Bank Forecast . . . . . 2-45

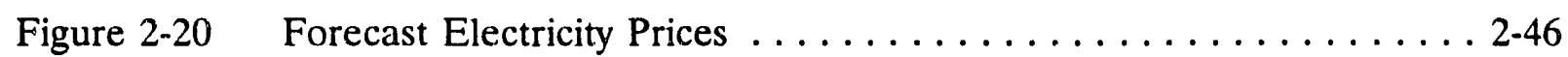

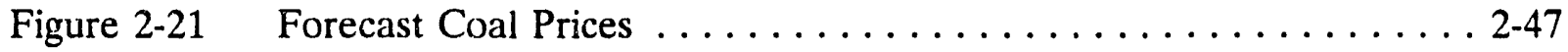

Figure 2-22 Forecast Prices for Individual Consumers of Coal-Derived Fuels ........................... 2-47

Figure 3-1 Estimated Current Emissions, by Equipment Type $\ldots \ldots \ldots \ldots$ 3-3 


\section{LIST OF TABLES}

Table 2-1 Solid Fuel-Fired District Heating Boilers in Krakow, 1990 . . . . . 2 2-2

Table 2-2 Distribution of Smaller, Single Room, Flat, or Building

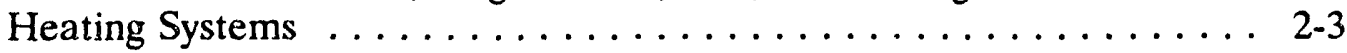

Table 2-3 Analysis of Fuels Tested at Balicka $\ldots \ldots \ldots \ldots \ldots \ldots \ldots . \ldots \ldots$

Table 2-4 Results of Baseline Tests with Coal from Ziemowit Mine . . . . . . 2-9

Table 2-5 Results of Tests with Unwashed Coal from the Staszic

Mine - No Overfire Air . . . . . . . . . . . 2 . 10

Table 2-6 Results of Tests with Unwashed Coal from the Staszic

Mine - Full Overfire Air .................... 2-11

Table 2-7 Results of Tests with Washed Coal from the Staszic

Mine - No Overfire Air $(1$ of 2$) \ldots \ldots \ldots \ldots \ldots \ldots \ldots \ldots \ldots \ldots \ldots \ldots \ldots \ldots .12$

Table 2-7 Results of Tests with Washed Coal from the Staszic

Mine - No Overfire Air $(2$ of 2$) \ldots \ldots \ldots \ldots \ldots \ldots \ldots \ldots \ldots \ldots \ldots \ldots .13$

Table 2-8 Results of Tests with Washed Coal from the Staszic

Mine - Full Overfire Air $(1$ of 2$) \ldots \ldots \ldots \ldots \ldots \ldots \ldots \ldots \ldots \ldots \ldots \ldots .14$

Table 2-8 Results of Tests with Washed Coal from the Staszic

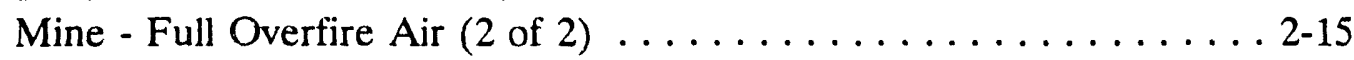

Table 2-9 Typical Analysis of Mineral Solid Fuels Used in U.K.

Residential Heating ........................ 2-20

Table 2-10 Analysis of Coal Stove Test Fuels $\ldots \ldots \ldots \ldots \ldots \ldots \ldots . . \ldots .2-31$

Table 2-11 Summary of the Tile Stove Tests Results - Normal

Operating Conditions ..................... 2-41

Table 2-12 Summary of Cast Iron Stove Test Results . . . . . . . . . . . . 2-41

Table 2-13 Tile Stove - Results of Tests with Both Doors Fully

Opened for the Entire Firing Cycle $\ldots \ldots \ldots \ldots \ldots \ldots \ldots \ldots \ldots \ldots \ldots \ldots .42$

Table 2-14 Tile Stove - Results of Tests with Doors Opened for

One Extra Hour . . . . . . . . . . . . . . . . . . . . . 


\section{LIST OF TABLES (Continued)}

Table 2-15 Maximum Permissible Concentrations of Selected Air

Pollutants ............................. 2-51

Table 2-16 Maximum Permitted Emissions $\ldots \ldots \ldots \ldots \ldots \ldots \ldots \ldots \ldots . \ldots \ldots 2-52$

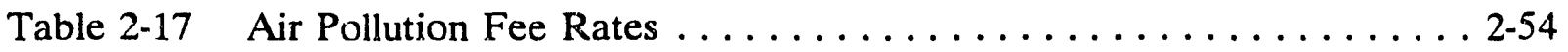

Table 2-18 Emission Factors for Fee Calculation . . . . . . . . . . . . 2-55

Table 2-19 Fees for Coal, Coke and Gas Boilers . . . . . . . . . . . . . . . . 2-57 


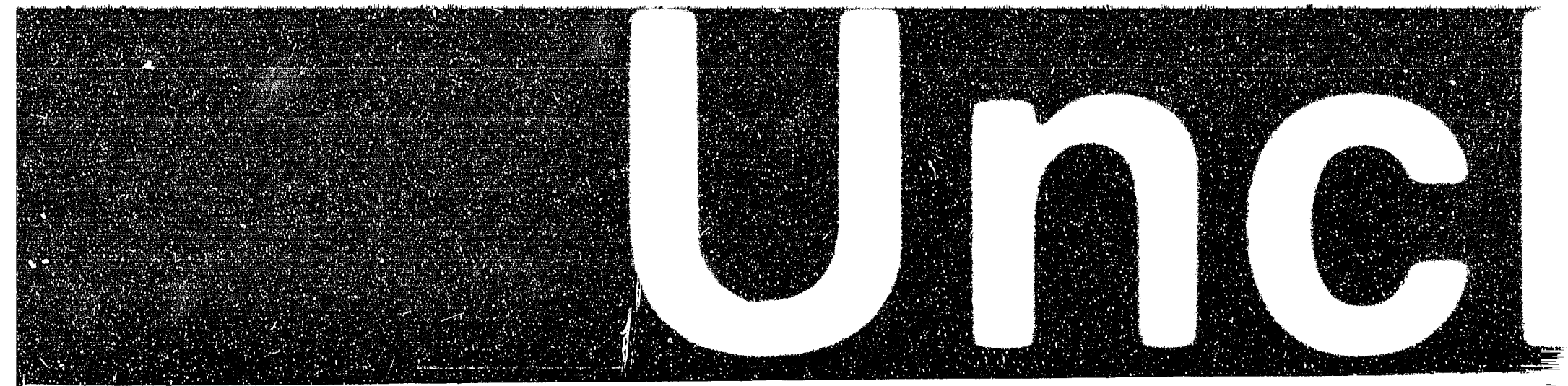

\section{PREFACE}

The information gathering phase of the Krakow Clean Fossil Fuels and Energy Efficiency Program began in the spring of 1991 and will continue to the fall of 1993. This report has been prepared as an information appendix to the Program Opportunity Notice \#DE-PN2292PC92178 (PON), issued by the Pittsburgh Energy Technology Center of the U.S. Department of Energy. Its purpose is to provide a summary of the results available to date.

For this BNL report, background information has been summarized and included in Chapter 1, Project Overview.

Many organizations have contributed to the work which is summarized in this report. On the U.S. side, in addition to Brookhaven National Laboratory, this includes the Pittsburgh Energy Technology Center and Burns and Roe Services Corporation. On the Polish side the primary lead for this phase of the work is the Krakow Development Office (Biuro Rozwoju Krakowa or BRK). Their subcontractors who have contributed to the work in this report include: the Academy of Mining and Metallurgy (AGH-coal stove testing), Polinvest Consultants (incentives analysis), City Prof (oversight and analysis), Krakow Polytechnik Institute (boiler testing), Ekopol (environmental regulations and air quality analysis), and the Krakow District Heat Utility (MPEC-boiler test site host). 


\section{PROJECT OVERVIEW}

The southern portion of Poland, around Krakow and Katowice, is one of the most heavily polluted areas in the world. Forty years of heavy industrialization, subsidized energy prices, and a general disregard for the environment have left a legacy of poisoned land, water, and air. The ancient Polish capital of Krakow is symbolic of both the environmental disregard of the old order and the commitment of the West to assist in improving the situation.

One of the few Medieval Eastern European cities to escape destruction in World War II, Krakow has been designated an international treasure by the United Nations. The "faceless statues" of Krakow attest to the severity of the pollution problem. On a visit to Poland in 1989, U.S. President George Bush stated: "Today, Krakow is under siege by pollutants. Its priceless monuments are being destroyed. Krakow must be reclaimed, and the United States will help" (PETC 1990). The project discussed in this paper is one part of that commitment.

\section{BACKGROUND}

Almost half of the energy used for heating in Krakow is supplied by low-efficiency boilerhouses and home coal stoves. Within the city, there are more than 1,300 boilerhouses with a total capacity of $1,071 \mathrm{MW}$, and about 100,000 home stoves. More than 600 boilerhouses and 60 percent of the home stoves are situated near the city center. These facilities are referred to as "low emission sources" because they have low stacks. They are the primary sources of particulates and hydrocarbons in the city, and major contributors of sulfur dioxide and carbon monoxide.

The air quality in Krakow has improved during the past decade, due primarily to the economic recession and decreased production at the nearby Sendzimir steel works. However, pollution from vehicles and the low emission sources has increased. In 1990, Krakow was estimated to be the most polluted town in Poland (Görlich 1992). Poor natural ventilation of the Krakow area, situated in the Vistula valley, and the frequent occurrence of thermal inversions contribute to the air quality problems in the town.

Seven permanent continuous air monitoring stations have been operating around Krakow since August, 1991. Data from this equipment allow observations on changes in air quality at the beginning of the heating season. Pollutant concentrations increase drastically with the onset of the heating season, and far exceed Polish standards.

In particular, $\mathrm{SO}_{2}$ concentrations show significant increases in downtown Krakow compared to areas of the city with district heating; local boilers and home stoves contribute up to 60 to 70 percent of local concentrations of sulphur dioxide and particulates during the heating season. On an annual basis, low emission sources contribute about 35 percent of ambient $\mathrm{SO}_{2}$ concentrations, and significantly higher percentages of $\mathrm{CO}$, particulate and phenol concentrations (Görlich 1992). 


\section{U.S. Invoivement}

The Support for Eastern European Democracy (SEED) Act of 1989 directed the U.S. Department of Energy (DOE) to undertake an equipment assessment project aimed at developing the capability within Poland to manufacture or modify industrial-scale combustion equipment to utilize fossil fueis cleanly. This project is being implemented in Krakow as the "Krakow Clean Fossil Fuels and Energy Efficiency Program." Funding is provided through the U.S. Agency for International Development (AID). The project is being conducted in a manner that can be generalized to all of Poland and to the rest of Eastern Europe.

In 1991, AID and DOE signed an interagency agreement to conduct the project. U.S. and Polish officials established an eight-member Bilateral Steering Committee (BSC) to plan and oversee the project. In October 1991, the U.S. Secretary of Energy and the Polish Minister of Environmental Protection, Natural Resources and Forestry signed the Memorandum of Understanding that initiated the Krakow Clean Fossil Fuels and Energy Efficiency Program.

The project is being conducted in three phases. In Phase I, testing and analytical activities will establish the curreve ic vel of emissions from existing equipment and operating practices, and will provide estirnites of the costs and emission reductions of various options. Results from Phase I will provide information for Phase III (joint ventures) as well as provide input to the city of Krakow for the development of its Master Plan.

Phase II consists of a series of public meetings in both Poland and the United States to present the results of Phase I activities. These meetings will serve to provide information to private firms who may be interested in forming joint ventures to implement recommendations from Phase I. In Phase III, DOE will issue a solicitation for Polish/U.S. joint ventures to perform commercial feasibility studies for the use of U.S. technology in one or more of the areas under consideration.

This report provides interim results from Phase I.

\section{PROJECT ORGANIZATION}

Phase I of the project is designed to identify practical ways to reduce emissions from the low emission sources in Krakow. The Bilateral Steering Committee approved five subproject areas for study. Each focuses on specific alternatives to eliminate boilers or stoves, or to improve their performance. The five subprojects are:

- district heating;

- replacement with gas heating;

- electric heating;

- boilerhouses; and

- home stoves. 
The Phase I studies involve efforts both on the Polish and the U.S. side. Because of the emphasis on conservation in Subproject 1, DOE's Office of Conservation and Renewable Energy is the lead DOE office for this subproject; subproject 1 results are not included in this report. Subprojects 2 through 5 are being managed by DOE's Office of Fossil Energy through the Pittsburgh Energy Technology Center (PETC). Brookhaven National Laboratory (BNL) as well as Burns and Roe Services Corporation (B\&RSC) are supporting PETC. Work in Krakow is being managed by the Biuro Rozwoju Krakowa (BRK or Krakow Development Office) and for Subprojects 2 through 5 BRK is working under subcontract to BNL.

Each subproject includes testing, engineering analysis, and incentive analysis components, as appropriate. Boiler and stove testing is establishing baseline performance and emissions using current fuels and operating conditions. Additional tests utilize alternative fuels such as washed and graded coal and briquettes, and alternative cperating conditions. Particulates and condensable organics are being measured.

The engineering analyses include evaluation of local and regional air quality improvements due to the various alternatives being considered, as well as cost estimates for conversions or replacements. The incentive analyses include fuel price projections, examination of any legal or regulatory impediments to the various alternatives, evaluation of joint venture opportunities, and recommendations to the local government on ways to encourage implementation of those alternatives found to be worthwhile.

In addition, a public relations effort has been defined to inform the citizens of Krakow about the project and to provide the means for public attitudes to be measured and incorporated into project decision-making. Surveys will measure the relative importance of issues as well as consumer purchase elasticities. Results will be incorporated in the incentives analyses.

The five subprojects are briefly described below.

\section{District Heating}

About half of the heat demand in Krakow is supplied by the municipal district heating system. The distribution system serves most parts of the city, except the center. A large portion of the heat supplied to the system comes from cogeneration plants, but these are currently underutilized. Expanding the district heating system in six areas of the city and improving its efficiency could eliminate approximately 290 local boilerhouses with a total capacity of about $250 \mathrm{MW}$. Further, the large multi-family buildings served by the district heating system are inefficient. This subproject includes a demonstration of efficiency improvements to four of these buildings, including shell measures and installation of individual apartment meters. The district heating portion of Phase $\mathrm{I}$ is being managed by Pacific Northwest Laboratory and is not included in the remainder of this report. 


\section{Converting Old Town Solid Fuel-Fired Boilerhouses to Natural Gas}

As mentioned above, district heating does not provide a way to eliminate low sources of air pollution in the Old Town because the area cannot be accessed by the urban district heating system. Some Old Town boilers have already been converted to gas; this subproject will examine the possibility of using the excess capacity of the natural gas distribution system for further conversions. The pricing of natural gas will be examined, along with possible incentives to encourage consumers to consider converting to natural gas. Other areas of the city are also being considered for conversion to natural gas.

Because some of the existing coal- or coke-fired units are relatively new and not likely to be replaced, this subproject also includes testing of a typical Old Town fixed grate boiler to establish if use of different fuels or different operating procedures would result in decreased atmospheric emission levels.

Chapter 2 of this report includes natural gais rice projections and results of the analysis of the costs of converting Old Town boilers to natural gas. An evaluation of Poland's current system of air pollution fees is also presented, with emphasis on its potential for encouraging fuel-switching.

\section{Selected Conversion of Home Stoves to Electric Heat}

A one square kilometer area immediately adjacent to the historic Old Town quarter is also inaccessible to the heat distribution network due to its dense character, including narrow streets with extensive underground infrastructure. Heating is based on solid fuel, mostly home stoves. An electric substation in the center of this area has a reserve output in the range of $50 \mathrm{MW}$ that could be used for heating purposes. To use this reserve, some coal stoves would be retrofitted with electric inserts or replaced by electric thermal storage heaters. Electricity price projections are included in Chapter 2.

Costs include upgrading the distribution system and modifications to individual buildings, as well as equipment and electricity costs to consumers. As with natural gas, other areas of the city are being considered for electric heating.

\section{Modernization of Boilerhouses}

At present, there are more than a dozen larger boilerhouses (10-40 MW capacity) operating in Krakow. Because of their role in the town's heating system, they will not be eliminated even in the distant future. This subproject considers options to modernize these boilerhouses.

The Municipal Heating Authority (MPEC) at Krakow suggested that the boilerhouse at Krzesł awice be used for testing and dernonstration. The boilerhouse consists of four traveling grate boilers and several smaller boilers for a total output of 23 tonnes of steam per hour. Preliminary evaluation of expected future demand in the area has indicated that the capacity 
of this boilerhouse should be increased to about 50 tonnes of steam per hour. The modernization combined with extension would allow 9 nearby boilerhouses (with a total of about $10 \mathrm{MW}$ capacity) to be eliminated.

As an alternative to repiacing the boilerhouses, the possibility of using different fuels is being examined in the boiler test program. Changes in emissions, air quality, and costs will be calculated, and the results will be evaluated to determine the applicability of this approach for pollution reduction in other Krakow boilerhouses.

Tests have been completed for one of the four boilers scheduled for testing, a mechanical stoker-fired boiler with cyclone dust collectors at the Balicka boilerhouse. Results are presented in Chapter 2. Testing at the Krzesławice boiler, which is also connected to the municipal district heating system, has been completed but results have not yet been analyzed. Tests at two hand-fired units will be done in the fall, at the beginning oi the next heating season.

\section{Replacement of Existing Coal Stoves}

he improvement of stove-based heating by simple replacement of existing low-efficiency stuves by modern units could give considerable savings in coal consumption, and would lead to reductions of pollution by coal combustion products. The combination of more efficient stoves with application of improved fuel, such as washed, briquetted coal, may translate into substantial emission reductions.

This subproject includes testing of modern stoves and conducting air quality analyses. As an alternative to replacing the present home heating stoves, the work under this subtask also includes testing to evaluate pollution reduction achievable by use of alternate fuels and operating procedures in existing stoves.

Stove testing is being carried out at a facility built at the Academy of Mining and Metallurgy $(\mathrm{AGH})$ in Krakow, under the direction of BNL. The system uses a dilution tunnel method to determine gaseous pollutant emission rates and flue gas energy loss on a continuous basis. Particulate emissions are averaged over firing cycles. Preliminary stove test results are included in Chapter 2, as well as a review of modern stove technology.

\section{References}

B'tcher, Thomas A. et al. July 1992. "Krakuw Clean Fossil Fuels and Energy Efficiency Project". Presenied at the Eighth Annual Coal Preparation, Utilization, and Environmental Control Contractors Conference, Pittsburgh, PA.

Cracow Development Office. 1991. "Proposal of the Cracow Development Office To Perform Selected Tasks Under the Project of Low Emission Elimination in Cracow." 
Görlich, Krzysztof. 1992. "Market Approaches to Solve Kraków’s Environmental Problems." Kraków, Poland.

Gyorke, D.F., Blinn, M.B., and T.A. Butcher. 1992. "The Krakow Clean Fossil Fuels and Energy Efficiency Project." Presented at Air \& Waste Management Association 1992 Annual Meeting, Kansas City, MO.

LaMontagne, Jerome, Barbara Pierce, and Krzysztof Görlich. 1992. "How Much Will Pollution Reduction in Krakow Cost?" Proceedings from the ACEEE 1992 Summer Study on Energy Efficiency in Buildings, Volume 9. American Council for an Energy-Efficient Economy, Washington, D.C.

PETC Review. September, 1990. 


\section{RESULTS TO DATE}

This chapter presents results of activities that have been completed to date. The first section contains a summary of the boiler population in Krakow, based on surveys conducted by the City in preparation for this project. The second section presents results from boiler testing.

The following two sections address the home stoves. It is estimated that the home coal stoves supply about 13 percent of the energy required for heating in the city. These are large masonry stoves, covered with ceramic tile, and are usually located in the main living space of an apartment. Many of these stoves are used for heating in the historic buildings in the center of town, and the emission of combustion gases from these sources adversely affects the air nuality in the town. Results to date include a review of new stove technology, performed by BNL, and preliminary test results.

The last three sections report results from tasks associated with analysis of incentives. These are fuel price projections, an estimation of the costs of converting Old Town solid fuel-fired boilers to gas, and an evaluation of Poland's current system of fees and penalties associated with emissions of air pollutants. The status of privitization activities is briefly described in the section on fuel price projections.

Chapter 3 discusses results to date in the context of the overall project. It presents current estimates of total emissions from the low stack boilers and home stoves, by type of equipment. The schedule for remaining activities is discussed.

\section{CHARACTERISTICS OF KRAKOW'S LOW EMISSION SOURCES}

In preparation for this project the city of Krakow conducted two surveys of the low emission sources. The first survey covers boilers which supply heat to more than one building. This includes large boiler houses which provide a combination of steam to local industries and hot water for either the central or local district heating systems. This first survey also includes smaller boiler "rooms" which may be located in the basements of buildings and supply heat to a few neighboring buildings. The survey includes the type, size, make and model, location, age, ownership, utilization and fuel consumption for every district heating boiler in the city. It provides a basis for assessing the relative importance of each of the boiler types.

There are more than 2,900 boilers in Krakow's 1,344 boilerhouses, providing about 35 percent of the heating needs of the city. About 77 percent of the boilers, representing 86 percent of the capacity and almost 90 percent of the fuel use, are so'id-fuel fired. More than 370,000 metric tons of coal and coke are consumed annually in the boilers. Eighty-eight percent of the boilers operate only during the heating season. Nearly half of the solid fuelfired boilers are less than 10 years old (Gyorke et al. 1992). 
The solid fuel-fired boilers include two basic types: gravity feed, traveling grate boilers and hand-fired boilers (Kirchstetter 1992). Most of the boilers, more than 2,000, are small handfired units. These boilers primarily use coke. Hand-fired boilers account for about half of the total capacity and almost 40 percent of the fuel use. There are 227 traveling grate (mechanical) boilers, which use coal and represent 48 percent of the total capacity and almost 60 percent of the fuel use.

The table below summarizes the survey information for the district heating solid fuel-fired boilers. There is a very recent trend toward increased coke use in the hand-fired boilers and this will affect the values given in this table. Further, since 1990 when the survey was undertaken, some boilers in the Old Town area have been converted to gas.

The only pollution control equipment (PCE) used at Krakow boilerhouses are cyclones for particulate removal. About 10 percent of the boilers are equipped with PCE's; most of these are larger mechanical boilers. Approximately 60 percent of the annual solid-fuel consumption is in boilers with PCE's. Eighty-five percent of coal consumption in mechanical boilers is in bollers which have cyclone dust collectors. Only 19 percent of the fuel consumed in hand-fired boilers is in boilers with cyclones.

The second survey conducted by the city covered stoves and boilers which heat only one room, one flat or one building. This provides much less detail than the district heating boiler survey. The most useful information is the area (square meters) of living space and commercial space for each heating system type. From this the number of heating units and fuel consumption can only be estimated. Table $2-2$ lists the distribution of the smaller heating units, based on the second survey conducted by the city of Krakow.

Results of boiler and stove testing conducted to date are presented in the following sections. Polish emissions factors for different source types, used for calculating fees for air pollution, are given in the last section of this chapter. Estimates of total emissions by source are presented in Chapter 3.

\begin{tabular}{lcccc}
\hline \multicolumn{4}{c}{ Table 2-1. Solid Fuel-Fired District Heating Boilers in Krakow, 1990} \\
\hline Boiler Type & Number & $\begin{array}{c}\text { Design } \\
\text { Capacity }\end{array}$ & $\begin{array}{c}\text { Coai Use } \\
\text { (tonnes/year) }\end{array}$ & $\begin{array}{c}\text { Coke use } \\
\text { (tonnes/year) }\end{array}$ \\
\hline $\begin{array}{l}\text { Overfeed, traveling } \\
\text { grate stoker }\end{array}$ & 227 & $518 \mathrm{MW}$ & 233,224 & 1,250 \\
$\begin{array}{l}\text { Hand-fired } \\
2021\end{array}$ & $452 \mathrm{MW}$ & 52,023 & 85,119 \\
\end{tabular}


Table 2-2. Distribution of Smaller, Single Room, Flat, or Building Heating Systems

\begin{tabular}{lrrr}
\hline \multicolumn{3}{c}{ Area Heated (Square Meters) } \\
\hline Coal Stoves & Living Area & Non-Living Area & \multicolumn{1}{c}{ Total } \\
\cline { 2 - 4 } Coal Boilers & $1,822,000$ & 150,000 & $1,972,000$ \\
Gas & 292,000 & 61,000 & 360,000 \\
Electric & $1,427,000$ & 53,000 & $1,480,000$ \\
& 458,000 & 118,000 & 576,000 \\
\hline
\end{tabular}

\section{References}

Gyorke, D.F., M.B. Blinn, and T.A. Butcher. 1992. "The Krakow Clean Fossil Fuels and Energy Efficiency Project." Presented at Air \& Waste Management Association 1992 Annual Meeting, Kansas City, MO.

Kirchstetter, Thomas. 1992. "Krakow Boilerhouse Survey Analysis." Brookhaven National Laboratory, Upton, NY.

\section{BOILER TESTING}

Four boilers have been selected for testing in this project. Two of these are large, stokerfired boilers and results available to date with these units are discussed below. The two other boilers are smaller, hand-fired units. One of these is a model KZ-5 sectional cast iron boiler designed (as are most Krakow cast iron boilers) for firing coke. This boiler is very common in Krakow. During the last 10 years there has been a coke shortage and many of these boilers have been operating on coal or a coal-coke mixture, a practice which leads to high pollutant emission levels and sooting problems. More recently, as a result of the economic recession, there is more coke available and many of these boilers are once again using their design fuel. The last boiler for which testing is planned is a small, hand-fired steel boiler. This type of boiler is specifically designed for burning the smokier coal. Testing of the two hand-fired boilers is scheduled to begin with the 1992/1993 heating season.

\section{Results of Tests at the Balicka Boiler House}

\section{Site Description}

The tests described in this section were performed on an overfeed, traveling grate boiler, model WR-10, located in the "Balicka" boiler house on Lindego street in Krakow. This is one of the boiler houses owned and operated by the district heat utility, MPEC. It is a "hot water" boiler feeding the district system and only operates during the heating season. The boiler was built in 1972 and is one of seven at Balicka. Main technical parameters of the test boiler are: 
Maximum continuous rating:

Water pressure

Feed water temperature

Outlet water temperature

Flue gas te $e_{::}$perature
11.6 MW Thermal Output

230 psi

$160 \mathrm{~F}$

$300 \mathrm{~F}$

$390 \mathrm{~F}$
$(10 \mathrm{G} \mathrm{cal} / \mathrm{h})$

(1.6 MPa)

$\left(70^{\circ} \mathrm{C}\right)$

$\left(150^{\circ} \mathrm{C}\right)$

$\left(200^{\circ} \mathrm{C}\right)$

A battery of six cyclones are installed for particulates control and the unit is of the balanced draft type. An overfire air fan is installed although it is normally not used. The overtire air fan was put back into service specifically for this test program. The boiler has no combustion controls and no instrumentation for flue gas analysis or smoke emission measurement. In normal practice at this site the main air dampers controlling flow of combustion air under the grate are adjusted only once annually, a practice which leads to very high excess air at low loads. This boiler is the largest of the "low emission sources" in Krakow.

\section{Objective}

The objectives of the test program were to obtain baseline performance data for the unit and to evaluate the effects of coal cleaning and overfire air on performance.

\section{Test Fuels}

The fuel normally used at Balicka is unwashed duf $(0 \times 20 \mathrm{~mm})$ from the Ziemowit mine in the nearby upper Silesean coal basin. For these tests arrangements were made to obtain fuels from another mine, Staszic, which has capability of washing the duf. Baseline testing was done with coal from the Ziemowit mine at the beginning and end of the program. The main part of the testing was with washed and unwashed coal from the Staszic mine. Analysis for each of these coals is given in Table 2-3 below.

All three of the test fuels had a size distribution finer than is appropriate for boilers of this type. Figure 2-1 shows measured, as-fired size distributions along with recommended size limits.

\section{Instrumentation}

Measurement of flue gas oxygen, $\mathrm{NO}_{\mathrm{x}}, \mathrm{CO}$ and $\mathrm{SO}_{2}$ was made using a portable, electrochemical-cell based analyzer. Flue gas volatile hydrocarbons were measured with a flame ionization detector analyzer, following an ice-trap sample conditioner. These measurements were made both at the boiler exit and the cyclone outlet. Figure 2-2 shows the basic arrangement of the boiler and test equipment.

A standard EPA-5 train was used to determine flue gas particulates at the cyclone outlet. In addition to filterable particulates, semi-volatile organics condensed in the impinger section of the EPA-5 train were extracted and weighed. All particulates measurements were done in strict agreement with EPA procedures. 
Table 2-3. Analysis of Fuels Tested at Balicka

\begin{tabular}{|c|c|c|c|c|}
\hline & & Ziemowit & Staszic Unwashed & Staszic Washed \\
\hline \multirow[t]{7}{*}{ Ultimate: } & $\mathrm{C}$ & 53.12 & 61.33 & 72.03 \\
\hline & $\mathrm{H}$ & 3.46 & 3.66 & 4.57 \\
\hline & $\mathrm{N}$ & 0.44 & 0.93 & 0.95 \\
\hline & 0 & 14.45 & 7.52 & 9.44 \\
\hline & $S^{1}$ & 0.79 & 0.47 & 0.31 \\
\hline & Water $^{2}$ & 4.83 & 2.99 & 5.38 \\
\hline & Ash & 22.91 & 23.10 & 7.32 \\
\hline \multicolumn{5}{|c|}{ Lower Heating Value } \\
\hline & $\mathrm{Btu} / \mathrm{lb}$ & 8653 & 9881 & 11803 \\
\hline & $(\mathrm{KJ} / \mathrm{Kg})$ & (20104) & $(22957)$ & $(27424)$ \\
\hline & Total Sulfur & 1.50 & 0.73 & 0.59 \\
\hline & Volatiles & 27.21 & 26.91 & 31.92 \\
\hline \multicolumn{2}{|c|}{1 "Combustible" sulfur. } & \multicolumn{3}{|c|}{${ }^{2}$ Air-dried basis. } \\
\hline
\end{tabular}

To determine boiler load, the existing water flow nozzle was used in conjunction with inlet and outlet te gerrture measurements. Pressure transducers were used to monitor and log nozzle $\Delta \mathrm{P}$, combustion air pressure and furnace drafts throughout the tests. Thermocouple probes were used to monitor temperatures above the fuel bed and throughout the boiler during the tests.

\section{Test Plan}

For the Staszic mine fuels a basic test matrix was planned. This included tests at $50 \%, 75 \%$ and $100 \%$ of the highest load which could be practicably achieved. At each load tests would be done both with and without overtire air at three excess air levels. It was originally planned to set the excess air based upon flue gas oxygen. However, in preliminary tests it was found that changing the position of the air inlet dampers below the grate had no significant effect on flue gas oxygen. Reduced combustion air flow was simply replaced by increased leakage. Attempts to reduce furnace draft and so control the leakage were not successful because the induced draft fan inlet dampers were not operational. As a result of this situation, the position of the main air inlet damper was used in place of tlue gas oxygen as a test parameter. 


\section{LOWER RANK COALS SHOULD FALL NEARER THE UPPER CURVE \\ HIGHER RANK COALS SHOULD FALL NEARER THE LOWER CURVE}

$\%$ Passing Screen

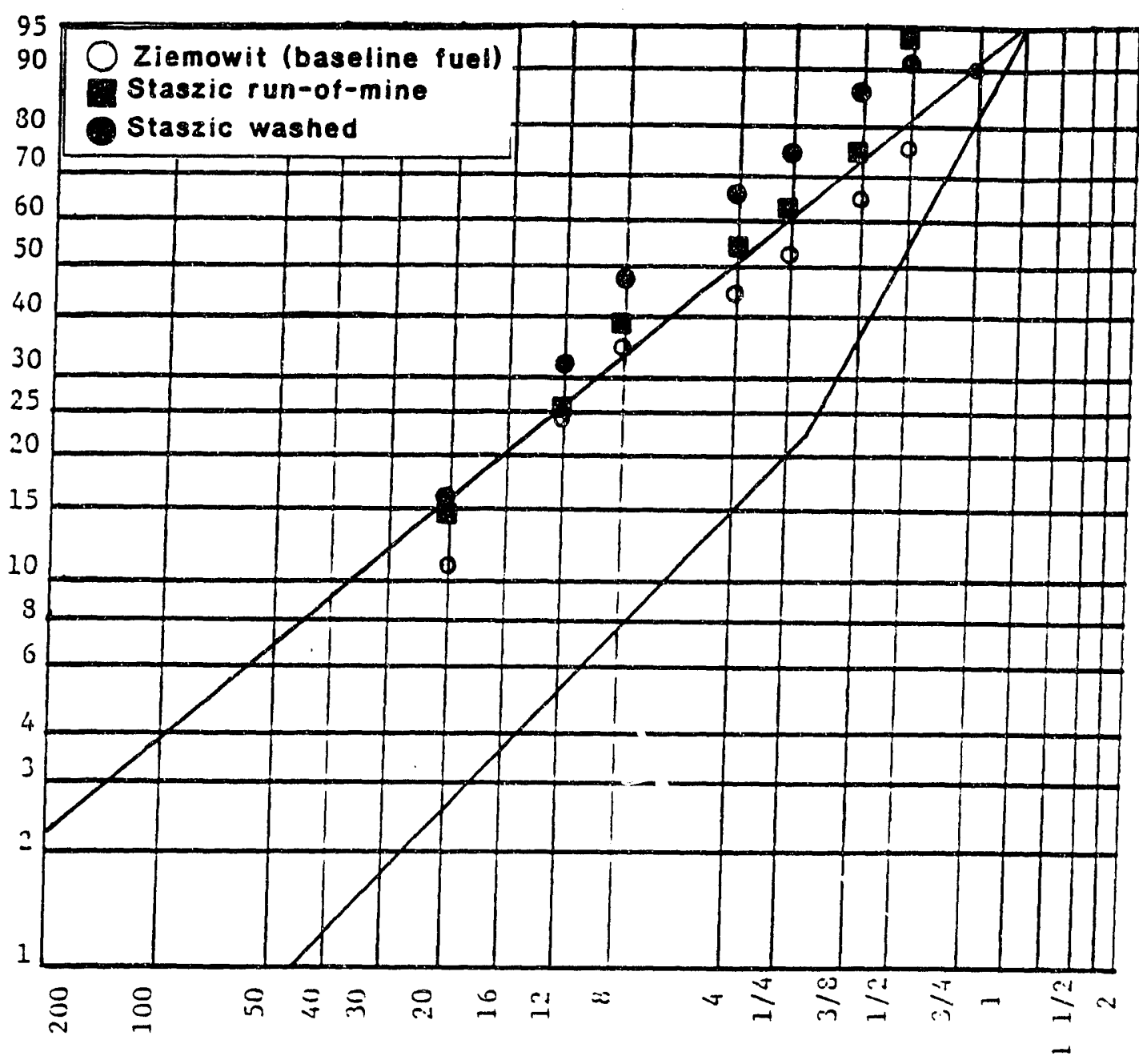

U.S. STANDARD SIEVE SIZE SQUARE MESH SCREEN, IN.

Figure 2-1. Comparison of the size distribution of the tested fuels with limits recommended by the American Boiler Manufacturers Association. 


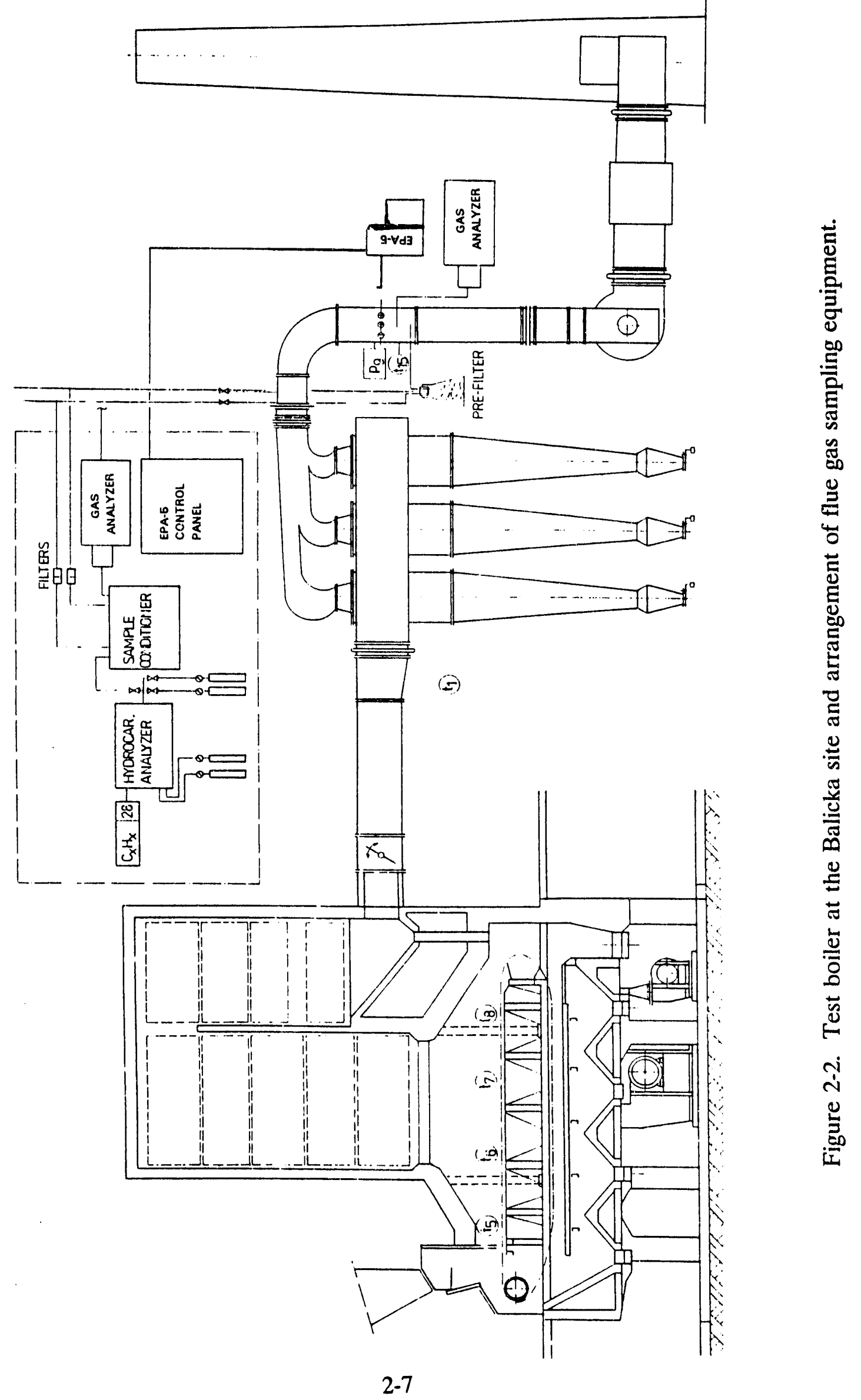


The testing program was conducted according to Polish standards. These call for 6 hours of stabilization and 9 hours of measurements for each test. For all fuels the maximum practicably achievable load was limited to $60-70$ percent of the rated capacity. Above this load, coal dropping into the ash pit was obviously still burning.

\section{Results of Tests at the Balicka Site}

Summarized results of all tests are listed in Tables 2-4 to 2-8. The baseline tests with coal from the Ziemowit mine, Table 2-4, were intended to provide data under normal operating conditions. For this reason the inlet air dampers were left fully open and the overfire air (OFA) fans were off in these tests. At low load excess air reaches very high levels and thermal efficiency falls to 50 percent.

In normal operation, grate speed is fixed at 11.2 meters/hour and bed thickness alone is varied to follow the load. In preliminary tests with the Staszic coal this grate speed was found to produce excessive unburned carbon losses and the speed was reduced to 8 meters/hour. For all Staszic coal tests included in the summary tables this was the grate speed. All Ziemowit tests were done at the higher grate speed.

In general, operation of the boiler with 50 and 75 percent open settings of the main air damper was poor. This is most notable in the case of the washed coal from the Staszic mine with overfire air (Table 2-8). For this reason, data at the 100 percent open position is considered the most useful. A general comparison of the performance of the three fuels tested with the main air damper open 100 percent and no overfire air is provided in Figure 2-3. The baseline tests with the Ziemowit coal clearly gave the highest emissions of particulates and $\mathrm{CO}$ at low and moderate loads. Also, washing the Staszic coal did not produce any emissions benefits at this site.

Effects of using overfire air are illustrated in Figure 2-4, again with the main air damper 100 percent open. Generally, effects were small.

\section{Discussion of Balicka Results}

Estimated emission factors for stoker-fired boiler and many other sources are compiled by the U.S. EPA (EPA 1985) for the purpose of allowing source comparisons. Emissivis factors currently listed for boilers like the unit tested, with cyclones, are $4.5,3$, and $3.25 \mathrm{~g} / \mathrm{Kg}$ for particulates, carbon monoxide and $\mathrm{NO}_{x}$ respectively. The level of $\mathrm{NO}_{x}$ measured at the Balicka site is generally greater than the value listed by the EPA. Certainly, in some tests much higher levels were also found for $\mathrm{CO}$ and particulates but under most circumstances these levels were less than the EPA values. Overall, the emission levels seem reasonable.

In the early 1980's an extensive testing program was completed in the U.S., involving 18 coal-fired-stoker boilers (ABMA 1981). Included were evaluations of effects of load, excess air, overfire air, coal properties and coal sizing. These results provide a source for comparison of the results at the Balicka site. In most respects the boiler performance at Balicka is similar to the sites tested by ABMA. Perhaps the most notable difference is the 


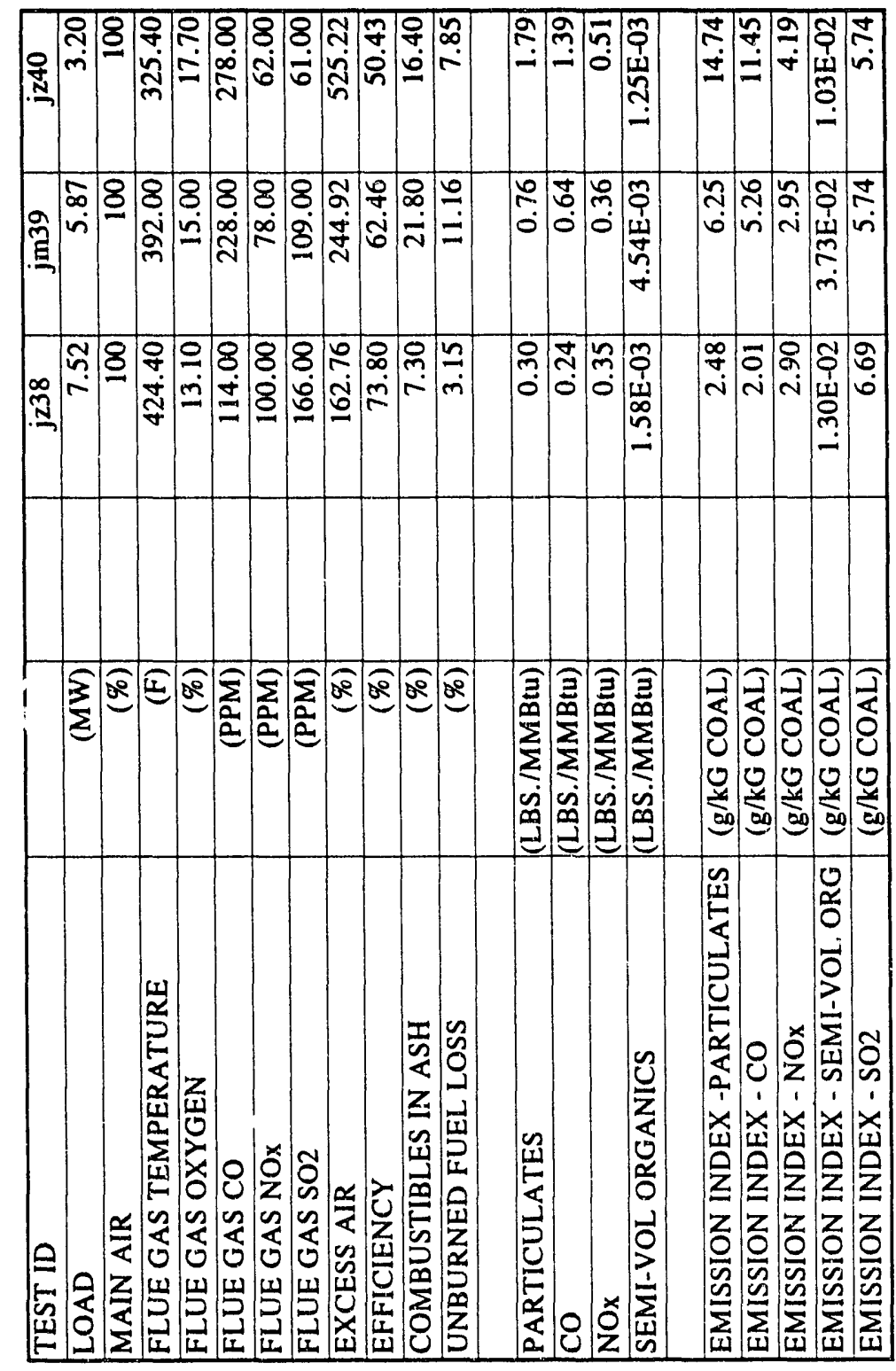

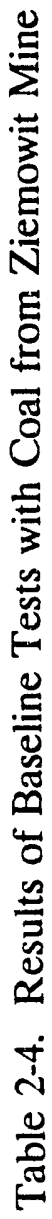




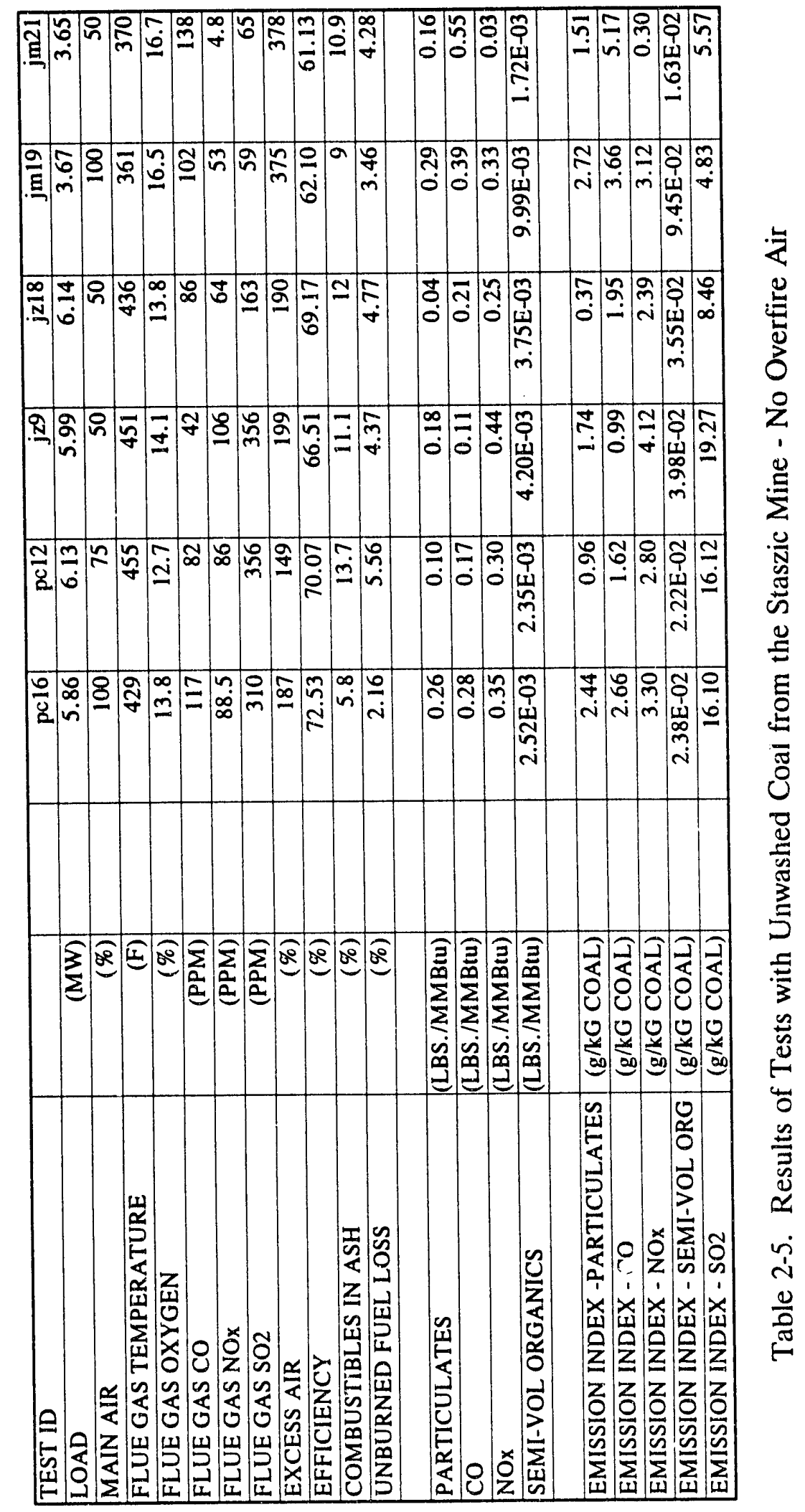




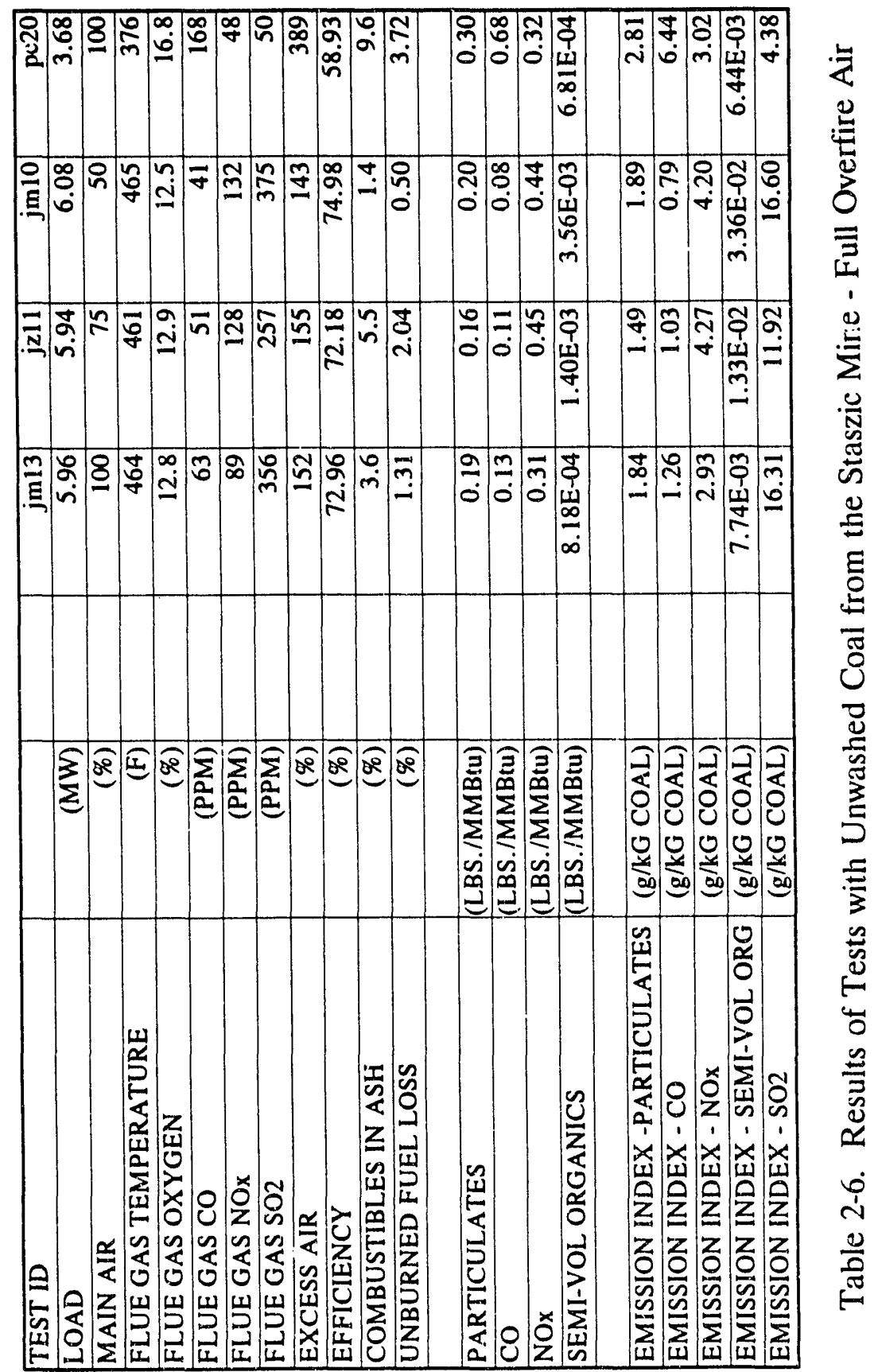




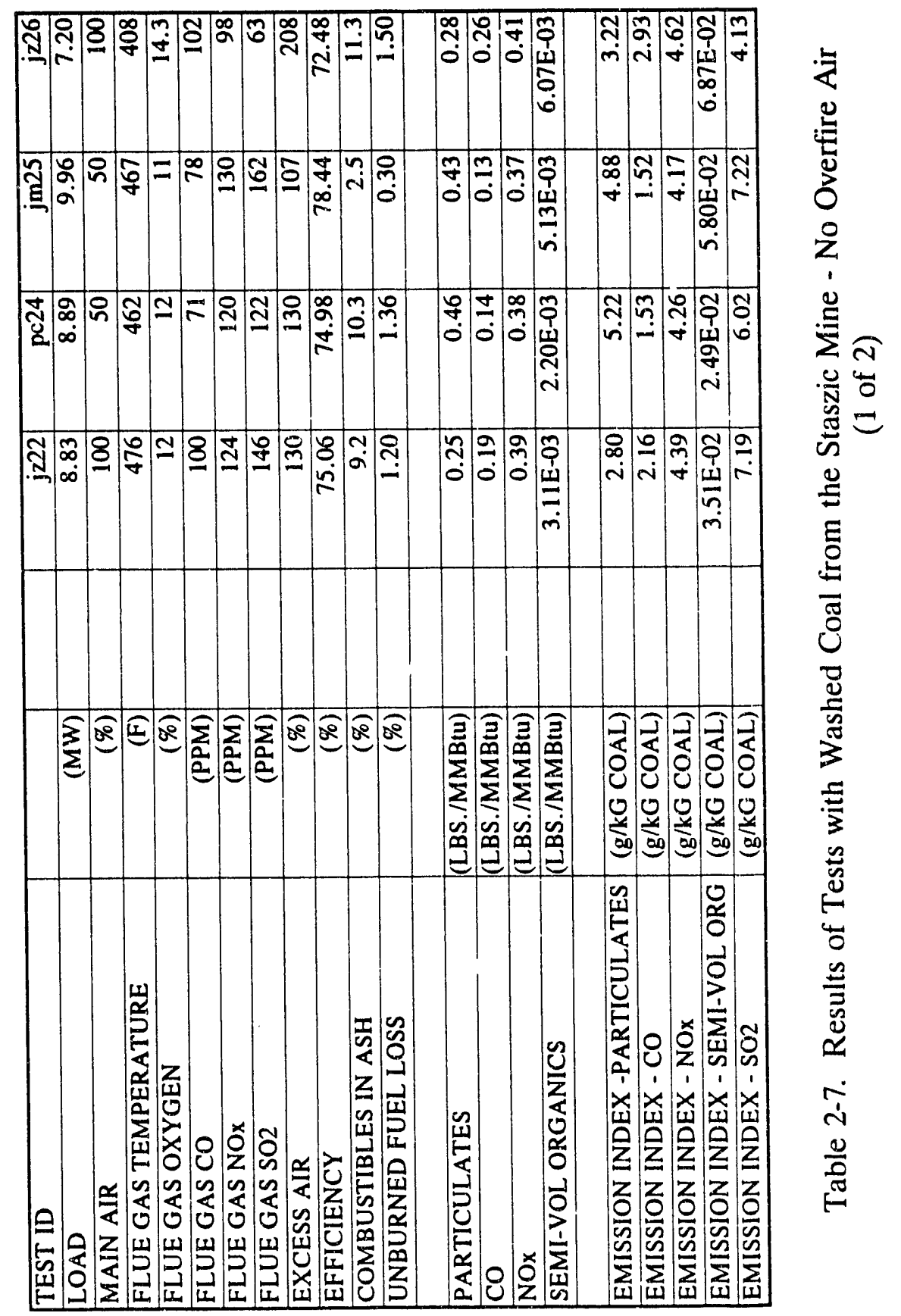




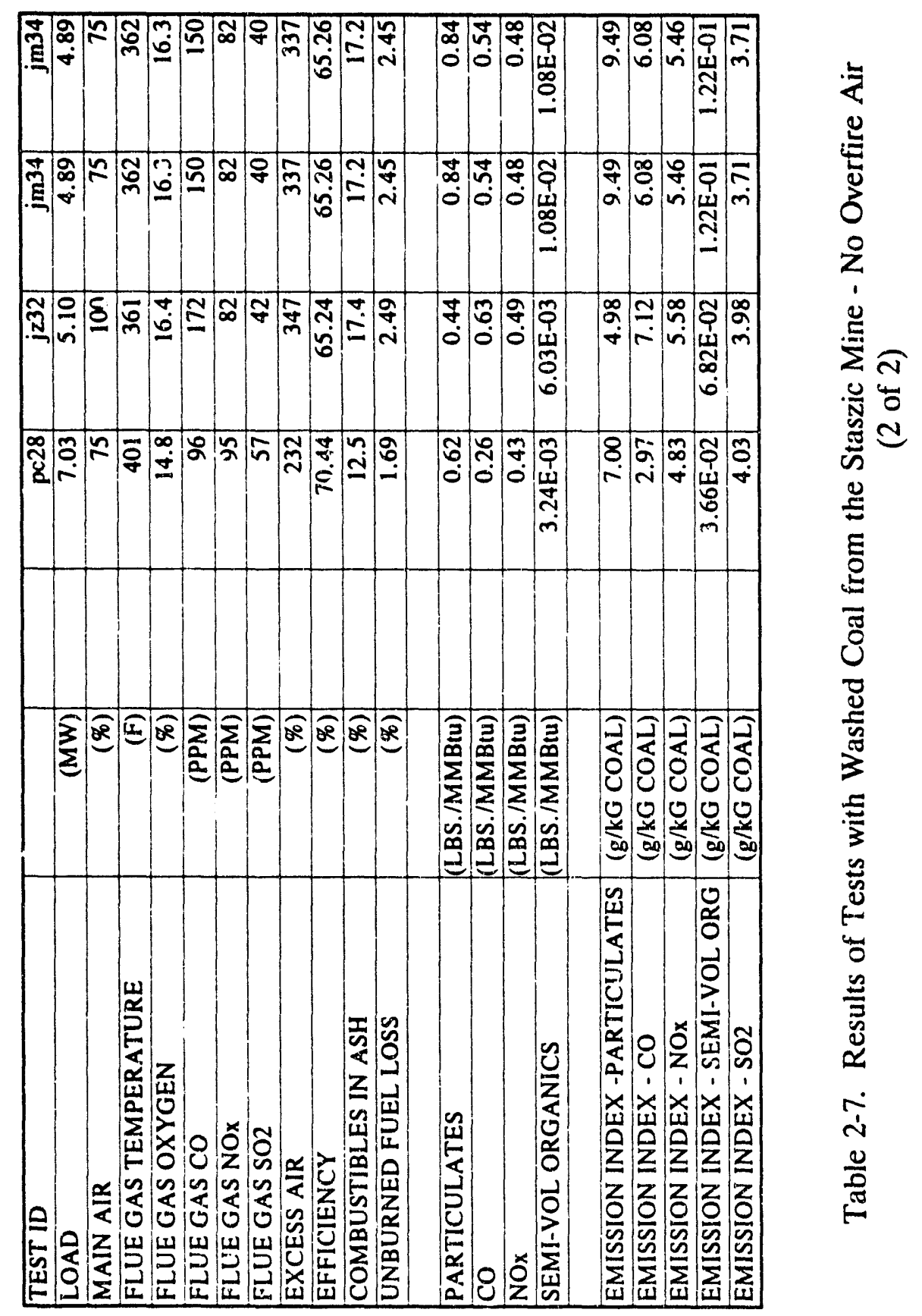




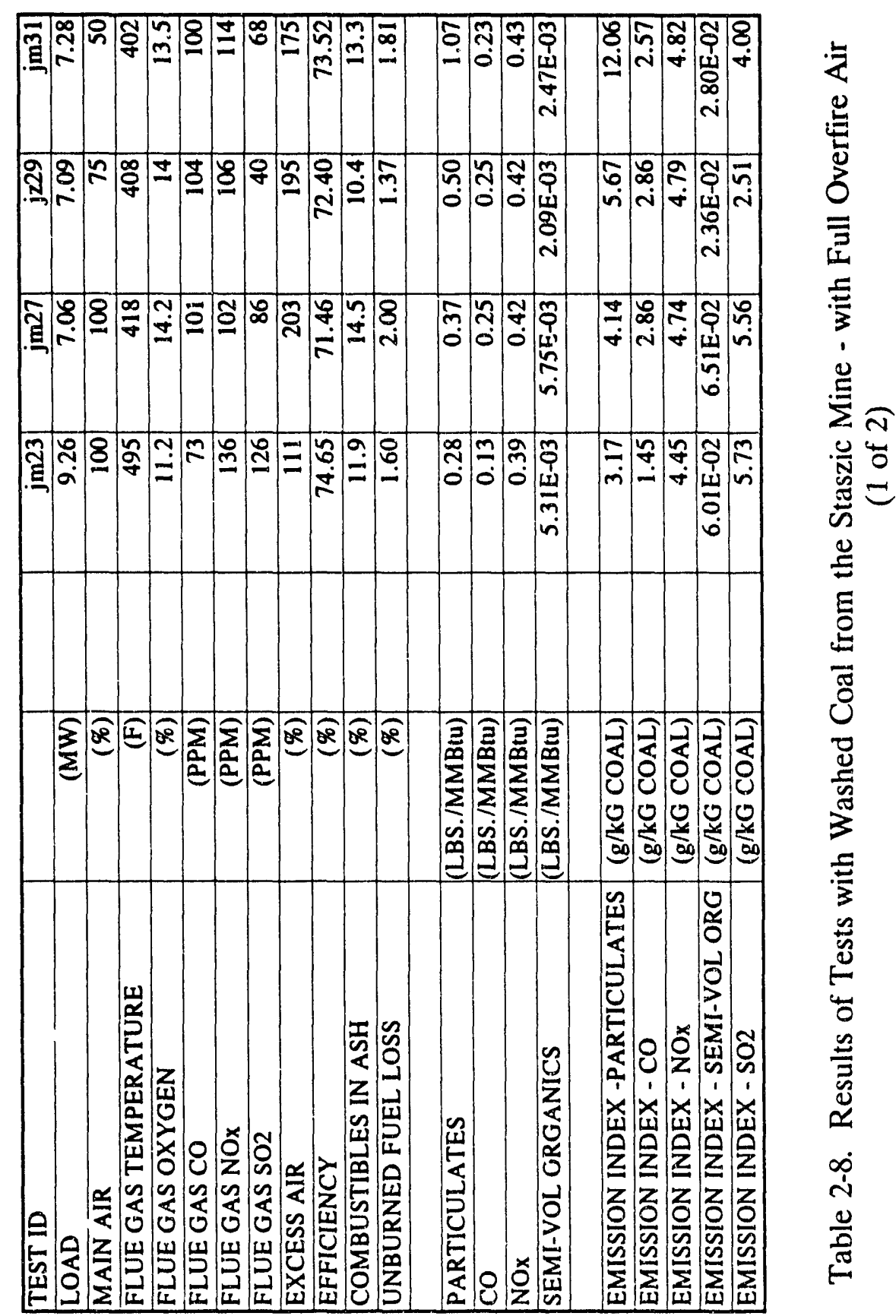




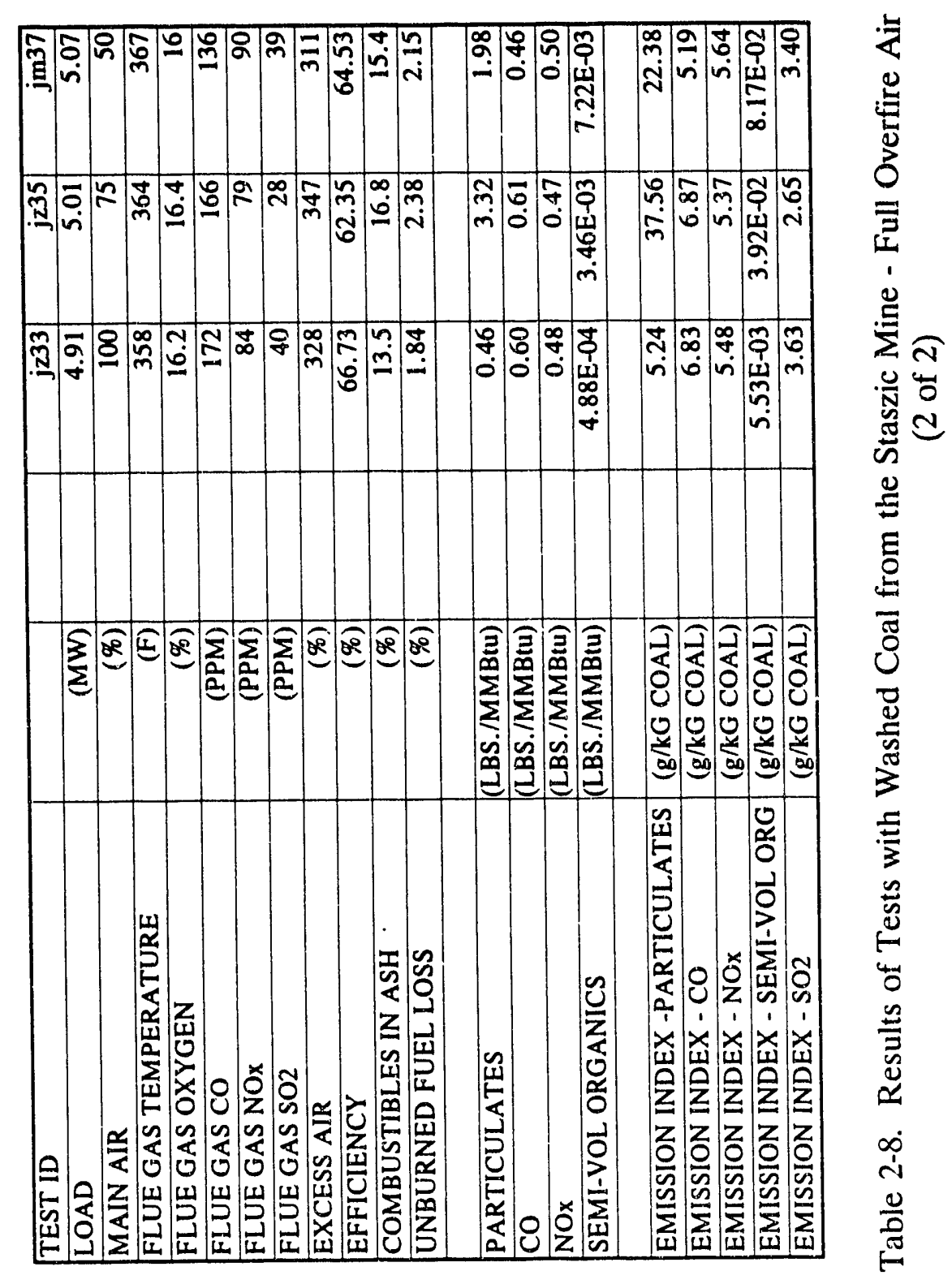



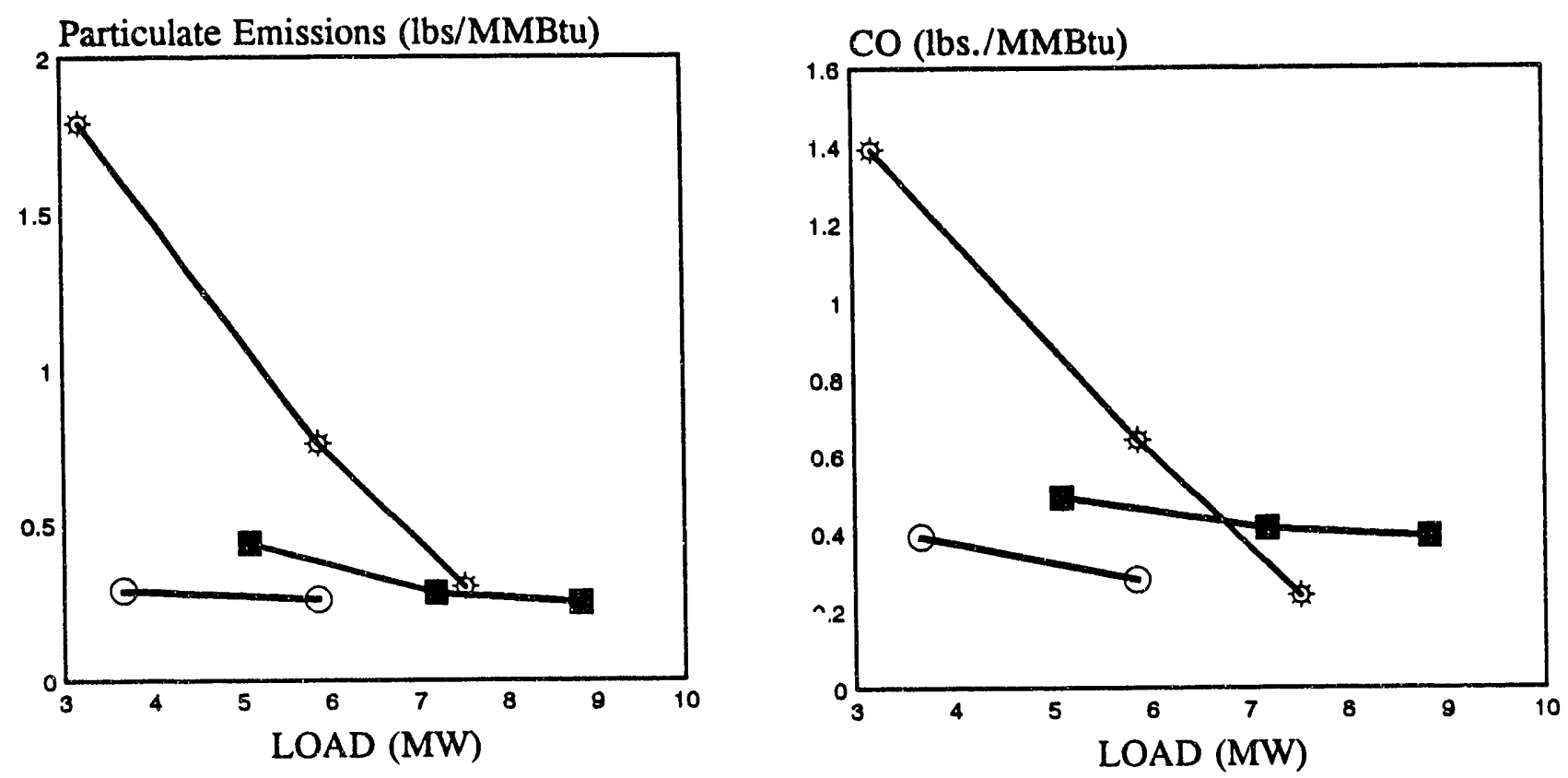

* Ziemowit $\theta$ Staszic unwashed - Staszic washed
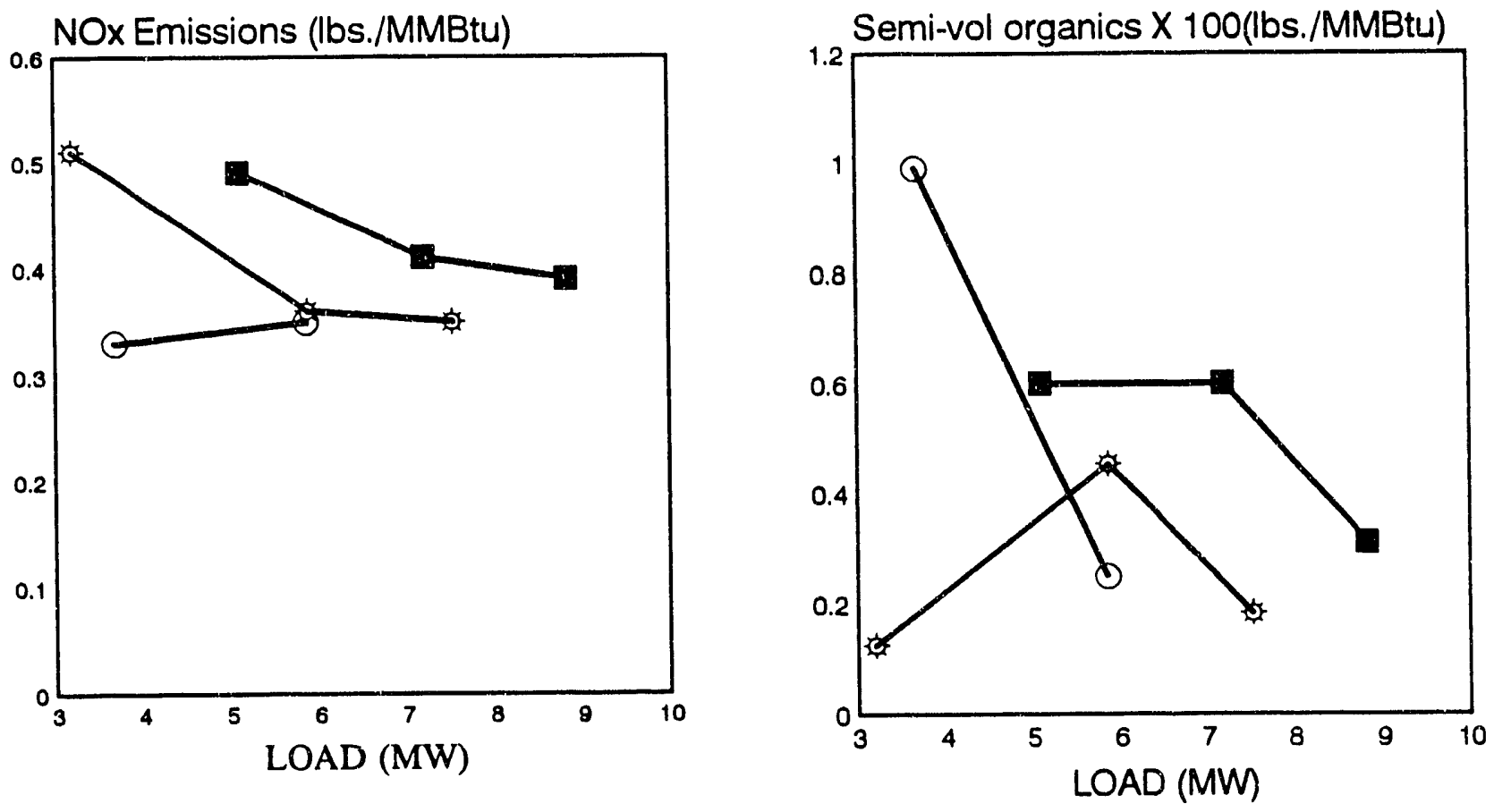

Figure 2-3. Fuel Effects: Comparison of emissions for three fuels tested at Balicka. With main air damper $100 \%$ open and no overfire air. 

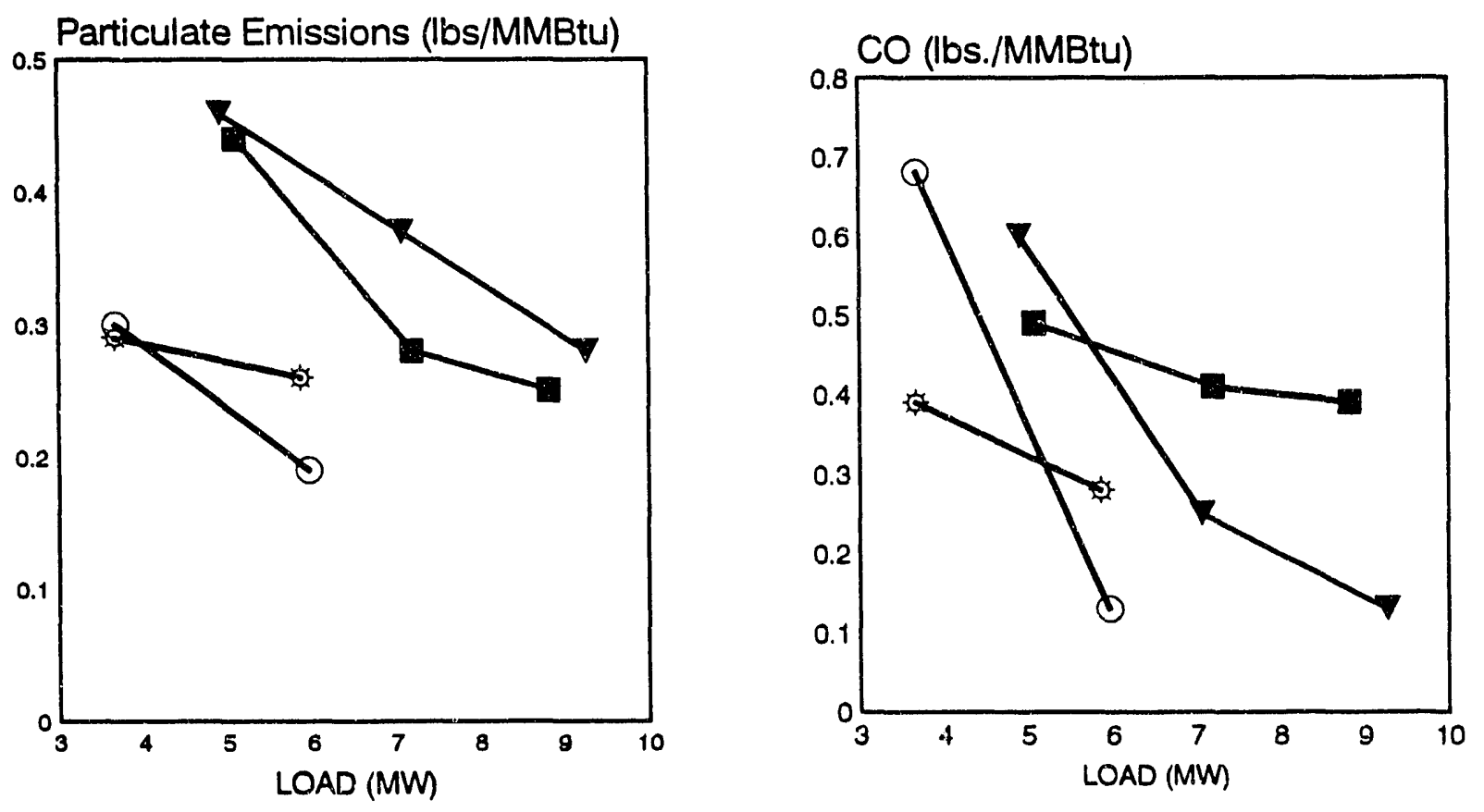

* Staszic unwashed NO OFA $\leftrightarrow$ Staszic unwashed with OFA

- Staszic washed no OFA $\quad$ Staszic washed with OFA
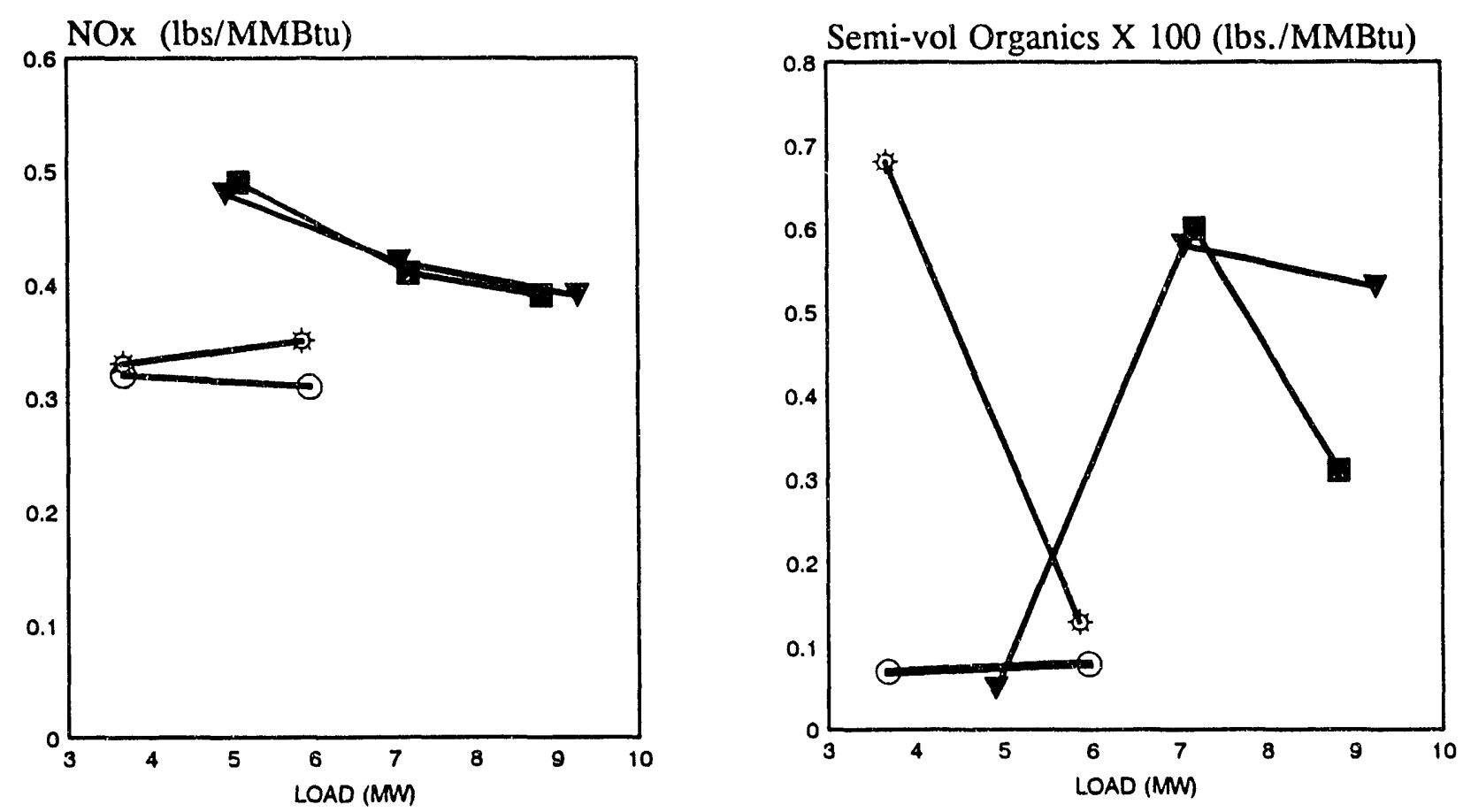

Figure 2-4. Over Fire Air Effects: Comparison of emissions with and without overfire air: Washed and unwashed Staszic Coal. Main air set at $100 \%$. 
extremely high excess air level at Balicka and the resulting low efficiency. Boilers of this type should be capable of operating with up to 100 percent excess air (or less) and with thermal efficiencies of 75 to 85 percent.

Overfire air is often used to improve the performance of boilers of this type and this approach has been shown to be quite effective in promoting air/fuel mixing above the bed and reducing smoke and particulates. A possible reason why overtire air was apparently not very effective in the Balicka tests is the very high excess air levels. With an abundance of air available fuel/air mixing may be less critical.

The Balicka tests showed no apparent benefit of coal cleaning on particulate emissions. One of ABMA test sites also evaluated coal cleaning effects. With coal cleaning a factor of 3 reduction in particulates was measured at the boiler outlet. After the cyclone dust collecting however, the difference between the particulates loading before and after the cycle were reported to be slight.

The coal normally used at Balicka as well as in the other Krakow boiler houses clearly contains an excessive amount of fines. While the tests done here do not provide a basis for assessing the effects of fines on emissions, results from ABMA and others show that this is an area where emission improvements could be achieved.

Currently, a full report on the Balicka tests is being completed by the Polish team from Krakow Polytechnic University. This should be finalized by October, 1992.

\section{Test Program at Krzesławice}

The second stoker-fired boiler tested in this program is a smaller unit, located in the Krzesi awice boiler house. As of the date of this interim report, the tests are completed but no results are yet available. Test fuels at this site include the same Staszic fuels, a coal graded to fall about in the center of the recommended range in Figure 2-1, a coal graded to remove all fines, and a semi-coke.

While no formal results are yet available some general comments can be made based on observations during the test program. Like the boiler at the Balicka site this boiler has no combustion controls or on-line tlue gas analyzers. The furnace is divided and two independent grates feed the fuel. Balancing the fuel and air inputs between the two grates proved to be both very difficult and very important for performance in the test program. Differences between test fuels may be secondary to these operational effects. Observed levels of $\mathrm{CO}$ at this site were much greater than Balicka and the performance was found to be unstable. Use of the graded coal improved stability. Full results of the test program are expected to be available within two months. 


\section{References}

U.S. Environmental Protection Agency. 1985. Compilation of Air Pollutant Emissions Factors, Report AP 42, September.

American Boiler Manufacturers Association. 1981. Emissions and Efficiency Performance of Industrial Coal-Stoker-Fired Boilers, Report to the U.S. Department of Energy DOE/ET/10386-T1, August.

\section{COAL STOVE TECHNOLOGY REVIEW}

This section briefly reviews the emission of "smoke" from residential heating units burning coal and the approaches that have been taken to minimize such emission.

Non-gaseous emission from coal-burning units can consist of particulates and smoke. The particulates consist mainly of fly ash and unburned or partially burned coal. The smoke is generated primarily from the volatile matter of the coal. The particulates are generally of larger size than the smoke particles, and smoky operat: . seems to be associated with respirable particles (Chuang et al. 1992). Generation of particulates is significant if the fuel contains a significant amount of fines and if the combustion intensity is fairly high (for example, with a forced draft). Therefore, residential units where large reasonably sized pieces of coal are burned on a fixed grate without the use of combustion air fans would not generate significant amount of particulates. However, such operation can still generate significant smoke depending, among other things, on the volatiles content of the coal.

It has been suggested that the tendency of a hand-fired installation to produce smoke is approximately proportional to the amount of tar produced by the coal during carbonization (Mayers 1945). Such a view of smoke generation suggests that smoke emission can be minimized either by using fuels which have a low content of tar producing volatiles ("Smokeless Fuels") or by use of combustion equipment designed to burn up the smoke before emission ("Smokeaters"). These two approaches have been used successfully in the United Kingdom in areas where smoke had been a problem (Payne 1987). Although a similar strategy had been proposed earlier in Pittsburgh, U.S.A., a shift to natural gas was instead the major contributor to city-wide smoke abatement (Tarr 1981).

\section{Smokeless Fuels}

In the U.K., a smokeless fuel is defined as a fuel that, when burned in a conventional open fire in accordance with British Standard 3841, gives a total particulate emission of less than 5 grams per hour (Payne 1987). A bituminous coal burned in a similar way is reported to give emissions of about 25 grams per hour. Anthracite and some steam coals having low volatile content are considered natural smokeless fuels. The Solid Smokeless Fuels Federation lists a variety of approved smokeless fuels and approved appliances for burning these fuels. 
Table 2-9. Typical Analysis of Mineral Solid Fuels Used in

U.K. Residential Heating

\section{(NATURAL SMOKELESS FUELS AND BITUMINOUS COALS)}

\begin{tabular}{|c|c|c|c|c|}
\hline Fuel & & $\begin{array}{l}\text { Welsh Dry } \\
\text { Steam Coal }\end{array}$ & Anthracite & $\begin{array}{l}\text { Bituminous } \\
\text { Coal }\end{array}$ \\
\hline Moisture & $\%$ & 0.8 & 1.4 & 9.1 \\
\hline Volatile Matter & $\%$ & 13.3 & 8.3 & 35.2 \\
\hline Ash & & 7.6 & 4.1 & 4.2 \\
\hline Fixed Carbon & & 78.3 & 86.2 & 51.5 \\
\hline $\begin{array}{l}\text { Calorific Value } \\
\text { (dry ash free) } \mathrm{kJ} / \mathrm{kg}\end{array}$ & & 36286 & 36286 & 33494 \\
\hline
\end{tabular}

(MANUFACTURED SMOKELESS FUELS)

\begin{tabular}{|c|c|c|c|c|c|c|c|}
\hline Fuel & & A & B & $\mathrm{C}$ & $D$ & $\mathrm{E}$ & $\mathrm{F}$ \\
\hline Moisture & $\%$ & 0.8 & 4.9 & 3.5 & 3.0 & 5.3 & 1.5 \\
\hline Volatile Matter & $\%$ & 0.8 & 9.3 & 4.7 & 3.5 & 20.9 & 4.1 \\
\hline Ash & $\%$ & 9.8 & 7.9 & 7.6 & 6.5 & 4.8 & 8.1 \\
\hline Fixed Carbon & $\%$ & 88.6 & 77.9 & 84.2 & 87.0 & 69.0 & 86.3 \\
\hline \multicolumn{2}{|c|}{$\begin{array}{l}\text { Calorific Value } \\
\text { (dry ash tree) } \mathrm{kJ} / \mathrm{kg}\end{array}$} & 33494 & 34192 & 33727 & 35122 & 32797 & 34000 \\
\hline
\end{tabular}

The major smokeless fuels available in the U.K. in 1985 are listed in Table 2-9 (Payne 1987). Most of them are produced by some type of carbonization of weakly coking coal (Needham 1961 ) and the low volatility compared with bituminous coal is to be noted. Some smokeless fuels are the result of a briquetting process utilizing low volatile coal and anthracite fines or other starting materials. It should be noted that if the volatile content of the fuel is very small ( $\sim$ percent), it will be difficult to burn in simple, updraft open-fire type heaters.

In (West) Germany, hard coals which have less than 18 percent volatile matter on a moisture and ash-free basis, cokes, and processed lignite briquettes are defined as smokeless fuels (Martin 1982). It seems that the value of the byproducts of smokeless fuel manufacturing makes this marketable at a reasonable price (Needham, 1961). A similar consideration seems to underlie the study (Zielinski et al. 1991) for the manufacture of smokeless fuel in Poland. 


\section{Smoke-Reducing Heaters}

The operation of a traditional coal burning furnace can be described as follows. A horizontal grate carries the fuel and most of the combustion air (primary air) is drawn through the grate up through the fuel bed. In a number of designs there are openings above the grate (the "furnace" volume) for admission of secondary air. The coal releases the volatile matter which is burned (partially) above the fuel bed and the remaining char burns on the grate leaving ash behind. This is the typical updraft design. In normal operation of coal heaters most of the coal is burned over a relatively short time period compared to the time over which space heating is required. Hence the simple design, where most of the heat is transferred by radiation from the burning coal, has poor efficiency ( $\sim 30$ percent). One approach to increase this efficiency is to transfer part of the heat released to a large thermal mass which releases this heat to the living space over a longer period of time. Such heaters include masonry and ceramic tiled heaters. Another option is to include a highoutput back boiler and circulate the water through the heated space.

These efficiency improvement measures do not reduce the smoke (and particulates) emission substantially on a grams per kilogram of fuel basis. However, they would contribute to overall reductions as more of the heat input is channeled to the living space and so less fuel needs to be burned. To reduce the smoke emission from a fuel such as bituminous coal, the burning conditions have to be altered so that the volatiles are burned more effectively. British Coal, in collaboration with appliance manufacturers, has developed such heating systems since the 1960's (Payne 1987). Some work has also been done in the U.S.

The basic requirements for successful volatile burning are provision of acondary air which must be mixed well with the volatiles, while maintaining the gases hot enough and with enough residence time for the combustion to be completed. One way these requirements have been met in practice is by basing the design on the so-called downdraught principle (Dickinson et al. 1982; Waslo et al. 1983). In this type of heater, primary air flows downward through the coal and up through a ceramic combustion chamber before exiting through the chimney. Volatiles, released from the coal, are forced to pass through the active flame zone and burned. The ceramic chamber gets hot and secondary air is introduced into) it to complete burning of the volatiles. A proposed design that evolved into a commercial product is shown in Figure 2-5 (Dickinson et al. 1982). The commercial product was shown in one test to emit particulates up to 6 times lower than an updraft heater (Waslo 1983). It should be noted that, as approved in the U.K., these stoves perform well with particular bituminous coals which are double-screened for size. It may be anticipated that the performance would suffer if, for example, strongly caking coals were used.

In (West) Germany, a downdraft design has also been developed for smokeless combustion of solid fuels (Martin 1982). Figure 2-6 from Martin, 1982 illustrates the design. The primary combustion air is preheated as it moves upward in a cavity around the doublewalled stove and is pulled down by the chimney draft through the fuel along with the partially burned volatile matter. Secondary air is provided from underneath the grate. The design criteria are set in a German engineering standard. 


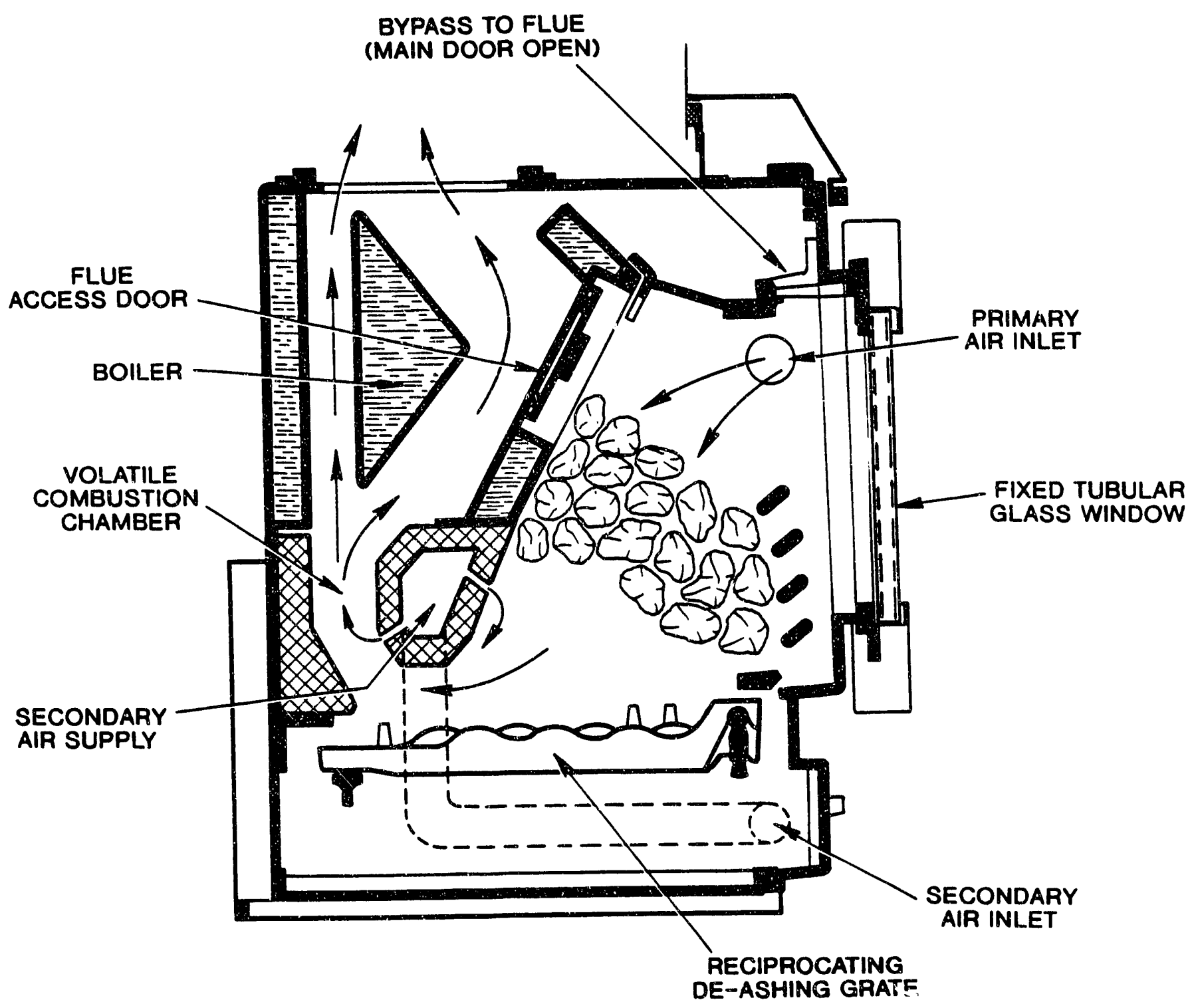

Figure 2-5. Example of a Smoke-Reducing Heater for Bituminous Coal. This design incorporates downdraft through the fuel bed and a secondary combustion chamber. 


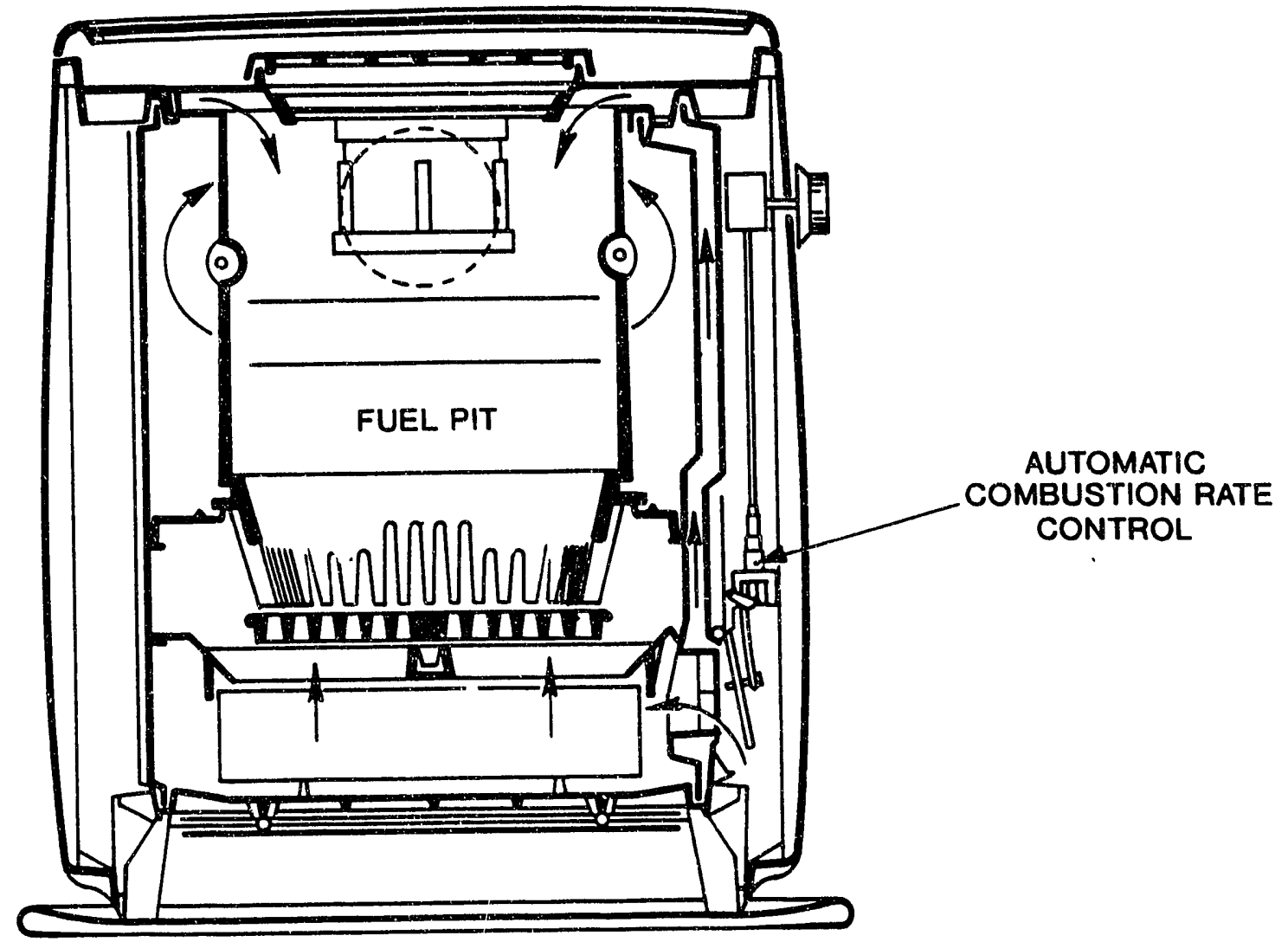

Figure 2-6. Example of a Smoke Reducing Heater for Bituminous Coal. Incorporates air-preheat and downdraft. 
In the United States, a smokeless stove for burning bituminous coal was developed in the 1940's (Landry 1950). The test results for a commercial design do show significant reduction in smoke emission measured using an optical smoke meter (Landry 1950).

\section{Discussion}

The review has indicated that the substitution of smokeless fuels for bituminous coal and the use of down-draft smokeless heaters with some bituminous coals can reduce the measured amount of smoke emission. It must be noted, however, that these reductions are for particulates as defined in standard tests (Payne 1987 and Waslo 1983); their relation to respirable particles (Chuang et al. 1992) and health effects needs to be ascertained. A natural smokeless fuel is anthracite which might be available for use in Krakow at a reasonable price. Contact with the manufacturers of smokeless fuels in the U.K. indicates that the retail price of these fuels is about 50-70 percent higher than that of bituminous coal on a weight basis. The actual cost to the consumer will depend also on the differences in heating value and operating efficiencies.

A recent listing of British residential solid fuel appliances shows a small number of smokeless-type heaters approved for burning bituminous coal in smoke-control areas. Payne indicates that, in 1985-86, about a quarter of a million tons of bituminous coal were burned in such appliances compared to the consumption of about 3.4 million tons of natural and manufactured smokeless fuel during the same period. The conclusion from this is, at least in the U.K., use of smokeless fuels seems to be the preferred approach to reduce smoke in smoke-control areas. The reasons could be availability of these fuels at a reasonable price and the avoidance of the one-time cost of replacing the heater. In the case of Pittsburgh, local smoke abatement seems, primarily, to have come from a shift to natural gas, as it became available at affordable prices (Tarr 1981). No sources of manufactured domestic smokeless fuel or of smokeless stoves for bituminous coal are located in the U.S. at present. Most commonly anthracite is used in conventional coal stoves.

\section{References}

Chuang, T.C., Wise, S.A., Cao, S., and Mumford, J.L. 1992. "Chemical Characterization of Mutagenic Fractions of Particles frcm Indoor Coal Combustion: A Study of Lung Cancer in Xuan Wei, China." Environ. Sci. Technol., 26, 999-1004.

Dickinson, R.D. and Payne, R.C. 1982. "United Kingdom Efficiency Tests and Standards for Residential Solid Fuel Heating Appliances". Proceedings 1981 International Conference on Residential Solid Fuels Environmental Impacts and Solutions.

Landry, B.A. and Sherman, R.A. 1950. "The Development of a Design of Smokeless Stove for Bituminous Coal". Transactions of the ASME.

Martin, W. 1982. "European Experiences and Activities in Assessing the Environmental Impacts trom Wood Combustion". Proceedings 1981 International Conference on Residential Solid Fuels Environmental Impacts and Solutions. 
Mayers, M.A. 1945. "Combustion in Fuel Beds". Chemistry of Coal Utilization, Vol. II, H.H. Lowry, Editor.

Needham, C.E. 1961. "Reactive Fuels and Chemicals from Coal". I.P. Review.

Payne, R.C. 1987. "Living with Coal in Smoke Control Areas". Coal Research Conference, Wellington, New Zealand.

Tarr, J.A. 1981. "Changing Fuel Use Behavior and Energy Transitions: The Pittsburgh Smoke Control Movement, 1940-1950." Joumal of Social History, Carnegie Mellon University, Volume 14, \#4.

Waslo, D. and Jaasma, D.R. 1983. "Emissions, Efficiency, and Combustion Chamber Conditions of a Smokeless, Hand-fired Coal Heater." Proceedings of Solid Fuel Heating Symposium, NTIS Publication CONF-830381.

Zielinski, H., Kaczmarzyk, G., Sciazko, M., Rychły, J. and Chmielniak, T. 1991. "Clean Energy Production by Use of Smokeless Fuel Manufacturing and ICGCC Systems", United Nations Economic Commission for Europe, Fifth Seminar on Emission Control Technology for Stationary Sources, Nurnberg, Federal Republic of Germany.

\section{COAL STOVE TESTING}

\section{Description of the Stoves Tested}

The masonry tile stove tested during this program is very typical of those used in Krakow. It was built specifically for these tests by a local craftsman in a laboratory at the Academy of Mining and Metallurgy. During construction great care was taken to record dimensions and the types of materials used. A series of thermocouples were installed in selected locations within the stove mass to monitor heat storage during the firing cycle. The stove was tailt with a sampling port about $0.7 \mathrm{~m}$ above the grate to allow gas composition or gas temperature profiles to be measured. This has not been used to date. Vertical cross-section drawings of the tile stove tested are shown in Figures 2-7 and 2-8. The stove has three flue gas passes. The first and largest vertical pass acts as the combustion chamber, and is full width across the front of the stove. The second (down) and third (up) passes are half width across the back. There is an ash clean-out port at the bottom of the second pass. The section in Figure 2-7 is through the center of the second pass and the left side of the first pass. The section in Figure 2-8 is through the center of the third pass and the right side of the first pass. Figure 2-9 shows several horizontal cross-sections at planes defined in Figure $2-7$.

Figure 2-10 shows the locations of the internal thermocouples. Thermocouple \#6 is central at the stove base. Thermocouples 7 and 8 are in the center of the high temperature (Chamotte) brick which lines the combustion chamber (see 2-9 D-D). Points 10 and 11 are 


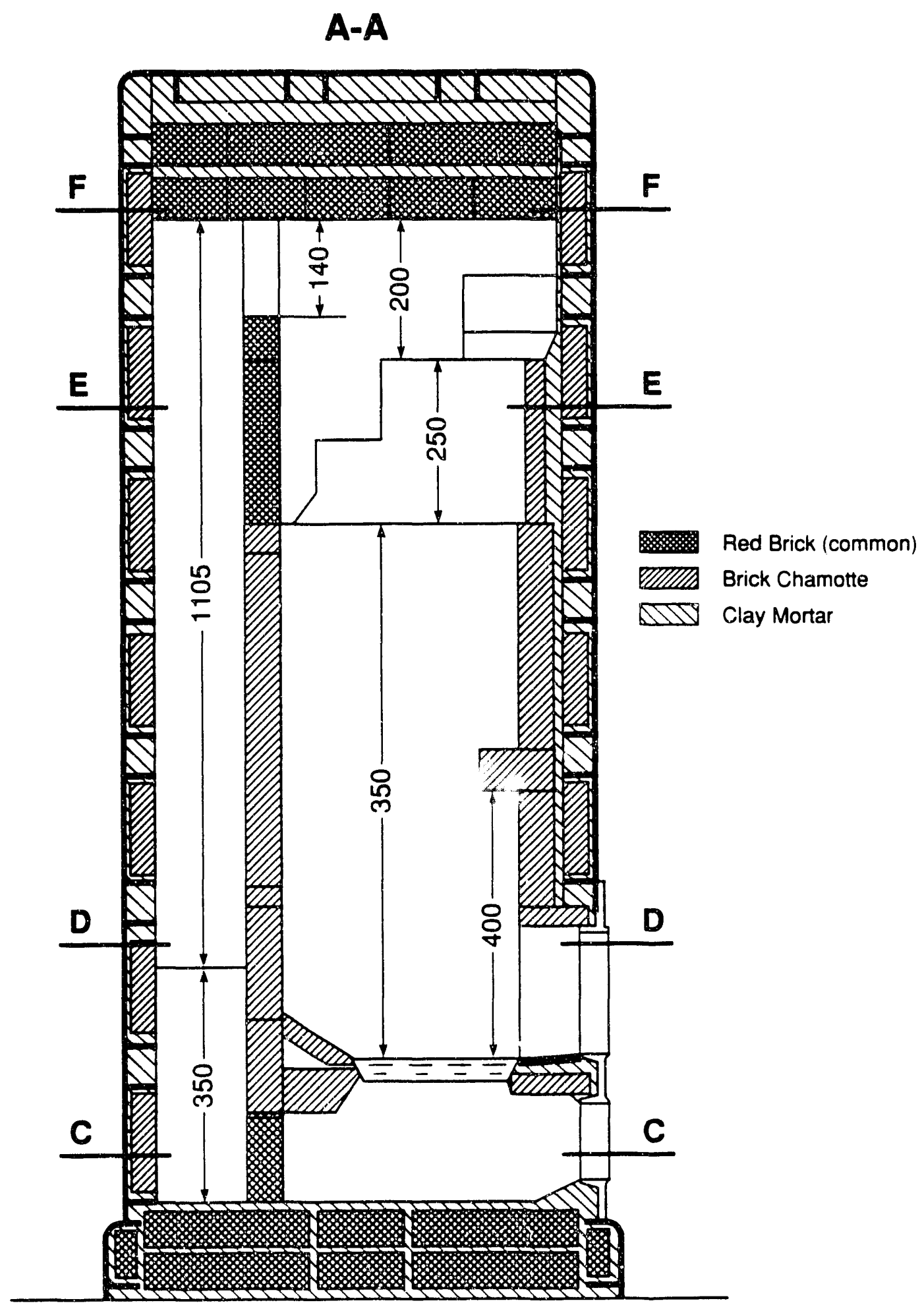

Figure 2-7. Vertical Cross-Section of Polish Tile Stove Showing First and Second Passes. (dimensions in millimeters) 


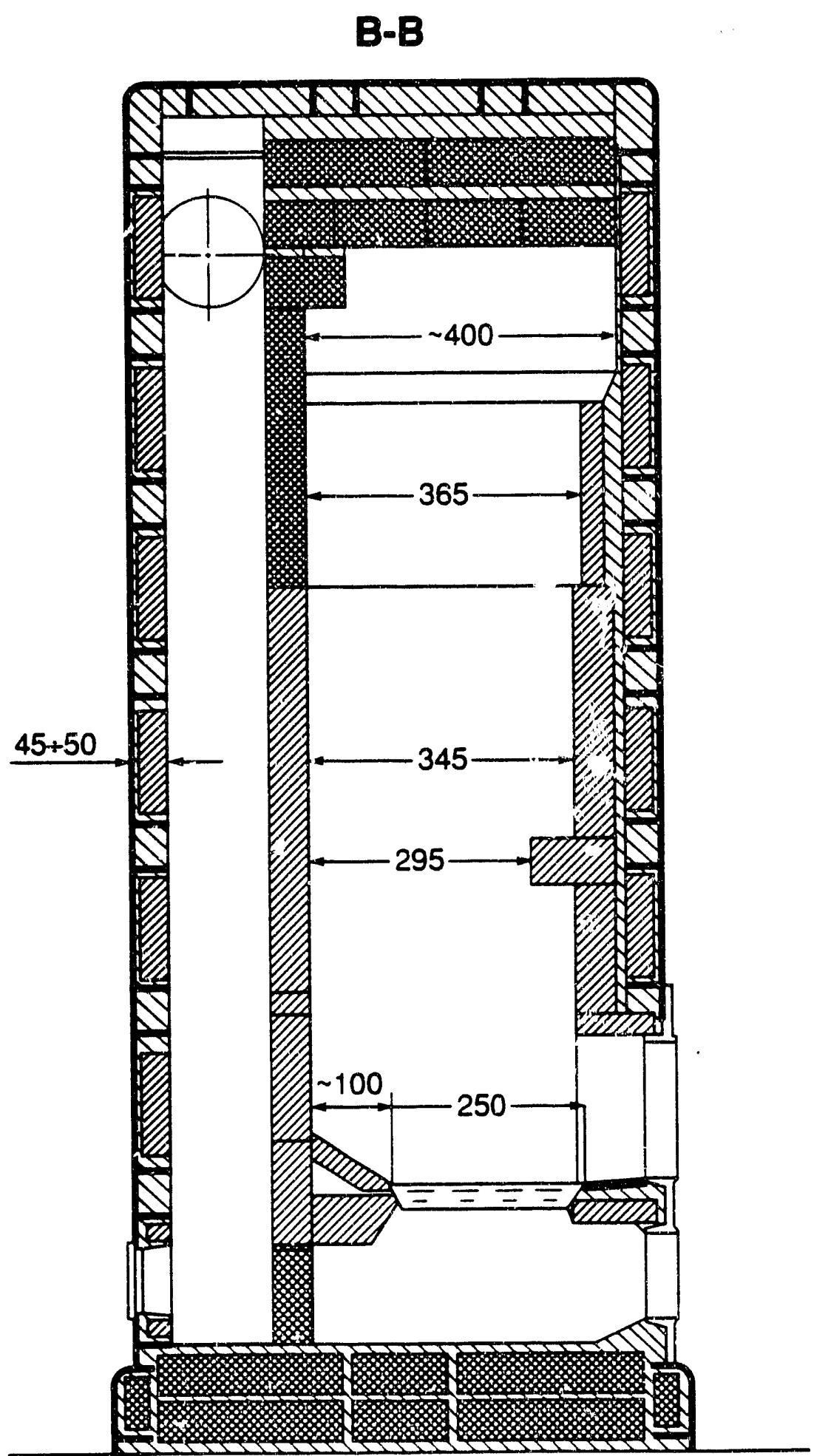

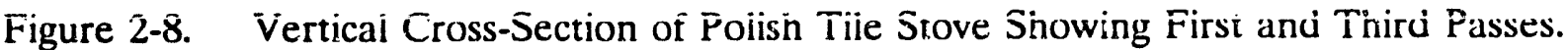
(dimensions in millimeters) 


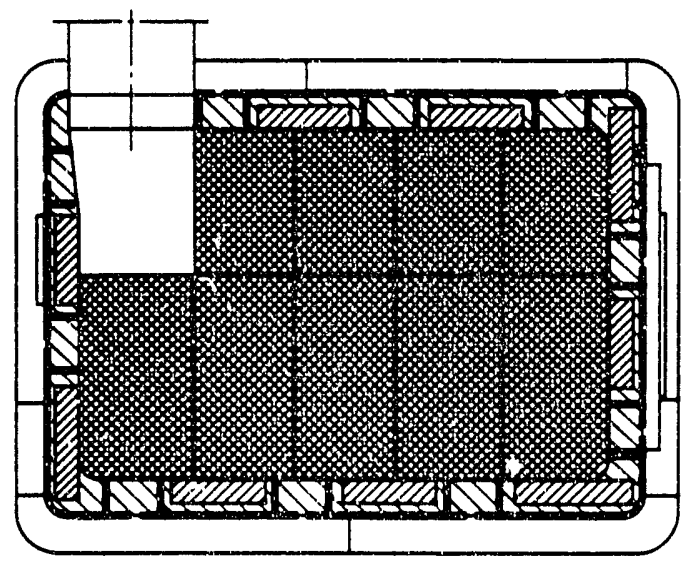

F-F

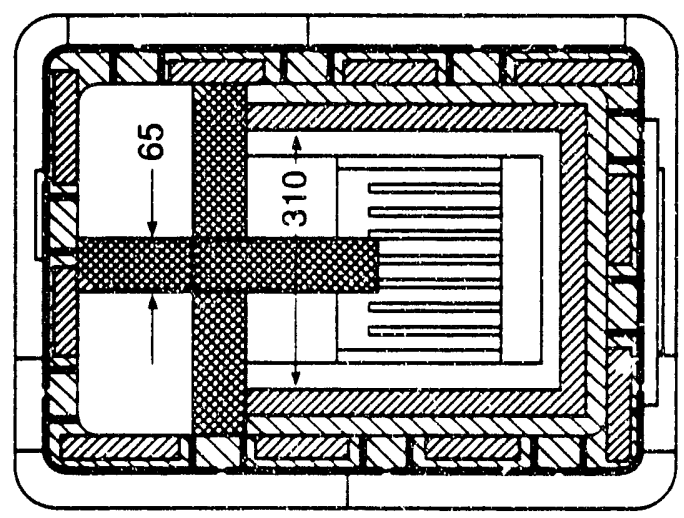

E-E

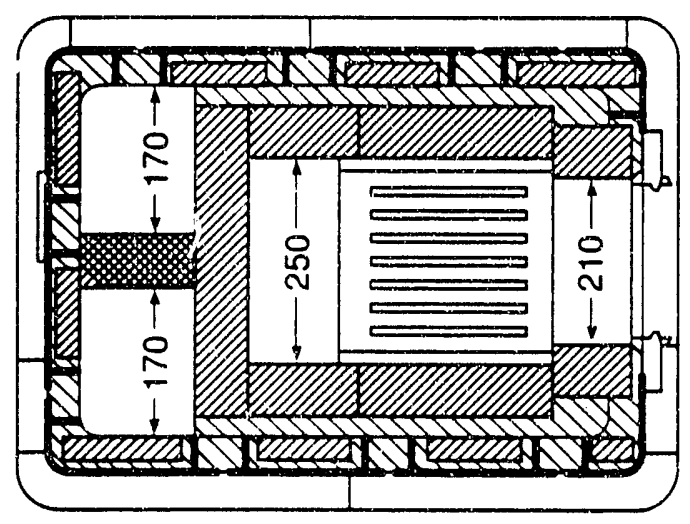

D-D

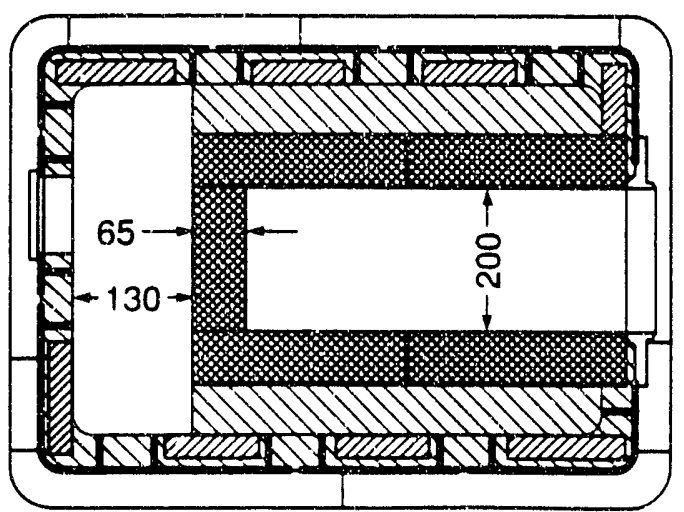

C-C

Figure 2-9. Horizontal Cross-Sections. (dimensions in millimeters) 


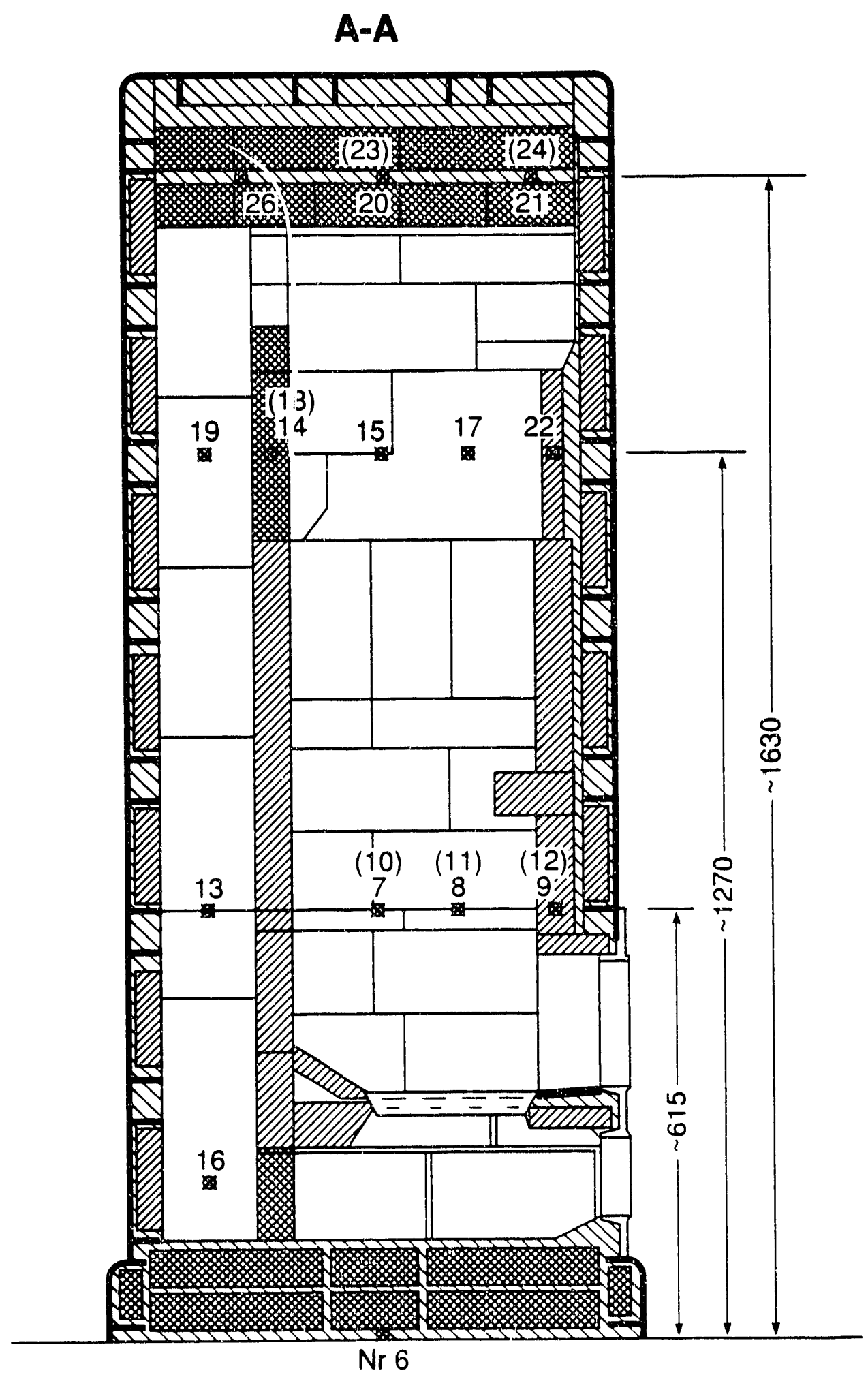

number of thermocouple and channel

Figure 2-10. Location of Internal Thermocouples. (dimensions in millimeters) 
simply on the opposite side. Points 9 and 12 are in the high temperature brick on the front wall. Points 15 and 17 are in the center of the dividing wall (see 2-9 E-E). Points 14 and 18 are in the center left and center right of the walls which separate passes 2 and 3 from the combustion chamber (see 2-9 E-E). Point 22 is centered in the front wall at the same elevation. Points 20, 21 , and 26 are between brick layers on the left center side of the roof. Points 23 and 24 are on the right center side. Point 16 is not in a brick but rather measures gas temperature between passes 2 and 3. Points 13 and 19 are in the center of the dividing wall between passes 2 and 3 .

In addition to the Polish tile stove, tests were also performed using a Polish cast iron stove. This unit is a typical, "open-fire" slow burn type stove without advanced features for smoke control.

\section{Test Objectives}

The objectives of these tests were to obtain baseline performance data for the Polish stoves and to evaluate effects of coal quality, smokeless fuels and operating habits on performance.

\section{Test Fuels}

Normally, unwashed fuel is used in the house stoves, delivered to the homes by truck and stored in the basement until used. Test coals included a "premium" fuel from the Wujek mine as well as a cheaper home fuel from the Bolesław Smiały mine. In addition to these coals, tests have also been done using smokeless briquettes prepared by the Institute for the Chemical Processing of Coal, Zabrze, Poland. In this process, hot char from a circulating fluid bed gasifier is combined with a preheated coking coal. The mixture feeds into a roll press, forming the egg shaped briquettes (Zielinski et al. 1991). No additional binder is used.

Properties of the three test fuels are listed in Table 2-10. The most notable difference between the Zabrze briquettes and the other coals is in the volatiles content, which is the parameter making the briquettes "smokeless."

The top size for the coals was about 4 inches. During handling all of the fuels generated some fines (about 5\%) and these were usually fed into the stove along with the normal charge.

\section{Instrumentation}

A facility for studying the emissions and efficiency of the home coal stoves has been built at the Academy of Mining and Metallurgy $(\mathrm{AGH})$ in Krakow with guidance from BNL and equipment provided from the U.S. under this program. The system uses a dilution tunnel method (Macumber 1981; U.S. Code of Federal Regulations, 1990) to determine gaseous pollutant emission rates and flue gas energy loss on a continuous basis. Particulate emissions are averaged over firing cycles. 
Table 2-10. Analysis of Coal Stove Test Fuels

\begin{tabular}{|c|c|c|c|c|}
\hline & & Wujek & Bolesław Smiały & Zabrze Briquettes \\
\hline \multirow[t]{7}{*}{ Ultimate: } & $\mathrm{C}$ & 80.04 & 61.15 & 79.20 \\
\hline & $\mathrm{H}$ & 4.81 & 4.15 & 1.60 \\
\hline & $\mathrm{N}$ & 1.19 & 0.98 & 1.16 \\
\hline & 0 & 8.22 & 9.22 & 4.42 \\
\hline & $S^{1}$ & 0.28 & 0.65 & 0.26 \\
\hline & Water $^{2}$ & 2.12 & 2.11 & 2.36 \\
\hline & Ash & 3.34 & 21.74 & 11.0 \\
\hline \multicolumn{5}{|c|}{ Lower Heating Value } \\
\hline & $\mathrm{Btu} / \mathrm{lb}$ & 13495 & 10595 & 11899 \\
\hline & $(\mathrm{KJ} / \mathrm{Kg})$ & 31354 & 24616 & 27646 \\
\hline & Volatiles & 32.1 & 30.3 & 8.14 \\
\hline
\end{tabular}

The dilution tunnel system is illustrated in Figure 2-11. All of the combustion products leaving the stove enter the dilution tunnel along with air from the room. The flue gas flow at the stove exit varies greatly during a firing cycle and is often too low to measure practically. The flow in the dilution tunnel, in contrast, is steady and can be easily measured. The emission rate of any gaseous pollutant is simply the product of the dilution tunnel concentration and the dilution tunnel flow rate.

Particulates are measured by sampling from the dilution tunnel using a heated filter. Beyond the filter semi-volatile organics are condensed in the icebath impingers. These organics are later extracted and total mass determined.

Stove thermal efficiency is determined by integrating the rate of energy loss from the stove over the firing cycle. This requires measurement of the mass tlow rate of flue gas from the stove. Infrared analyzers are used to monitor $\mathrm{CO}_{2}$ iri both the stove exhaust and the dilution tunnel continuously. These measurements, along with dilution tunnel flow, allow calculation of the stove mass flow.

\section{Test Plan}

Test procedures were planned so that the stoves would operate in a manner as close to typical as possible. In the case of the tile stoves each "firing" cycle lasted about 24 hours and a total of 5 cycles was used to evaluate each fuel. Before each such test series the 


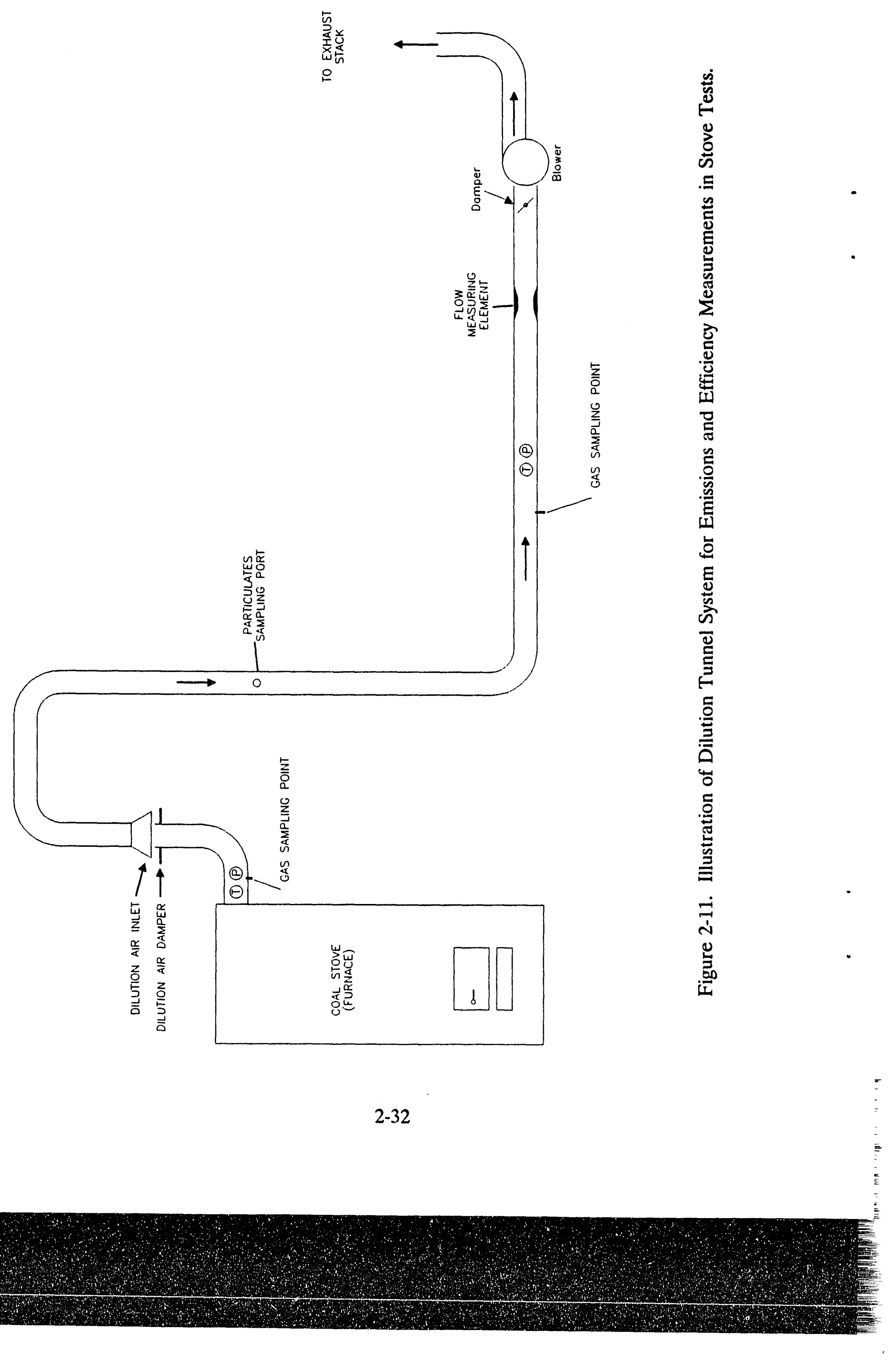


combustion chamber, ash pit and dilution tunnel were carefully cleaned to remove the remains of the previous series. After each firing cycle ash on the grate was removed for analysis but the char was left for the next run. The mass of fuel, char, kindling and ash were all carefully measured for each run.

In lighting the fire in the tile stoves the fuel charge was added in two stages, following normal practice. The first part (1/3 of total) was added initially with the kindling. The remainder was added 15 minutes later.

During the main part of the combustion in the tile stove the top door and the bottom (ash pit) door are both partially ajar. The top door is normally closed after "degasification is complete (long flame disappears)", about 1 hour. The ash pit door is cl ssed completely when the "glow is dark red", about $1 / 2$ hour later.

In all tests, for which results are available to date, the doors were closed tightly after combustion ended. In this case measurements showed the total stove flow to be zero and there were no "off-cycle" flue energy losses. In most homes, however, the doors do not seal as tightly and some tests in the lab with simulated "leaky doors" were performed. Results of these tests are not yet available.

In typical home installations stoves from different floors are common-vented. Stove draft varies considerably over a firing cycle and will depend upon the number of stoves firing into the chimney at a given time. To develop a typical draft/time profile, field measurements were made before the test program started. Based on these, a target profile was developed and implemented by adjusting the dilution air damper position during the firing. After the firing part of the cycle the dilution air damper was closed completely and the tunnel blower was turned off. Natural draft from the fan exhaust stack provided the desired draft level for the remainder of the test period.

It is interesting to note that the practice of common venting floors has led to building codes which prohibit use of stoves with fan-assisted combustion air flow. This could impede the replacement of existing tile stoves with some advanced designs.

\section{Results}

The general nature of the operation of the tile stove and the dilution tunnel system is shown in Figures 2-12 to 2-15. All of these data were obtained using Wujek coal and the normal stove operating procedures described earlier. The emission rate of $\mathrm{CO}_{2}$ shown in Figure 212 can be used as a measure of the combustion rate. Initially the coal volatiles burn giving high combustion rates as well as high emission of $\mathrm{CO}$. After about 0.3 hours much of the volatiles are burned off, the combustion rate remains fairly high but the $\mathrm{CO}$ emission rate decreases. In addition to the lost volatiles it is likely that the higher temperatures of the combustion chamber and the masonry flue passages also help keep the $\mathrm{CO}$ down from about 0.4 to 0.9 hours. At the 1 hour point the top door of the stove was closed, leading to a gradual reduction in the combustion rate but a dramatic increase in the $\mathrm{CO}$ emission rate. 


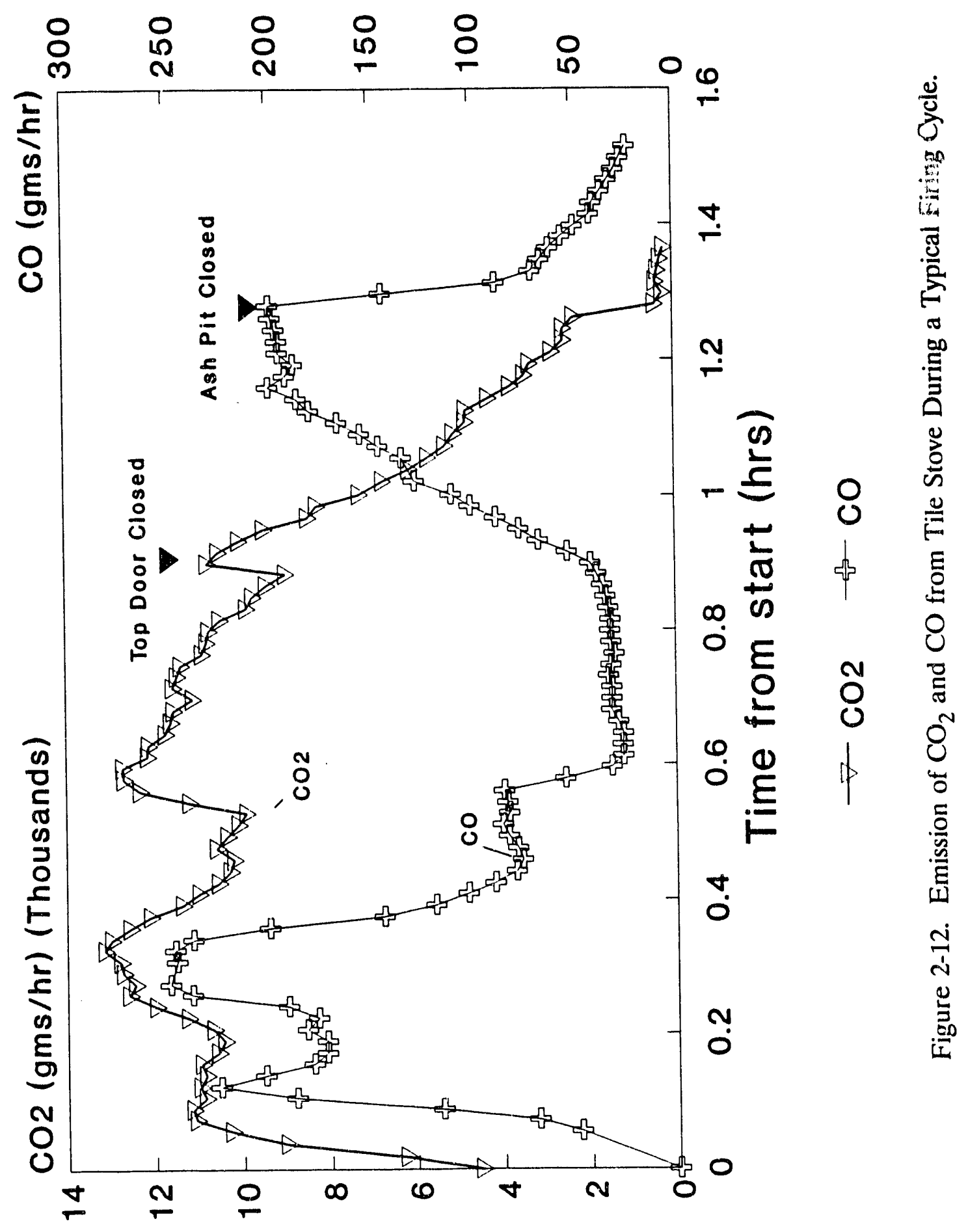




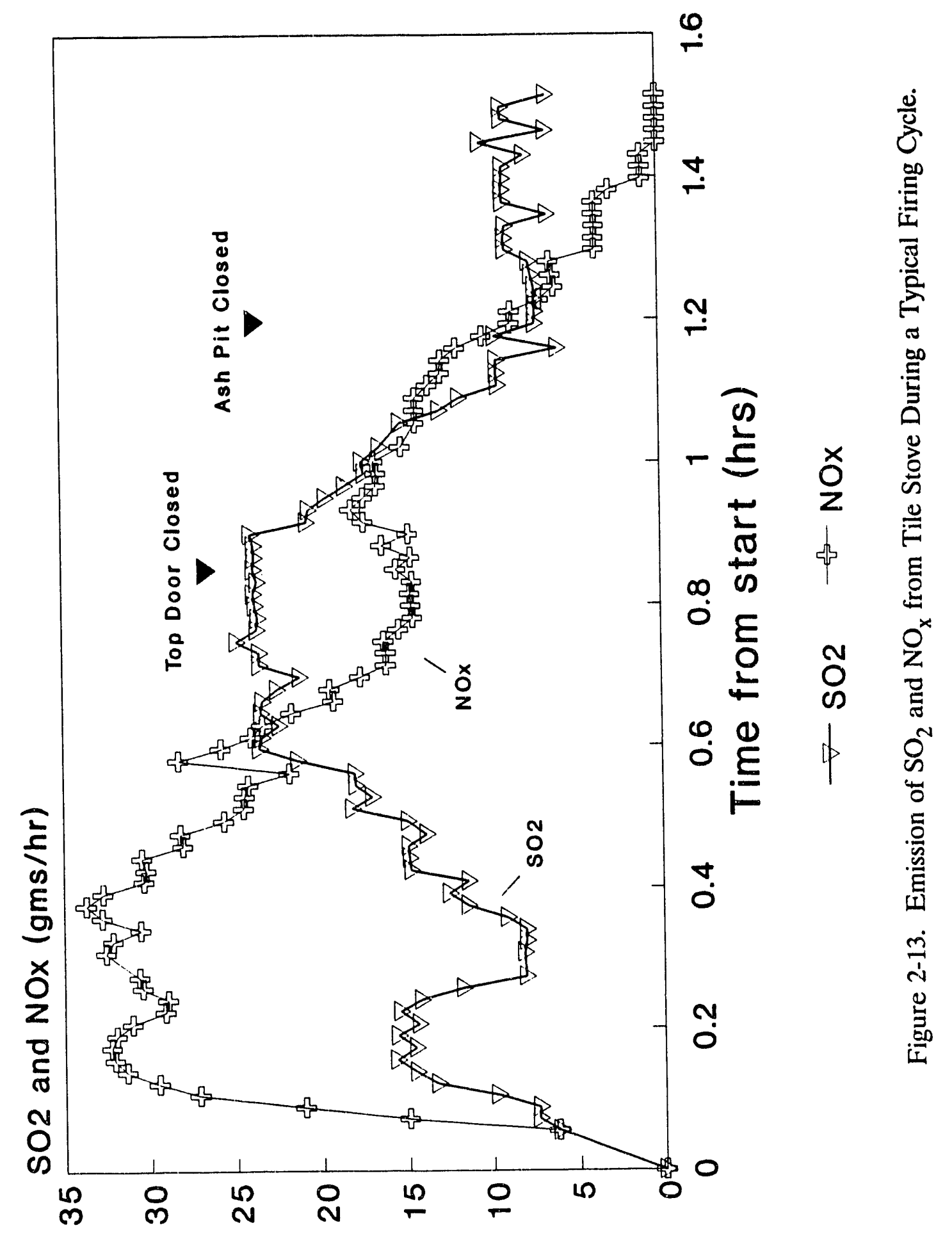




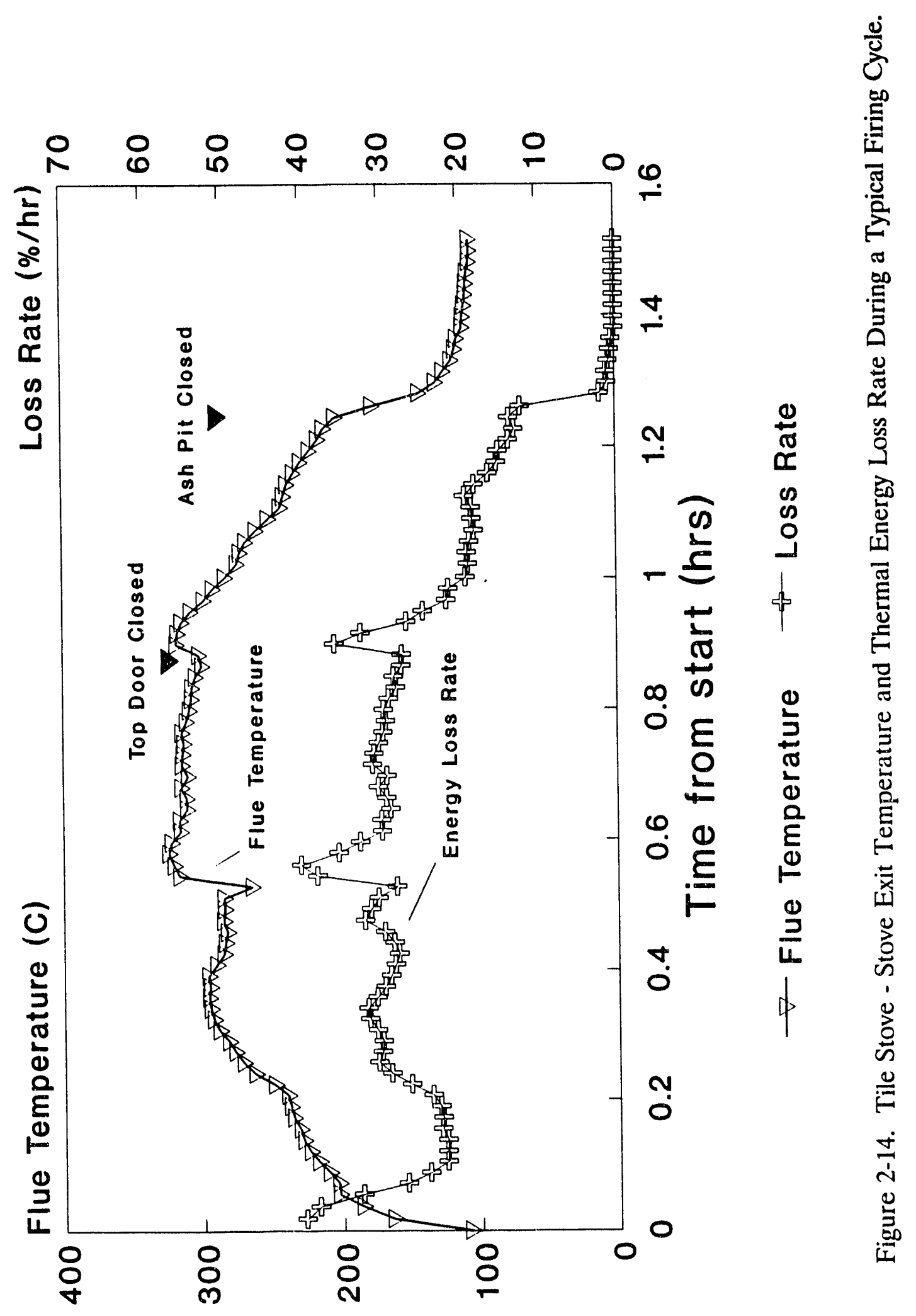




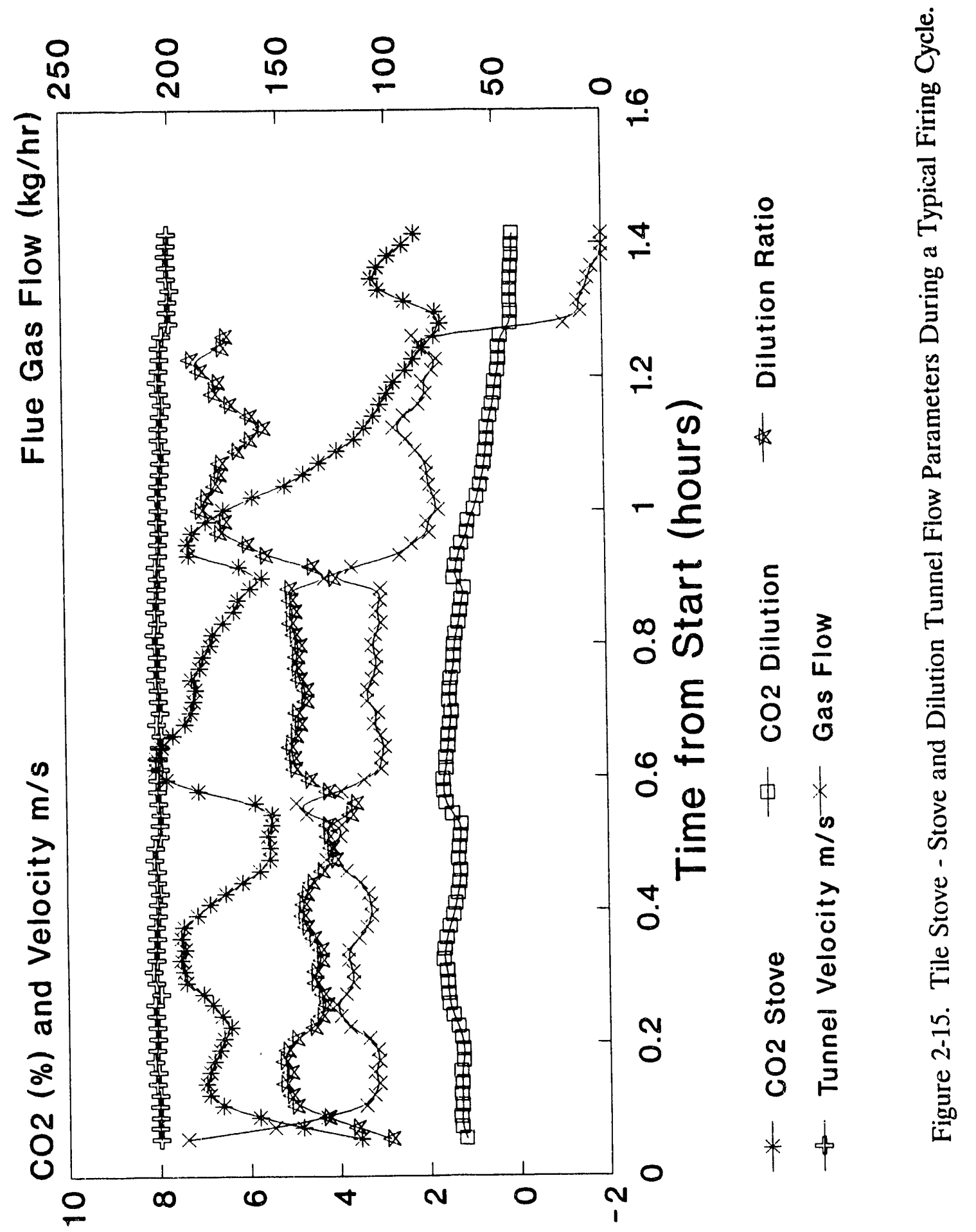


A very significant part of the total $\mathrm{CO}$ emission rate clearly occurs after this top door has been closed. When the lower, ash pit door is finally closed at about 1.3 hours the combustion process clearly stops.

Figure 2-13 shows the $\mathrm{SO}_{2}$ and $\mathrm{NO}_{x}$ emission profiles. Figure 2-14 illustrates the stove exit temperature and flue gas sensible and latent heat energy loss rate. The occasional peaks in temperature and loss rate are due to grooming of the fire. A selected group of flow parameters are given in Figure 2-15, including the stove mass flow, the dilution ratio and the dilution tunnel flow. As flue gas flow varies during the firing cycle the dilution ratio varies from about 3 to 7 but the dilution tunnel velocity (and flow rate) remain quite steady.

Figure 2-16 shows typical trends in the stove internal temperatures during a 20 hour firing cycle. The temperature points correspond to Figure 2-10 with the exception of point 25, which is the stove exit gas temperature. This data is also for the coal from the Wujek mine with normal operating procedures. Figure 2-17 shows the same data with an expanded scale covering only the "firing" part of the cycle.

Performance of the tile stove with each of the three fuels tested is summarized in Table 211. Relati .e to the stoker-fired boiler houses the emission factors for $\mathrm{CO}$, particulates, semivolatile organics and volatile (methane) organics are very much higher for the stoves as expected. Generally, the efficiency of the tile stove is quite high. Both efficiency and emissions with the coals are roughly similar to results which have been obtained with modern coal stoves (Waslo and Jaasma, 1983). A dramatic reduction in picticulate emissions is obtained by substituting the smokeless briquettes for the coal. Carbon monoxide, however, is increased.

A similar summary of test results with the slow burning, cast-iron stove is provided in Table 2-12. Particulate emissions are somewhat lower with this stove, but $\mathrm{CO}$, semi-volatile organics, and volatile organics very much higher. One important conclusion here is that replacement of tile stoves with the cast iron stoves produces no significant benefit. Again, dramatic reductions in the particulate emissions are obtained with the use of the smokeless briquettes. $\mathrm{NO}_{\mathrm{x}}$ emissions are considerably lower in the slow-burning cast iron stove generally. In both stoves the smokeless fuels, which inherently burn slower, have lower $\mathrm{NO}_{x}$ emissions.

With the tile stove, results are also available of some of the tests done with different operating conditions. Table $2-13$ shows results with the stove doors fully opened during the first 1-1/2 hours. Under more normal conditions the door would be open only slightly. Comparison with Table 2-11 shows that the effects on performance are small.

Table 2-14 shows results of tests in which the doors were left opened for an extra hour, a practice sometimes followed. This leads to lower efficiency and no emission improvement. 


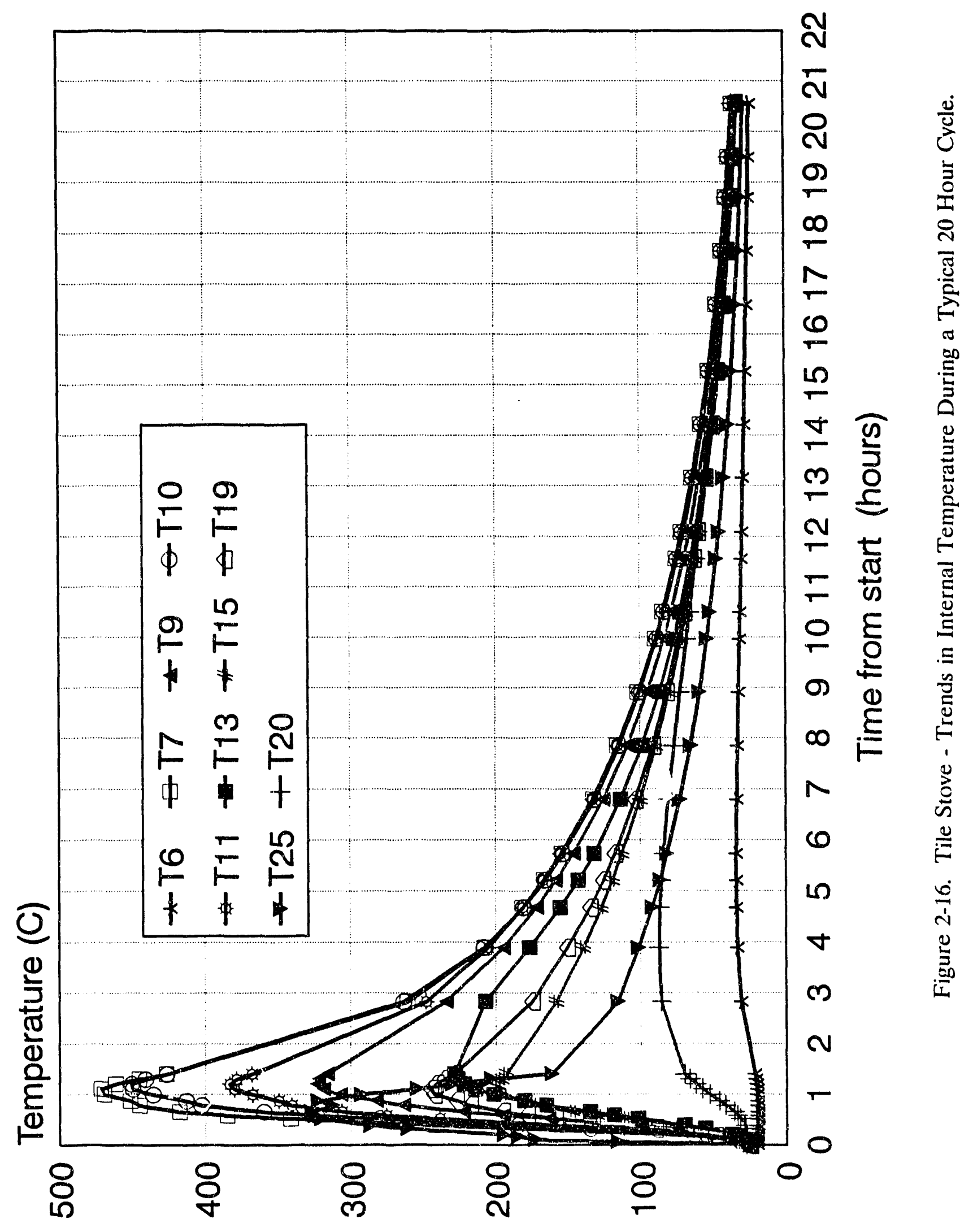




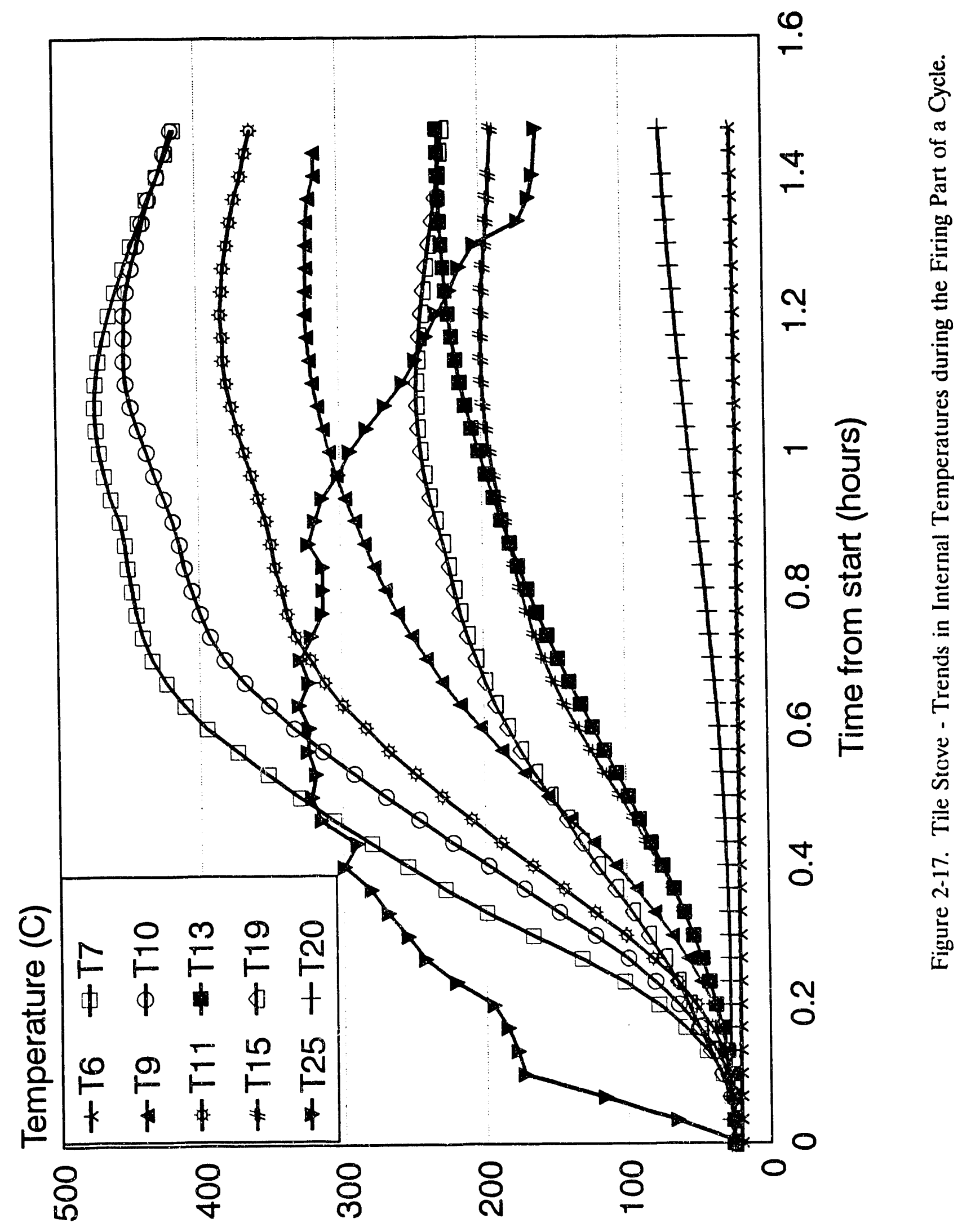




\begin{tabular}{|c|c|c|c|c|}
\hline FUEL & & Wujek & Boleslaw & Zabrze \\
\hline & & & Smialy & Briquettes \\
\hline Thermal Efficiency & (\%) & 68 & 62 & 57 \\
\hline & & & & \\
\hline PARTICULATES & (LBS./MMBtu) & 1.23 & 1.30 & 0.07 \\
\hline $\mathrm{CO}$ & (LBS./MMBtu) & 2.01 & 1.89 & .14 \\
\hline NOx & (LBS./MMBtu) & 0.51 & 0.31 & 0.20 \\
\hline SEMI-VOL ORGAANICS & (LBS./MMBtu) & $6.97 E-02$ & $8.40 \mathrm{E}-02$ & $3.70 \mathrm{E}-02$ \\
\hline VOLATILE ORGANICS & (LBS./MMBtu) & 0.13 & 0.32 & 0.20 \\
\hline & $(\sigma(Y) C o a)$ & & 138 & \\
\hline EMISSION INDEX-PARTICULATES & $(\mathrm{g} / \mathrm{Kg}$ Coal $)$ & $\frac{16.6}{27}$ & $\frac{13.8}{20}$ & $\frac{0.8}{19.3}$ \\
\hline EMISSION INDEX -CO & $(\mathrm{g} / \mathrm{Kg} \mathrm{Coal})$ & 27.1 & 20 & 49.3 \\
\hline EMISSION INDEX -NOX & $(\mathrm{g} / \mathrm{Kg}$ Coal $)$ & 6.9 & 3.3 & 2.41 \\
\hline EMISSION INDEX - SEMI-VOL ORG & $(\mathrm{g} / \mathrm{Kg}$ Coal $)$ & 0.94 & 0.89 & 0.44 \\
\hline EMISSION INDEX-VOLATILE ORGANIC & $(\mathrm{g} / \mathrm{Kg} \mathrm{Coal})$ & 1.77 & 3.35 & 2.42 \\
\hline EMISSION INDEX SO2 & $(\mathrm{g} / \mathrm{Kg}$ Coal $)$ & 5.11 & 5.6 & 3.33 \\
\hline
\end{tabular}

Table 2-11. Summary of the Tile Stove Tests Results - Normal Operating Conditions

\begin{tabular}{|c|c|c|c|c|}
\hline FUEL & & Wujek & Boleslaw & Zabrze \\
\hline & & & Smialy & Briquettes \\
\hline Thermal Efficiency & (\%) & 54 & 60 & 68 \\
\hline & & & & \\
\hline PARTICULATES & (LBS./MMBtu) & 1.10 & 0.78 & 0.03 \\
\hline $\mathrm{CO}$ & (LBS./MMBtu) & 14.82 & 4.44 & 6.93 \\
\hline \begin{tabular}{|l|l|} 
NOx \\
\end{tabular} & (LBS./MMBtu) & 0.15 & 0.05 & 0.01 \\
\hline SEMI-VOL ORGANICS & (LBS./MMBtu) & $8.89 E-01$ & $6.42 \mathrm{E}-01$ & $7.23 \mathrm{E}-02$ \\
\hline VOLATILE ORGANICS & (LBS./MMBtu) & 3.11 & 3.52 & 0.94 \\
\hline & & & & \\
\hline EMISSION INDEX-PARTICULATES & $(\mathrm{g} / \mathrm{Kg} \mathrm{Coal})$ & 14.9 & 8.3 & 0.4 \\
\hline \begin{tabular}{|l|} 
EMISSION INDEX -CO \\
\end{tabular} & (g/Kg Coal) & 200 & 47 & 82.5 \\
\hline EMISSION INDEX -NOx & $(\mathrm{g} / \mathrm{Kg}$ Coal $)$ & 2 & 0.5 & 0.14 \\
\hline EMISSION INDEX - SEMI-VOL ORG & $(\mathrm{g} / \mathrm{Kg}$ Coal $)$ & 12 & 6.8 & 0.86 \\
\hline EMISSION INDEX-VOLATILE ORGANIC & $(\mathrm{g} / \mathrm{Kg}$ Coal $)$ & 42 & 37.3 & 11.2 \\
\hline \begin{tabular}{|l|} 
EMISSION INDEX SO2 \\
\end{tabular} & $(\mathrm{g} / \mathrm{Kg}$ Coal $)$ & 1.7 & 1.8 & 2 \\
\hline
\end{tabular}

Table 2-12. Summary of Cast Iron Stove Test Results 


\begin{tabular}{|c|c|c|c|}
\hline FUEL & & Wujek & Zabrze \\
\hline & & & Briquettes \\
\hline Thermal Efficiency & $(\%)$ & 57 & 57 \\
\hline PARTICULAATES & (LBS./MMBtu) & 1.27 & 0.06 \\
\hline $\mathrm{CO}$ & (LBS./MMBtu) & 1.39 & 7.09 \\
\hline NOx & (LBS./MMBtu) & 0.19 & 0.14 \\
\hline SEMI-VOL ORGANICS & (LBS./MMBtu) & $5.11 \mathrm{E}-02$ & $5.46 E-02$ \\
\hline VOLATILE ORGANICS & (LBS./MMBtu) & 0.19 & 0.22 \\
\hline EMISSION INDEX-PARTICULATES & $(\mathrm{g} / \mathrm{Kg}$ Coai $)$ & 17.1 & 069 \\
\hline EMISSION INDEX -CO & (g/Kg Coal) & 18.8 & 84.4 \\
\hline EMISSION INDEX -NOX & $(\mathrm{g} / \mathrm{Kg}$ Coal $)$ & 2.57 & 1.65 \\
\hline EMISSION INDEX - SEMI-VOL ORG & $(\mathrm{g} / \mathrm{Kg}$ Coal $)$ & 0.69 & 0.65 \\
\hline EMISSION INDEX-VOLATILE ORGANIC & $(\mathrm{g} / \mathrm{Kg}$ Coal $)$ & 2.5 & 2.6 \\
\hline EMISSION INDEX SO2 & $(\mathrm{g} / \mathrm{Kg}$ Coal $)$ & 4.8 & 2.8 \\
\hline
\end{tabular}

Table 2-13. Tile Stove - Results of Tests with Both Doors Fully Opened for the Entire Firing Cycle.

\begin{tabular}{|c|c|c|c|}
\hline FUEL & & Wujek & Zabrze \\
\hline & & & Briquettes \\
\hline Thermal Efficiency & $(\%)$ & 48 & 49 \\
\hline PARTICULATES & (LBS./MMBtu) & 1.27 & 0.06 \\
\hline CO & (LBS./MMBtu) & 1.39 & 7.09 \\
\hline NOx & (LBS./MMBtu) & 0.19 & 0.14 \\
\hline SEMI-VOL ORGANICS & (LBS./MMBtu) & $5.11 \mathrm{E}-02$ & $5.46 \mathrm{E}-02$ \\
\hline VOLATILE ORGANICS & (LBS./MMBtu) & 0.19 & 0.22 \\
\hline EMISSION INDEX-PARTICULATES & (g/Kg Coal) & 17.1 & 0.69 \\
\hline EMISSION INDEX -CO & (g/Kg Coal $)$ & 18.8 & 84.4 \\
\hline EMISSION INDEX -NOx & (g/Kg Coal $)$ & 2.57 & 1.65 \\
\hline EMISSION INDEX - SEMI-VOL ORG & $(\mathrm{g} / \mathrm{Kg}$ Coal $)$ & 0.69 & 0.65 \\
\hline EMISSION INDEX-VOLATILE ORGANIC & $(\mathrm{g} / \mathrm{Kg}$ Coal $)$ & 2.5 & 2.6 \\
\hline EMISSION INDEX SO2 & $(\mathrm{g} / \mathrm{Kg}$ Coal $)$ & 4.8 & 2.8 \\
\hline
\end{tabular}

Table 2-14. Tile Stove - Results of Tests with Doors Opened for One Extra Hour 


\section{References}

Macumber, D.E. and Jaasma, D.R. 1981 "Efficiency and Emissions of a Hand-Fired Residential Coal Stove", in Proceedings of the International Conference on Residential Solid Fuels, Oregon Graduate Center.

U.S. Code of Federal Regulations. 1990. Title 40, Part 60, Appendix A. Methods 5G and 5H, U.S. Government Printing Office, Washington D.C.

Waslo, D.E. and Jaasma, D.R. 1983. "Emissions, Efficiency and Combustion Chamber Conditions of a Smokless, Hand-fired Coal Heater," Proceedings of Solid Fuel Heating Symposium.

Zielinski, H., Kaczmarzyk, G., Sciazko, M., Rychiy, J. and Chmielniak, T. 1991. "Clean Energy Production by Use of Smokeless Fuel Manufacturing and ICGCC Systems", United Nations Economic Commission for Europe, Fifth Seminar on Emission Control Technology for Stationary Sources, Nurnber, Federal Republic of Germany.

\section{FUEL PRICE PROJECTIONS}

Fuel prices in Poland have traditionally been set and subsidized by the government. In the current period of transition to a market economy, prices have risen rapidly and are now close to world levels; further increases are expected. Coal prices have been liberalized and subsidies are being removed. Two important goals of fuel price decontrol are to reach world levels, and to change the relationship of prices to industry and to end-users. Price levels and industry/consumer ratios are designed to meet requirements of the World Bank. Restructuring of the energy industries, which includes ownership changes, is also underway.

Fuel prices are a significant determinant of the relative costs and benefits of the options under consideration in this project. As part of the incentives analysis activity of the project, Polish analysts have prepared short-term (through 1996) price projections for natural gas, coal, and electricity, and also examined progress in restructuring the energy industries (Polinvest 1992).

\section{Natural Gas}

In 1990 natural gas represented approximately 9 percent of Poland's primary energy supply; between 65 and 75 percent of natural gas consumption is imported from the former Soviet Union (IE.A 1991). The price of Russian gas is expected to continue to rise rapidly. Polish analysts expect that by 2000 the amount of natural gas extracted in Poland will increase by 100 percent and that its cost will be slightly lower than imported gas.

Non-industry natural gas prices have risen dramatically from less than $\$ 30 / 1000 \mathrm{~m}^{3}$ in 1990 to $\$ 139 / 1000 \mathrm{~m}^{3}$ in early 1992. The agreement with the World Bank stipulates that hy 1996 
the price for individuals will rise to $\$ 216 / 1000 \mathrm{~m}^{3}$ and the price for industry will reach $\$ 135 / 1000 \mathrm{~m}^{3}$. Thus individual consumers will pay a price that is 1.6 times that of industry. The price to individual users has risen faster than planned; the World Bank may accept a 1.4 ratio. Figure 2-18 shows the range of projected prices to consumers, and Figure 2-19 shows the relationship between consumer and industry prices.

Restructuring of the gas sector is occurring more slowly than in the coal and electricity sectors; the Polish Oil Drilling \& Gas Engineering Company (PGNiG) controls both oil and gas exploration and drilling, as well as gas transmission and distribution. In 1991 an interdepartment committee was appointed to develop restructuring recommendations. It is likely to recommend that $\mathrm{PGNiG}$ be divided into two companies, one for extraction and processing, and one for transmission. This restructuring would be accomplished during 1993. PGNiG's monopoly over extraction is expected to be eliminated during 1992, as negotiations for licensing foreign companies to seek and extract natural gas are underway.

By the beginning of 1994 it will be possible to separate the distribution networks in Krakow. Some of these assets can be communalized to form a joint-stock company, the Krakow Gas Grid Joint-Stock Company. Initially all shares will belong to the city, eventually to be sold to interested purchasers or used as contributions to joint-ventures for developing the natural gas grid.

\section{Electricity}

The electricity price forecasts prepared by the Polish analysts are based on forecast coal prices, because most electricity in Poland is generated with coal. The forecasts include changing the relationships of industry and retail electricity prices to boiler coal prices. Achieving the desired structure is expected to begin in 1993 and take about five years. Figure 2-20 shows electricity price forecasts through 1996 . These prices are less than current U.S. prices of about $\$ 0.075 / \mathrm{kWh}$ for residential and commercial customers and less than $\$ 0.05 / \mathrm{kWh}$ for industry.

The night-time rate is for thermal stoves only, and is currently used by about 12 percent of Krakow's population. A new schedule of electricity rates is currently under consideration, and the various rates will be evaluated as possible incentives for fuel-switching.

Restructuring in the electricity sector is turther advanced than in the natural gas sector. The central government's Power Engineering and Brown Coal Community was abolished in the fall of 1990 (Kolakowski 1991). There are now a number of separate generating enterprises, a transmission company, and more than 30 distribution enterprises. The transmission company, the Polish Power Grid Company, was established as a joint stock company and is responsible for maintaining the grid as well as load dispatch (Coopers \& Lybrand 1991).

As part of the continuing restructuring and privatization activities, it is expected that the Power Company in Kraków will be restructured by the end of 1992. This will allow the separation of some of its assets which would be taken over by the city of Kraków. Sometime 


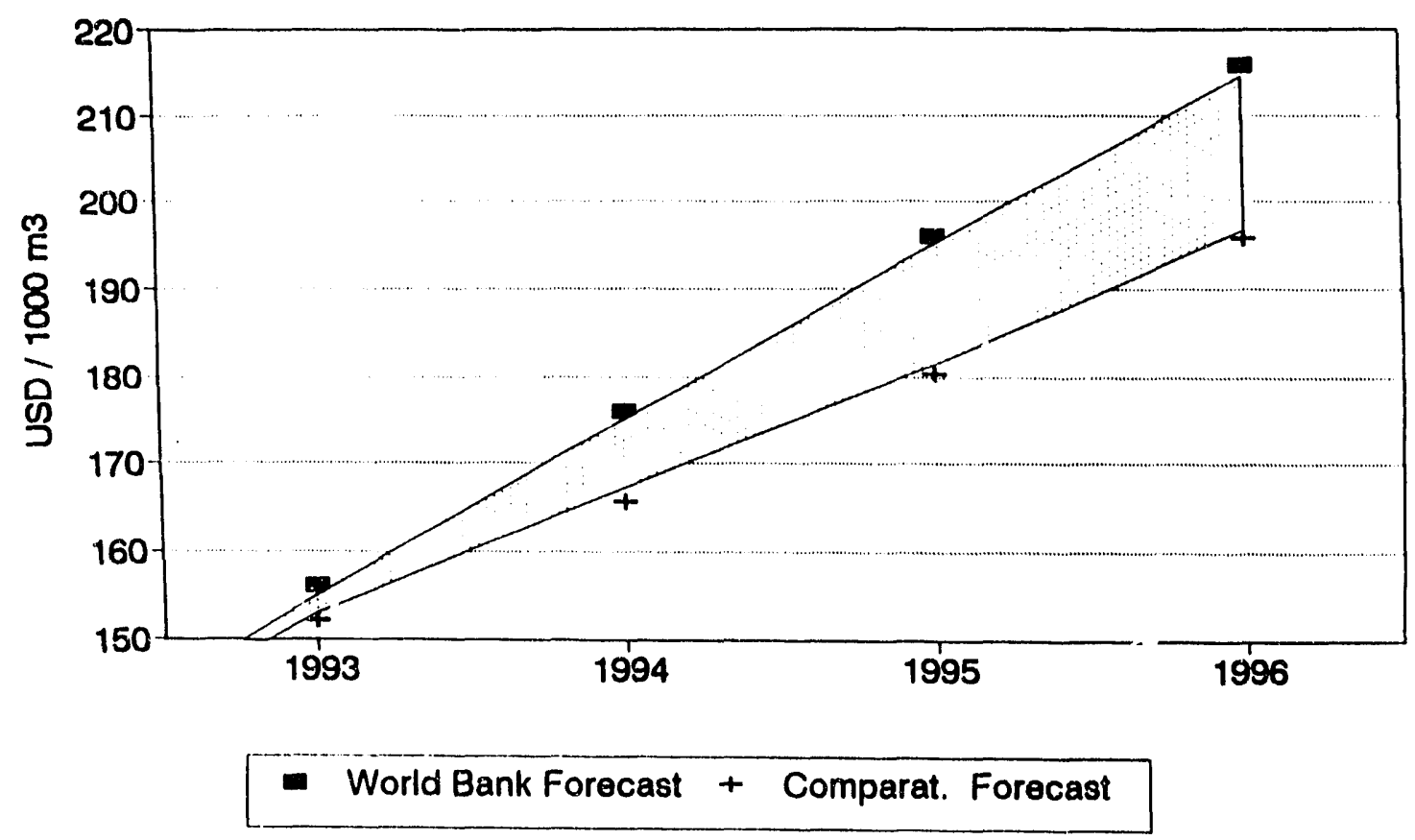

Figure 2-18. Forecast Range of Natural Gas Prices for Individual Consumers.

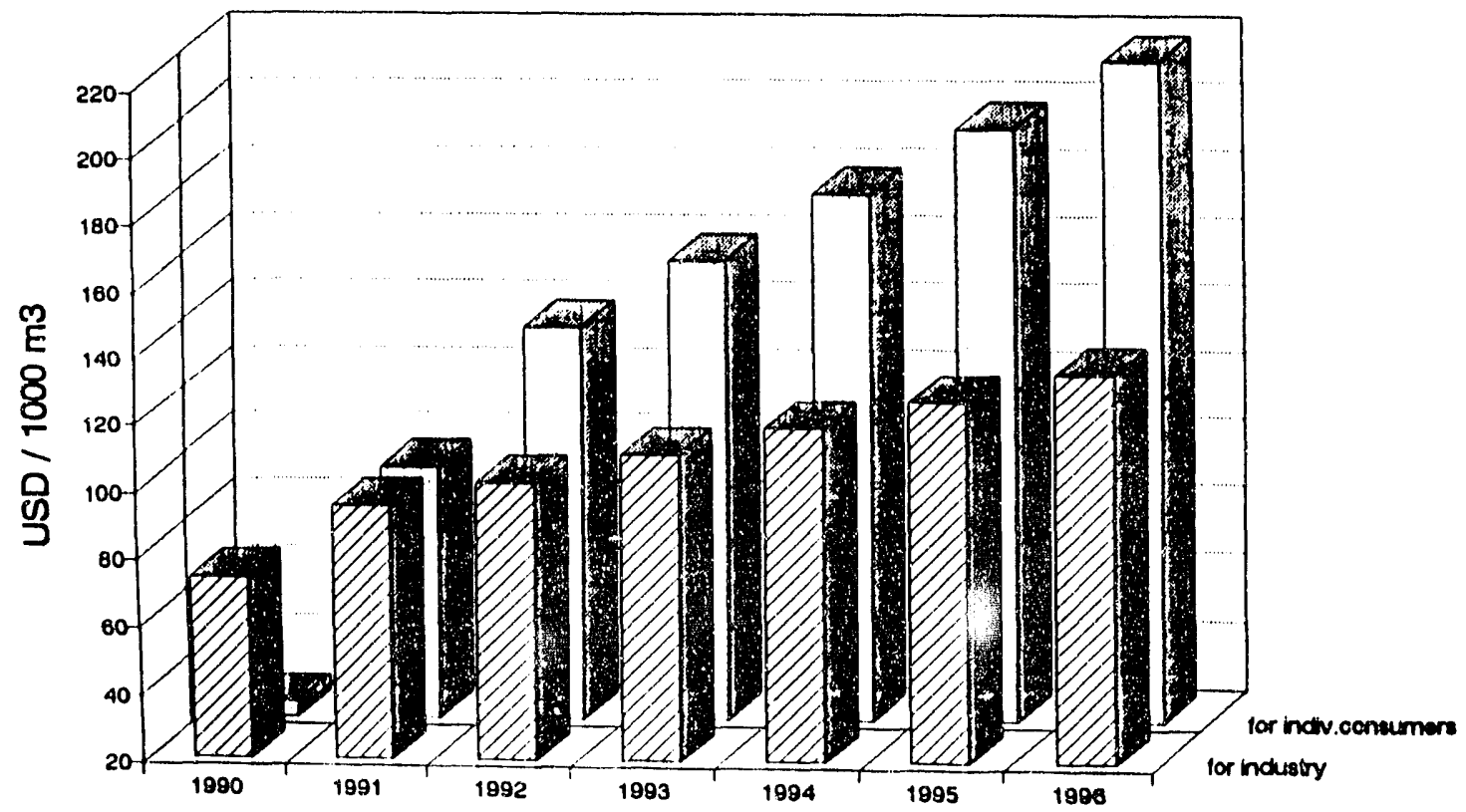

Figure 2-19. Forecast Natural Gas Prices based on World Bank Forecast. 


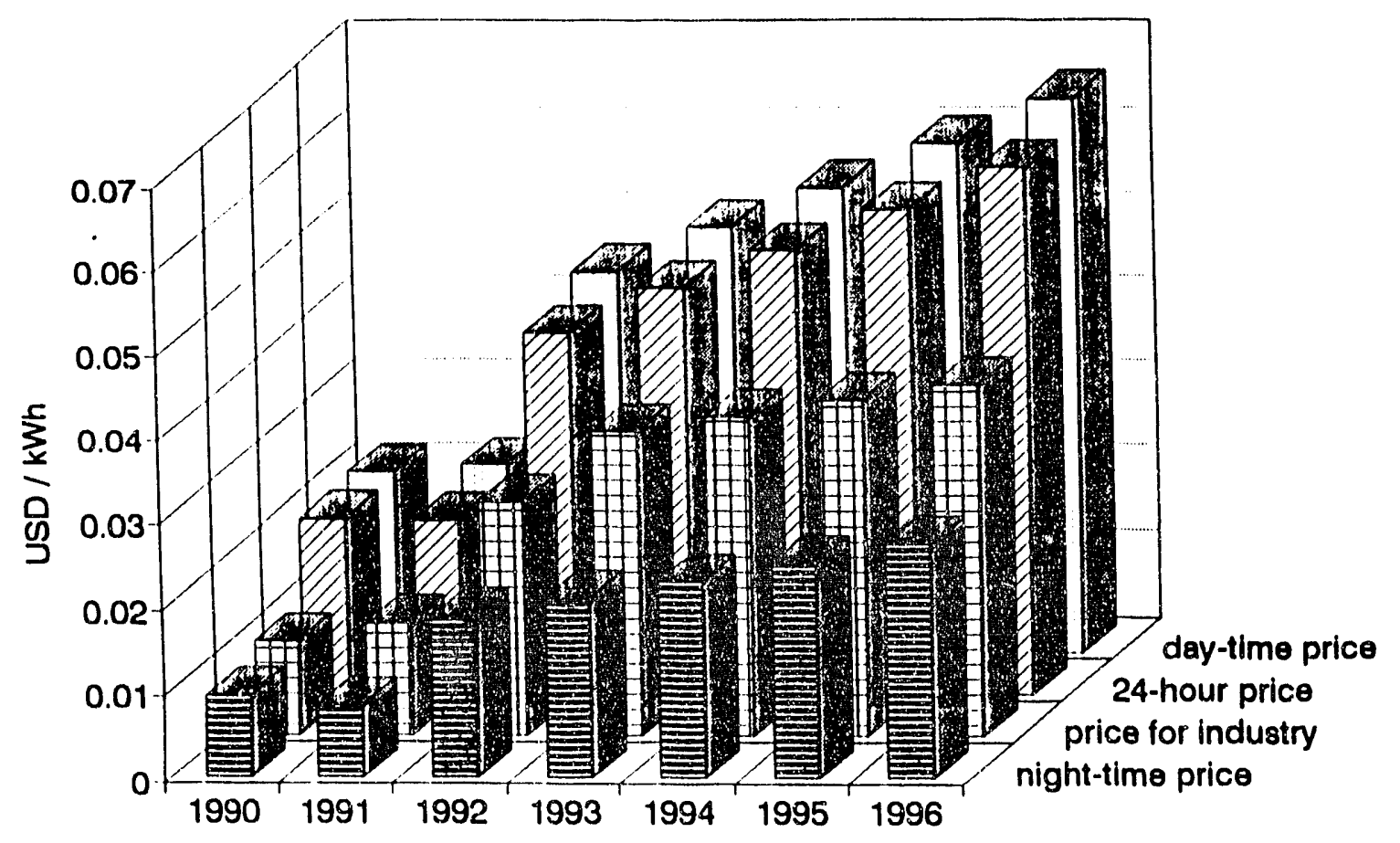

Figure 2-20. Forecast Electricity Prices.

in 1993, the Kraków Electric Grid Joint-Stock Company could be formed, with shares sold to private investors or used in joint ventures for developing the electric grid for consumers using electric heat. Consideration will also be given to the possibility of purchasing electricity directly from the $£$ eg and Skawina Power Stations.

Electricity prices in Poland have traditionally been below the cost of production, transmission, and distribution. In addition to giving customers incorrect signals on the relative value of electricity, the government has been required to reduce the industry's income taxes in order to finance investment projects (Makysa 1990). As privatization proceeds, it is essential that wholesale and retail electricity prices be carefully coordinated. It is planned that the accounting between production, distribution and consumption be restructured by the end of 1993.

Marginal cost pricing, such as in the U.S., is not currently being considered because excess capacity exists at the present time and actual costs are not well known. Policies under development will eventually lead to cost-base pricing and elimination of cross-class subsidies.

\section{Coal}

Coal prices in Poland have been liberalized, unlike those for natural gas, electricity, and oil. Remaining subsidies of coal prices are planned to be removed in 1992. Coal price forecasts are based on U.S. projections for coal from the Appalachian Mountains region, adjusted for transportation and loading costs. Retail and industry price projections through 1996 are shown in Figure 2-21. Retail prices for various sizes of coal and for coke are shown in Figure 2-22. 


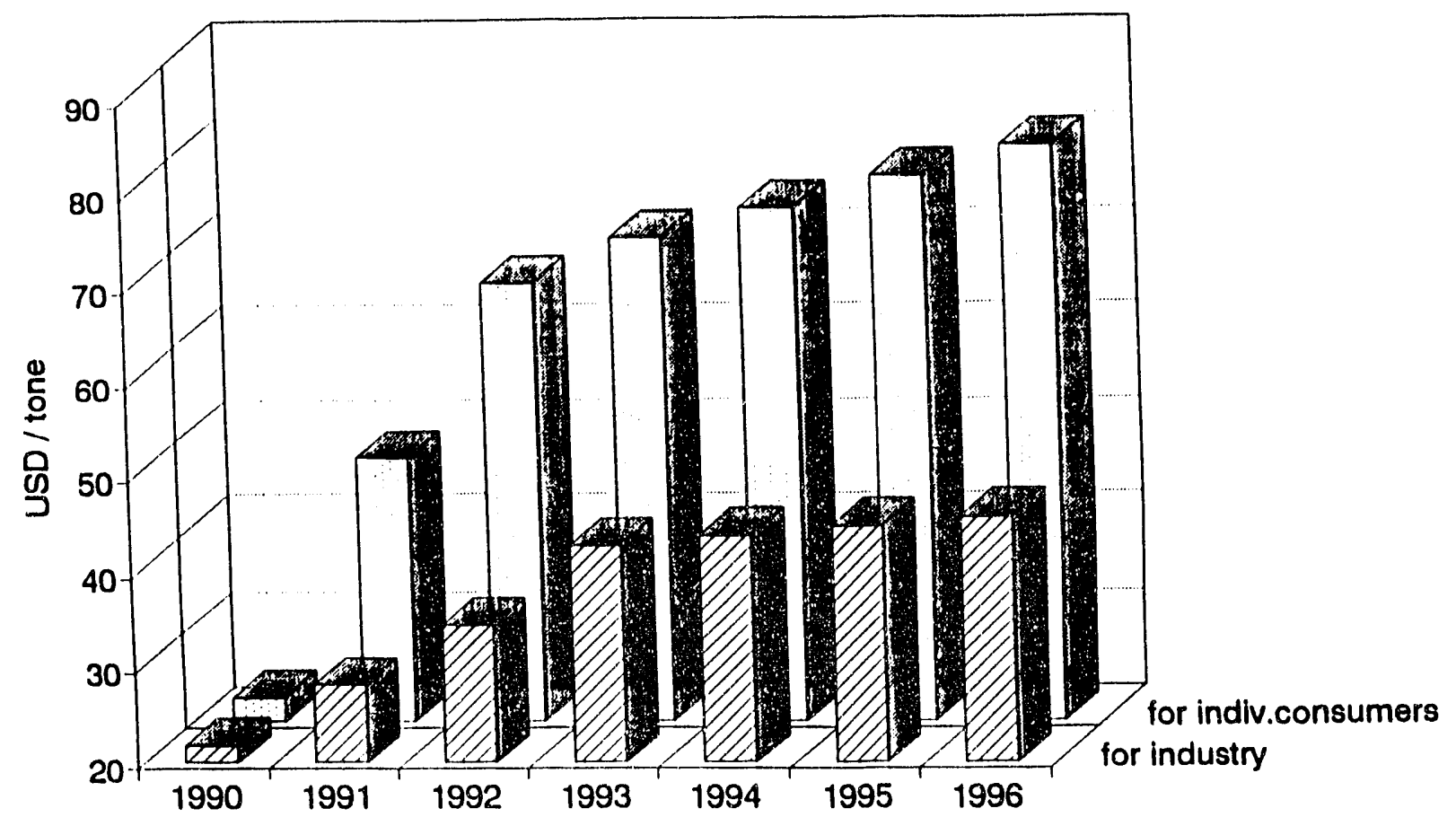

Figure 2-21. Forecast Coal Prices.

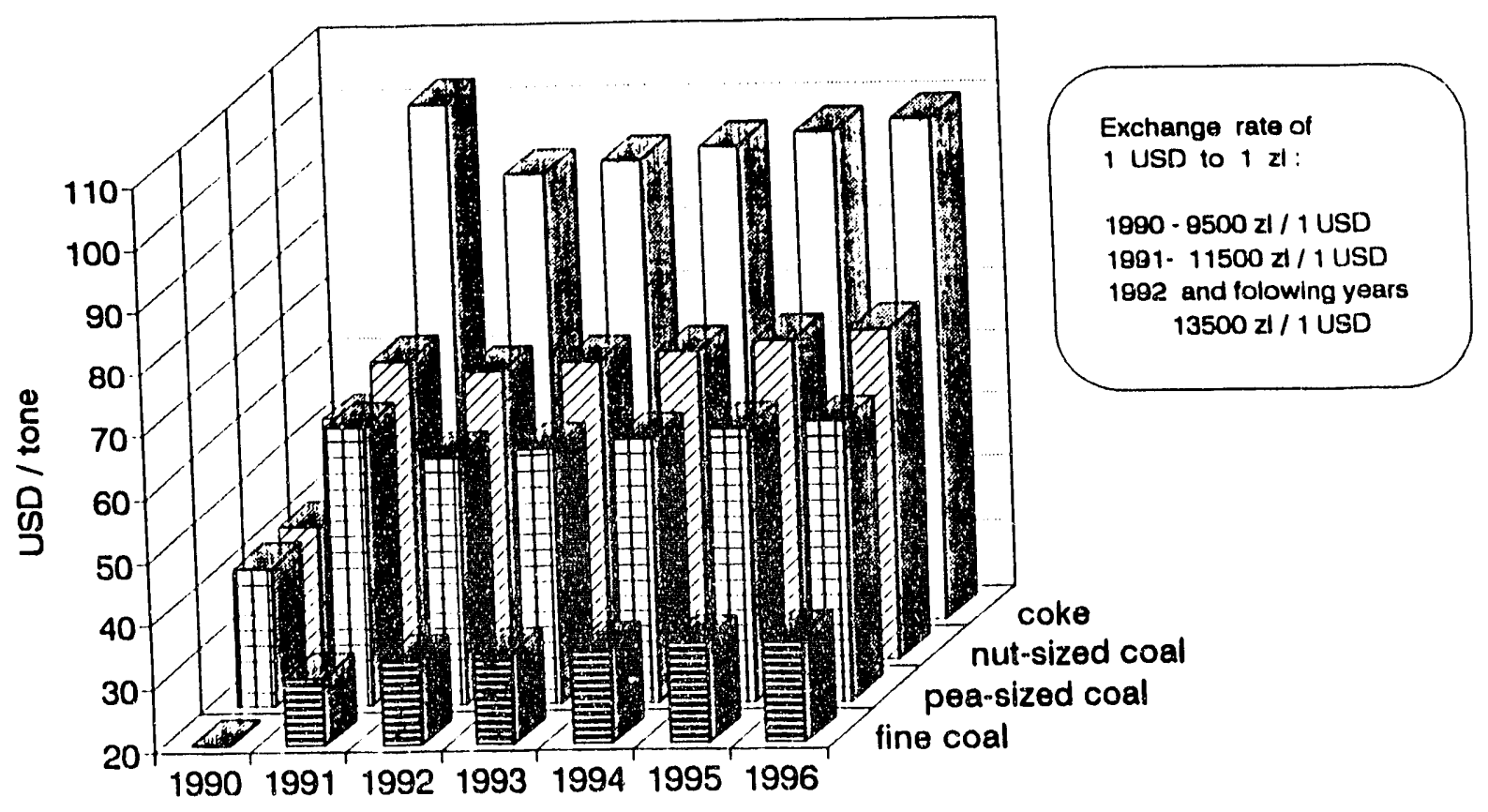

Figure 2-22. Forecast Prices for Individual Consumers of Coal-Derived Fuels. 


\begin{tabular}{||l|c|c|c|}
\hline \hline \multicolumn{4}{|c|}{ Table 2-18. Emission Factors (Continued) } \\
\hline d) liquid fuels & Unit & Fuel Oil & Gas Oil \\
\hline Pollutant & $\mathrm{kg} / \mathrm{m}^{3} \%$ & 19 & 19 \\
\hline sulphur dioxide & $\mathrm{g} / \mathrm{GJ}$ & 120 & 120 \\
\hline nitrogen dioxide & $\mathrm{kg} / \mathrm{m}^{3}$ & 0.6 & 0.4 \\
\hline carbon monoxide & $\mathrm{kg} / \mathrm{m}^{3}$ & 0.000002 & 0.000002 \\
\hline benzo- $\alpha$-pyrene & $\mathrm{kg} / \mathrm{m}^{3}$ & 1.8 & 1.0 \\
\hline dust (total) & not subject to balance \\
\hline soot &
\end{tabular}

NOTES: If test data are not available, assumed values are:

1. sulphur content in fuel:
- fuel oil
$2.5 \%$
- gas oil
$1.5 \%$

2. caloritic value of fuel:

$\begin{array}{ll}\text { - fuel oil } & 0.045 \mathrm{GJ} / \mathrm{m}^{3} \\ \text { - gas oil } & 0.049 \mathrm{GJ} / \mathrm{m}^{3}\end{array}$

Fuel densities accepted:
- fuel oil
$0.90 \mathrm{Mg} / \mathrm{m}^{3}$
- gas oil
$0.86 \mathrm{Mg} / \mathrm{m}^{3}$

\begin{tabular}{||l|c|c||}
\hline \hline e) natural gas & \multicolumn{2}{|c||}{} \\
\hline Pollutant & Unit & Index \\
\hline sulphur dioxide & $\mathrm{kg} / \mathrm{m}^{3}$ & $9.6 \mathrm{E}-6$ \\
\hline nitrogen dioxide & $\mathrm{g} / \mathrm{GJ}$ & 60 \\
\hline carbon monoxide & $\mathrm{kg} / \mathrm{m}^{3}$ & $3.2 \mathrm{E}-4$ \\
\hline dust (total) & $\mathrm{kg} / \mathrm{m}^{3}$ & $3.0 \mathrm{E}-4$ \\
\hline
\end{tabular}

NOTE: According to the data reported by the Cracow Gas Station, the calorific value of fuel amounits on an average to $0.046 \mathrm{GJ} / \mathrm{m}^{3}$. 
Due to increasing costs of extraction and environmental mitigation, coal prices are expected to grow at a rate of 1.8 percent per year from 1995 to 2000, by 2 percent per year until 2005, and by 1 percent per year to 2010 .

\section{References}

Coopers \& Lybrand, European Energy Group. 1991. "Energy in Eastern Europe," Energy Policy, Novemoer 1991, pp. 816-840.

International Energy Agency. 1991. Energy Policies Poland, 1990 Survey, OECD/IEA, Paris, Fance.

Kolakowski, Tomasz. 1991. "The Present and Anticipated Organization of Polish Electrical Power Engineering," in Proceedings of Seminar on Power Generation Management and Structures in East and West, June 26-28, Berlin, International Energy Agency, OECD/IEA, Paris, France.

Makysa, Penrik. 1990. "Energy Pricing in Poland in the Light of Market Developments", in Proceedings Seminar on Energy in East and West: The Polish Case, April 2-4, Copenhagen, International Energy Agency, OECD/IEA, Paris, France.

Polinvest Ltd. 1992. "American-Polish Program of Elimination of Low-Emission Sources in Krakow, Tasks 2.3.1, 2.3.2, 3.3.1, 3.3.2, 5.3.1," Krakow Development Office, Krakow, Poland.

\section{COSTS OF GAS CONVERSION}

One of the options under consideration in this program is the conversion of the remaining solid fuel-fired boilers located in the Old Town area of the city to natural gas. Not long ago, (1975-1980), the entire Old Town area was heated with solid fuel. As a result of a long-term elimination program, many solid fuel-fired boilers have been converted to gas. The boiler inventory, described in a previous section, showed 66 gas-fired boiler houses in Old Town, with a total capacity of $33,330 \mathrm{~kW}$, and 48 solid fuel-fired boiler houses (Ekopol 1992). The solid fuel-fired boiler houses contained 86 boilers with a total capacity of $18,653 \mathrm{~kW}$ and used 4,562 tons of fuel per year.

During 1991 nine additional boiler houses were converted to gas, at the initiative of their owners. Three additional boiler houses are being eliminated, with help from the Krakow Development Office, by connecting the buildings or areas they serve to other, existing boilers.

Polish analysts have determined the costs of converting the remaining 36 solid fuel-fired boiler houses (capacity 16,252 kW) and of modernizing the gas grid to supply these boilers (Krakow Development Office 1992). 
Total costs to convert the 36 boiler houses are estimated to be 21 billion zlotys, ar almost $\$ 2$ million using the December 1991 exchange rate of 11,012 zlotys per dollar. These costs are based on boiler-specific conversion plans prepared by the Krakow Development Office for 20 boiler houses and specifications prepared by others for an additional 12 boiler houses, as well as the actuai costs for the conversions that took place during 1991.

Costs are divided into three components; construction; equipment; and installation. Installation costs are for gas, water, sewage and electricity installations. Overall, construction costs account for about 35 percent of total costs, equipment costs for 45 percent, and installation costs for the remaining 20 percent. Material and labor costs were calculated using 1991 prices.

Individual boiler conversion costs depend on capacity as well as building characteristics. Costs can be significantly higher in buildings designated as having historic value; these buildings are legally protected and modifications may be restricted. Capacity-related costs range from $\$ 90$ per $\mathrm{kWh}$ for large boilers to $\$ 272$ per $\mathrm{kWh}$ for small boilers.

The gas supply must be increased by an additional $1500 \mathrm{Nm}^{3} / \mathrm{h}$. to allow the conversion of the remaining Old Town boilers. Necessary improvements to the distribution system include increasing the diameter of 4 sections of low-pressure pipelines totalling 585 meters, the reconstruction of 15 connections (total 141 meters) to buildings, and increasing the capacity at 2 reduction stations. Total cost is estimated at 1 billion zlotys, or $\$ 90,810$ using the 1991 exchange rate. The analysts recommend that gas network modernization be carried out by a single, specialized investor; individual building owners are unlikely to have the necessary funds or expertise.

Moreover, it is unlikely that city will be able to provide further assistance for boiler conversions any time soon.

Total investment costs for the Old Town boilers and distribution system are $\$ 123$ per $\mathrm{kW}$, or approximately $\$ 2$ million.

To extend the usefulness of the analysis, a conversion cost function was derived from the boiler house-specific data used for this analysis. This was done by eliminating small boiler houses (less than $50 \mathrm{~kW}$ ) which need little adaption work, and by eliminating those in buildings with special characteristics that increase the conversion costs dramatically.

For the remaining boiler houses, costs are separated into a fixed or base cost and a variable cost, which is dependent on capacity. The fixed part of the costs varies between 100 and 150 million zlotys; an average of 120 million zlotys is assumed. The function thus obtained is:

$$
\mathrm{K}(\text { million zlotys })=120+1.0 * \mathrm{Q}(\mathrm{kW})
$$

where: $\mathrm{K}=$ average investment cost, and

$\mathrm{Q}=$ boiler house capacity. 


\section{References}

Ekopol. 1992. "American-Polish Program of Actions in the Field of Elimination of Low Emission Sources in Cracow. Subproject 2. Replacement of solid fuel boiler-houses with gas boiler-houses in the "Old City" area. Task 2.3.3. Elaboration of calculations of fees and penalties to be paid by the user of solid fuel boiler-house because of the emission of atmosphere pollutions basing on the rules in force." Cracow Development Office, Cracow, Poland.

Krakow Development Office. April 1992. "Replacing Solid Fuel Fired Boiler Houses with Gas Fired Ones Within the Old City Area; Investment Costs Esiimate Summary." Krakow, Poland.

\section{AIR POLLUTION FEES AND PENALTIES}

Poland has enacted a system of fees and penalties regulating air pollutant emissions from large stationary combustion sources. In two areas of this project, replacing solid fuel-fired boilers with gas and boilerhouse modernization, this system is being evaluated to determine if it provides incentives to encourage fuel switching or modernization. To date, Polish analysts have prepared an overview of the current system (Ekopol 1991) and an analysis of its potential to encourage switching to gas (Ekopol 1992). A similar analysis is planned for the boiler house at Krzesławice.

\section{Overview}

Several laws and regulations serve to control air pollution in Poland. A law setting environmental policy was passed in April 1989; regulations setting maximum ambient air concentrations of many pollutants and limits on emissions were put forward by the Ministry of Environmental Protection, Natural Resources and Forestry in 1990. These are shown in Tables 2-15 and 2-16 (IEA, 1991). Emission limits apply to stationary combustion sources of over $0.2 \mathrm{MW}$. Fees are assessed for: dust (total); sulphur dioxide; nitrogen dioxide; carbon monoxide; benzo- $\alpha$-pyrene; and soot. Home stove owners are not subject to standards or fees.

Operators must apply to the Provincial Office (Department of Environmental Protection) to receive a decision on permitted emission levels for their facilities; this office also determines fees for permitted levels of emissions. Permitted emission levels are determined by local government and may not exceed those shown in Table 2-16; fees are based on emission factors defined by the government for each type of boiler, and on the amount and type of fuel used in the facility. Permits are granted on the basis that ambient air quality standaids will not be exceeded. Provincial offices monitor compliance and assess penalties for exceeding permitted levels. All fees and penalties are paid to the National Environment Protection Fund. 
Table 2-15. Maximum Permissible Concentrations of Selected Air Pollutants $\left.\mu \mathrm{g} / \mathrm{m}^{3}\right)^{1}$

\begin{tabular}{|c|c|c|c|c|c|c|}
\hline \multirow[b]{2}{*}{ Pollutant } & \multicolumn{3}{|c|}{ Protected Area ${ }^{2}$} & \multicolumn{3}{|c|}{ Special Protected Area } \\
\hline & $30 \mathrm{~min}$. & $24 \mathrm{hr}$. & Annual & $30 \mathrm{~min}$. & $24 \mathrm{hr}$. & Annual \\
\hline $\mathrm{NO}_{2}$ & 500 & 150 & 50 & 150 & 50 & 30 \\
\hline $\begin{array}{l}\text { Suspended } \\
\text { Particulate } \\
\text { Matter }\end{array}$ & - & 120 & 50 & - & 60 & 40 \\
\hline $\begin{array}{l}\mathrm{SO}_{2} \\
\text { Until } 1998 \\
\text { After } 1999\end{array}$ & $\begin{array}{l}600 \\
440\end{array}$ & $\begin{array}{l}200 \\
150\end{array}$ & $\begin{array}{l}32 \\
32\end{array}$ & $\begin{array}{l}250 \\
150\end{array}$ & $\begin{array}{l}75 \\
75\end{array}$ & $\begin{array}{l}11 \\
11\end{array}$ \\
\hline $\mathrm{CO}$ & 5000 & 1000 & 120 & 3000 & 500 & 61 \\
\hline $\begin{array}{l}\text { Elemental } \\
\text { Carbon }\end{array}$ & 150 & 50 & 8 & 50 & 20 & 4 \\
\hline $\begin{array}{l}{ }^{1} \text { Ground lev } \\
\text { model. }\end{array}$ & ncentr: & of po & ts are & ated & Pasq & sion \\
\hline
\end{tabular}

The fees can be considered an environmental tax, and are incorporated in the price of the product. If a plant has received a permit, but does not comply with its terms, the fee applies to emissions up to the limit of the permit. Above this, the penalty is 10 times the fee and is accounted for as an extraordinary loss and deducted from after-tax profit. If a plant has no permit, the plant pays a small penalty (fee times 2 ) which is treated as a regular cost.

Enforcement is difficult. Violations are determined by measuring stack gas concentrations, and there are only three teams engaged in doing this for the entire province. No measurements have been taken in Old Town during the last seven years. Rulings can also be appealed in court, and penalties are suspended during the period of appeal. Continuous monitoring is required only for plants emitting more than 100 tons/hour of $\mathrm{SO}_{2}$. Better enforcement options are currently being considered.

Interestingly, one of the problems identified by the analysts is technical. The sampling methods require the use of certain types of probes which cannot be put into old stacks with thick brick walls. Measurement holes often cannot be made either because of the poor condition of the building or because the building is protected as an historic monument. This is one of the main reasons why no measurements have been taken, or penalties applied, in the Old Town area in the past seven years. 


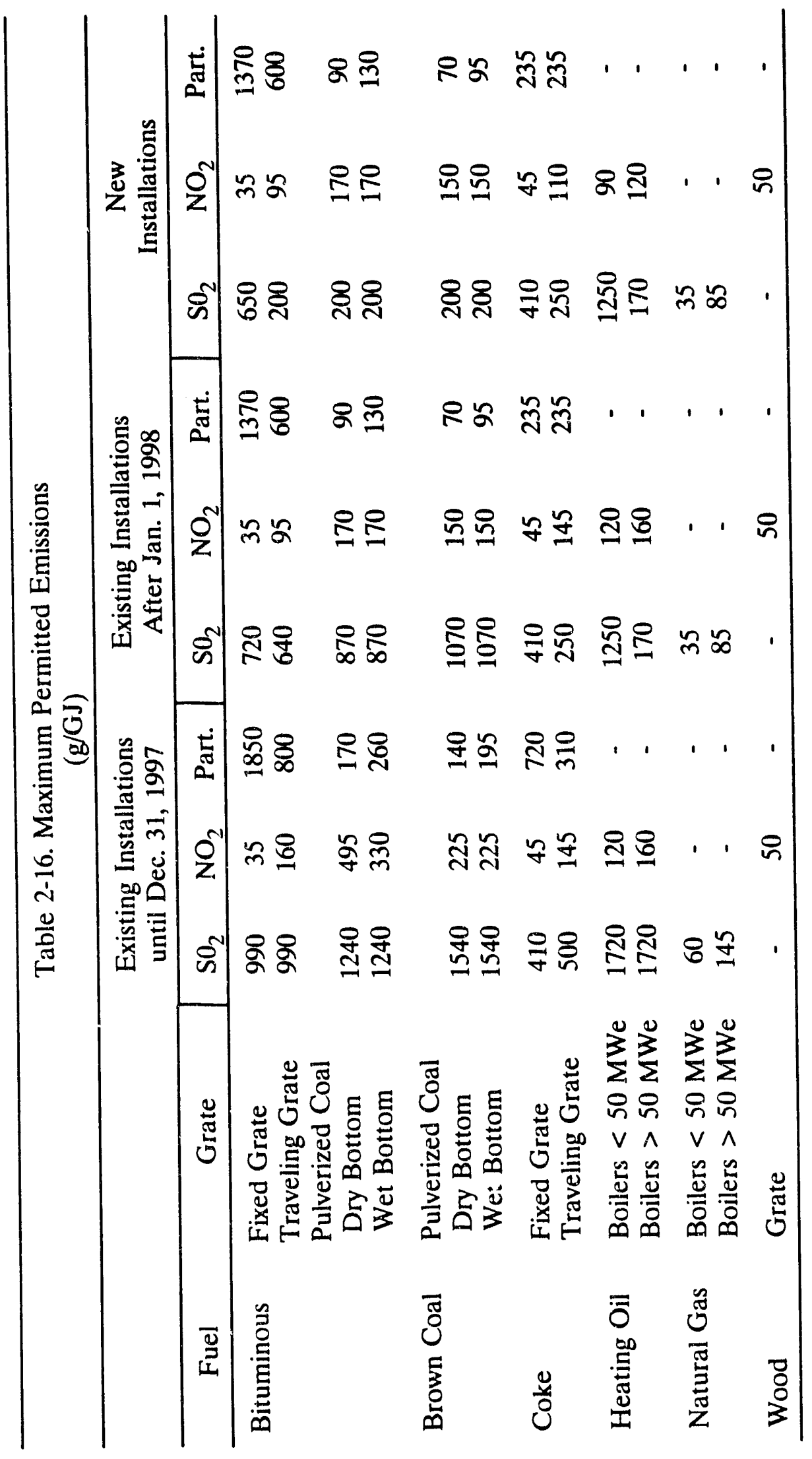


Regulations are currently in transition. In December of 1991, a new set of regulations increasing the fees was promulgated and quickly suspended. Both the existing and suspended regulations allow for a doubling of fees in seriously polluted areas, including Krakow. This provision has been appealed to the Constitutional Court. Table 2-17 shows the fees actually in effect as of December 31, 1991 as well as the fees contained in the currently suspended Order. A separate fee schedule is expected to be defined for $\mathrm{CO}_{2}$ in 1993.

Emission factors for each boiler type/fuel combination were defined by the Institute for Environment Formation in Warsaw. These are shown in Table 2-18. The regulations allow the regional offices to ignore fees of less than 2.5 million zlotys (or 5 million zlotys in the suspended Order); in practice, fees are not imposed on gas-fired equipment.

Polish analysts estimate that the total annual fee which could be collected in Krakow from low emission sources is about 23 billion zlotys (around $\$ 2$ million). This estimate uses the (lower) rates in place at the end of 1991 , the emission factors shown here, and typical boiler units from the boiler data base. The estimate also includes a doubling of the fees due to location in Krakow which, as discussed above, is no longer in force. Most of the estimated fees are from the municipal district heating company.

The analysis showed that the fee associated with burning 1 ton of coal in a fixed $g_{1}$ ate boiler is almost three times that for a larger mechanical boiler with a dedusting system. The estimated fees are from 7 to 19 percent of the price of coal, depending on the type of boiler, and about 3 percent of the cost of coke. Fees are negligible for natural gas. Further, the larger part of the fees are generally due to emissions of $\mathrm{SO}_{2}$ and benzo- $\alpha$-pyrene. Fees related to dust emissions are cnly important for large boilers. The difference in fees for small boilers with and without dedusting equipment is small, about 5,000 zlotys per $\mathrm{Mg}$ of fuel or about 300 zlotys per GJ of heat output. The small difference suggests that the fee structure would not encourage small boiler owners to add dedusting equipment.

\section{Impact on Gas Conversions in Old Town}

The total amount of fees which could have been collected from the 48 solid fuel-fired boiler houses in Old Town has been calculated to be 232 million zlotys (Ekopol 1992). This gives an average of 12,500 zlotys per $\mathrm{kW}$ capacity. Nearly 17 million zlotys of the total potential fees were not collected, by administrative decision.

The calculated fee due from a large $(1800 \mathrm{~kW})$ boiler house that has been recently converted to gas would be approximately 3 million zlotys. This is below the 5 million zloty threshhold in the proposed regulations, and would not be collected. Using an average of 1,740 zlotys per $\mathrm{kW}$ for gas boilers, gas boilers existing at the time of the boiler survey would theoretically owe a total of 58 million zlotys per year. This would not be collected under current policy. If all 48 solid fuel-fired boiler houses were converted to gas, an additional 32 million zlotys would be relinquished. These figures do not include a doubling of rates due to location in Krakow. 
Table 2-17. Air Pollution Fee Rates

Fees valid as of December 31, 1991:

\begin{tabular}{lr}
\hline \multicolumn{1}{c}{ Pollutant } & Unit rate $(\mathrm{Zl} / \mathrm{kg})$ \\
\hline Dust (total) & 180 \\
Sulphur dioxide & 680 \\
Nitrogen oxides (dioxide) & 680 \\
Carbon monoxide & 25 \\
Soot & 1,800 \\
Benzo- $\alpha$-pyrene & $1,800,000$ \\
& \\
Fees in suspended Order of December 21, 1991: & \\
\hline \multicolumn{1}{c}{ Pollutant } & Unit rate $(\mathrm{Zl} / \mathrm{kg})$ \\
\hline Dust (total) & 600 \\
Sulphur dioxide & 1,100 \\
Nitrogen oxides (dioxide) & 1,100 \\
Carbon monoxide & 300 \\
Soot & 3,000 \\
Benzo- $\alpha$-pyrene & $1,000,000$ \\
\hline
\end{tabular}

Using the fee rates in effect at the end of 1991, including a doubling of rates for Krakow, Polish analysts compared the fees for a small, fixed grate boiler with no cyclones burning either coal or coke and a gas-fired boiler. These are shown in Table 2-19.

It is likely that the fee rates will be increased by about 60 to 80 percent, but if the doubling of rates for Krakow and Katowice is not reinstated, these areas will actually see a decrease in rates.

The Polish analysts conclude that the fees are too small to encourage owners to convert to gas. The fee system will be further analyzed in future analysis activities. 
Table 2-18. Emission Factors for Fee Calculation

\begin{tabular}{|l|c|c|c|c|}
\hline \multicolumn{1}{|c|}{ a) coal, mechanical grate boilers } \\
\hline Pollutant & Unit & over $12 \mathrm{MW}$ & $3-12 \mathrm{MW}$ & below 3 MW \\
\hline sulphur dioxide & $\mathrm{kg} / \mathrm{Mg} \%$ & 17 & 16 & 16 \\
\hline nitrogen dioxide & $\mathrm{g} / \mathrm{GJ}$ & 160 & 160 & 160 \\
\hline carbon monoxide & $\mathrm{kg} / \mathrm{Mg}$ & 1.0 & 2.5 & 5.0 \\
\hline benzo- $\alpha$-pyrene & $\mathrm{kg} / \mathrm{Mg}$ & 0.0004 & 0.0016 & 0.0032 \\
\hline dust (total) & $\mathrm{kg} / \mathrm{Mg} \%$ & 3.0 & 2.5 & 2.0 \\
\hline soot & $\mathrm{kg} / \mathrm{Mg}$ & 0.0020 & 0.0040 & 0.0200 \\
\hline
\end{tabular}

\begin{tabular}{||l|c|c|c||}
\hline b) coal, fixed grate boilers & Unit & $\begin{array}{c}\text { Gravitation } \\
\text { Draught }\end{array}$ & Forced Draught \\
\hline Pollutant & $\mathrm{kg} / \mathrm{Mg} \%$ & 16 & 16 \\
\hline sulphur dioxide & $\mathrm{g} / \mathrm{GJ}$ & 35 & 35 \\
\hline nitrogen dioxide & $\mathrm{kg} / \mathrm{Mg}$ & 45 & 45 \\
\hline carbon monoxide & $\mathrm{kg} / \mathrm{Mg}$ & 0.020 & 0.020 \\
\hline benzo- $\alpha$-pyrene & $\mathrm{kg} / \mathrm{Mg} \%$ & 1.5 & 2.0 \\
\hline dust (total) & $\mathrm{kg} / \mathrm{Mg}$ & 0.050 & 0.050 \\
\hline soot & & & \\
\hline
\end{tabular}

NOTES: Values are for installations without sedimentation chambers.

If test data are not available, assumed values for coal are:
sulphur content
$1.5 \%$
ash content
$15.0 \%$
calorific value
$0.023 \mathrm{GJ} / \mathrm{kg}$

c) coke, fixed grate boilers

All emissions as in b), except no emissions of benzo- $\alpha$-pyrene and soot.

NOTE: If test data are not available, assumed values for coke are:
sulphur content
$1.0 \%$
ash content
$10.0 \%$
calorific value
$0.029 \mathrm{GJ} / \mathrm{kg}$ 


\begin{tabular}{|c|c|c|c|c|c|}
\hline Fuel & $\begin{array}{l}\text { Calorific } \\
\text { Value } \\
\text { (GJ/unit) }\end{array}$ & $\begin{array}{c}\text { Combustion } \\
\text { Efficiency } \\
(\%)\end{array}$ & $\begin{array}{c}\text { Heat } \\
\text { Output } \\
\text { (GJ/unit) }\end{array}$ & $\begin{array}{l}\text { Fee Rate } \\
\text { (Z1/unit) }\end{array}$ & $\begin{array}{c}\text { Fee Rate } \\
\text { Factor } \\
(\mathrm{Zl} / \mathrm{GJ}) \\
\end{array}$ \\
\hline Coal & 23 & 70 & 16.1 & 116,358 & 7,221 \\
\hline Coke & 29 & 70 & 20.3 & 30,770 & 1,516 \\
\hline Gas & 46 & 83 & 38.2 & 3,945 & 102 \\
\hline Fuel u & $1,1 \mathrm{Mg}$ & al Gas, 10 & & & \\
\hline
\end{tabular}

\section{References}

Ekopol. 1991. "Low Emission - Subject I/2.3." Krakow, Poland.

Ekopol. 1992. "American-Polish Program of Actions in the Field of Elimination of Low Emission Sources in Cracow. Subproject 2. Replacement of solid fuel boiler-houses with gas boiler-houses in the "Old City" area. Task 2.3.3. Elaboration of calculations of fees and penalties to be paid by the user of solid fuel boiler-house because of the emission of atmosphere pollutions basing on the rules in force." Cracow Development Office, Cracow, Poland.

International Energy Agency, 1991. Energy Policies Poland, 1990 Survey, OECD/IEA, Paris, France. 


\section{DISCUSSION}

The information gathering phase of the Krakow Clean Fossil Fuels and Energy Efficiency Program consists of 5 subprojects. These are:

- district heating;

- replacement with gas heating;

- electric heating;

- boilerhouses; and

- home stoves.

Each of these has testing, engineering analysis, and incentive analysis components. The district heating subproject is not being managed by Brookhaven National Laboratory and is not included in this report.

Chapter 2 presented results to date of tasks that are currently underway or have been completed. This chapter provides a discussion of those results in the context of the overall program. It draws conclusions where possible and outlines the work remaining to be done and its schedule. The current project schedule calls for completion of these activities in the fall of 1993.

\section{TESTING}

There are more than 2,900 boilers in Krakow's boilerhouses. Most of these supply heat to more than one building; altogether they provide about 35 percent of the heating needs of the city. About 77 percent of the boilers, representing 86 percent of the capacity and almost 90 percent of the fuel use, are solid-fuel fired. More than 387,000 tons of coal and coke are consumed annually in the boilers. Home coal stoves supply about 13 percent of the energy required for heating in the city. Most of these stoves are used for heating in the historic buildings in the Old Town area of Krakow. These boilers and stoves are the focus of this program.

The testing program is designed to determine the actual emission levels of the boilers and stoves, with existi. $\mathrm{g}$ fuels and current operating conditions, as well as to determine the effect on emissions of changing either the fuels or operating conditions.

Four boilers are being tested, two mechanical boilers and two hand-fired. These were selected to represent the population of Krakow's boilers; the boiler survey showed the importance of the hand-fired boilers. Tests have been completed at the two mechanical boilers, both belonging to the municipal district heating system. Results from the tests at one of these boilers (Balicka) were presented in Chapter 2; results from the other (Krzeslawice) will be available by the end of 1992 .

The Balicka boiler house has no combustion controls or flue gas analysis equipment and has excessive fines in the feed. Excess air is high, efficiency is low, and maximum load cannot 
be attained with acceptable combustion. Tests showed no apparent benefit of coal cleaning on particulate levels after the cyclones. Testing at both mechanical boilers suggests that operational effects (difficulties in balancing fuel and air inputs between two grates) may be more important than differences between test fuels.

Tests at the hand-fired boilers should all be completed in 1992 and test reports available early in 1993.

Stove testing has been performed on a typical masonry stove and on a cast iron stove. The tile stoves were quite efficient, around 60 percent or better. These high efficiencies can be achieved when the stove is operated very carefully; often in practice they are not. A dramatic reduction in particulate emissions occurs with the use of briquettes; $\mathrm{CO}$ emissions are higher, however. Cast iron stoves also show a decrease in particulate emissions with the use of briquettes. The briquettes are very attractive from a smoke perspective and more work on reducing $\mathrm{CO}$ emissions with this fuel may be justified. The practice of common venting floors in Krakow apartments has led to building codes which prohibit use of stoves with fan-assisted combustion air flow; this could reduce the use of some advanced designs.

A full report on the stove testing should be available by the end of 1992 . Some additional tests, including tests of a tile stove converted to an electric thermal storage heater, are planned for the next six months.

\section{Current Emissions}

To provide a preliminary assessment of the relative importance of each of the source types an emissions comparison has been prepared; Figure 3-1 shows estimated current emissions from the boilers and stoves. These emissions are based on fuel use from the boilerhouse survey and a combination of emission factors from the testing activity of this project and EPA emission factors. Test results are used for the coal stove emissions and for the semivolatile organics; EPA factors are used elsewhere because they represent the range of boiler test results.

The figure shows that the home stoves are responsible for almost two-thirds of the semivolatile organics, about half of the particulate emissions, over 40 percent of the $N O_{x}$ emissions, and almost one-third of the CO. Hand-fired boilers contribute just over 60 percent of the $\mathrm{CO}$ and almost 30 percent of the semi-volatile organics. Mechanical boilers are an important $\mathrm{NO}_{\mathrm{x}}$ source; $\mathrm{SO}_{2}$ emissions are not shown and are directly dependent on the sulfur content of the fuel and the : nount burned. These results will be updated as more testing results become available.

\section{ENGINEERING ANALYSES}

Engineering studies on gas conversion in the Old Town area have been completed, as discussed in Chapter 2. Polish analysts recommend that upgrading and modernization of the 


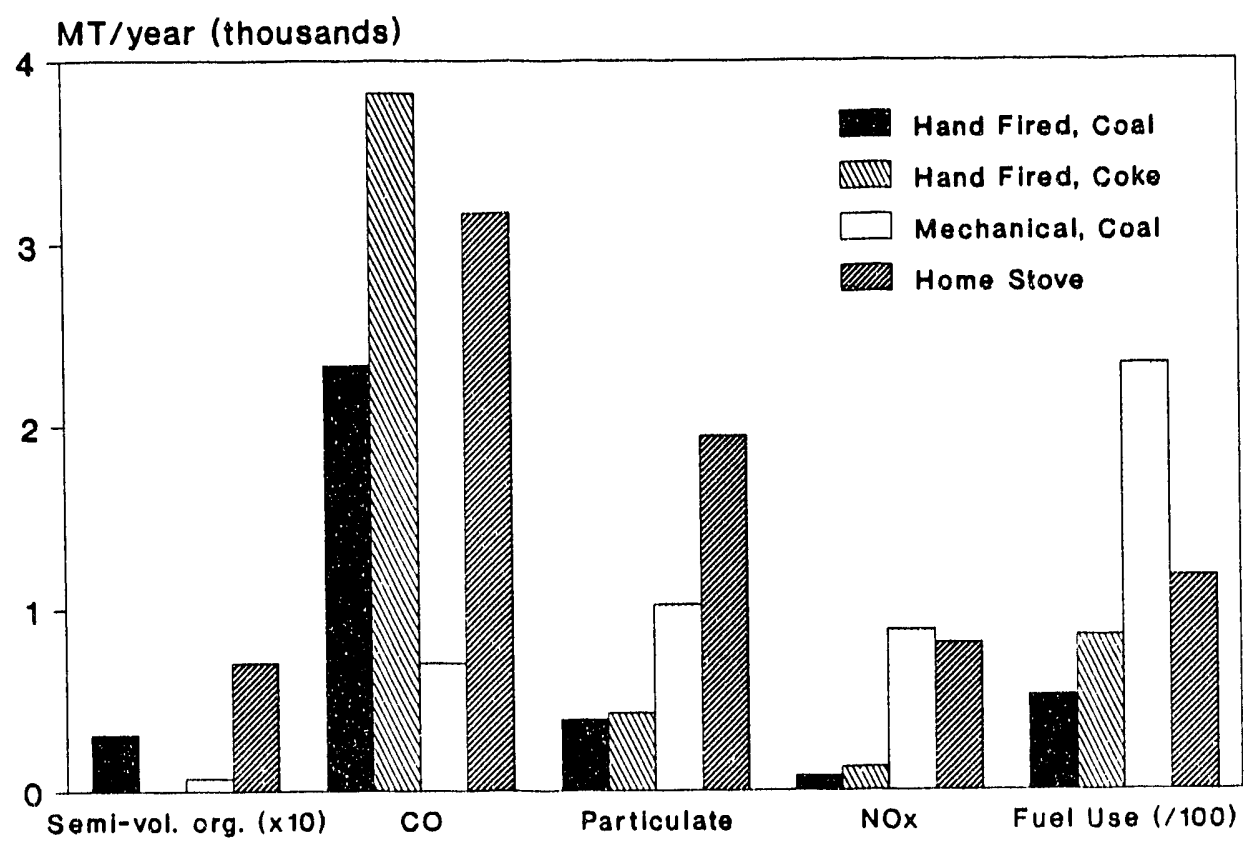

Figure 3-1. Estimated Current Emissions, by Equipment Type

distribution system be done by one organization; individual boiler house owners do not have the means for such an undertaking.

Studies of electric conversion are expected to be completed by the end of 1992 . A design study, addressing the modernization of the boiler house at Krzesławice, is being performed by Burns and Roe Engineering Co. in cooperation with Polish groups, and should be completed in the first quarter of 1993.

\section{INCENTIVES ANALYSES}

The objective of the incentive analysis activities is to evaluate different types and levels of incentives that the municipal government could implement to encourage the adoption of the various options under consideration for improving the air quality in Krakow. This work is being performed by Polish analysts under the direction of BNL.

Evaluation of possible incentives relies on results from other parts of the program. Emission levels from the testing activities will help identify options which are worthwhile. Cost estimates from engineering studies, along with fuel price projections, will provide the basis for an economic evaluation and the determination of required levels of incentives. Public survey results will provide price elasticities as well as estimates of participation to be expected from different incentive levels.

Incentives will be designed and evaluated for fue! and equipment manufacturing, energy 
distribution, and end use options, as appropriate for each subproject. Options currently under consideration include: converting solid fuel-fired boilers to natural gas; use of electric inserts in existing coal stoves; installation of new meters for alternative electric rate structures; use of different fuels in existing or new coal stoves; use of processed fuels (briquettes) in boilers; and use of new combustion technologies in boilers. This list will be expanded or narrowed as results from other project activities become available.

Financial, legal and institutional incentives will be evaluated for each option, as appropriate. Incentives under consideration include: income or property tax credits to encourage investments in equipment or for clean fuel producers and suppliers; legal requirements for fuel switching or modernization during renovation; discounted off-peak electric rates; release of import taxes on imported equipment used in the program; regulation of coal suppliers; and legal requirements for pollution abatement equipment.

Some of the specific tasks associated with incentives analysis have been completed. Fuel price trajectories have been prepared, and are summarized in Chapter 2. An evaluation of the current system of fees and penalties for emission of air pollutants has been completed; preliminary conclusions are that the fees in the current system are too small to encourage fuel-switching or modernization activities. The remainder of the incentive analysis activities are scheduled to be completed in 1993.

A Polish report on the first parts of the public survey work will be completed early in 1993. The final report will be available at the end of the project. Air quality analysis will be undertaken in 1993 and results will be included in the project's final report. 

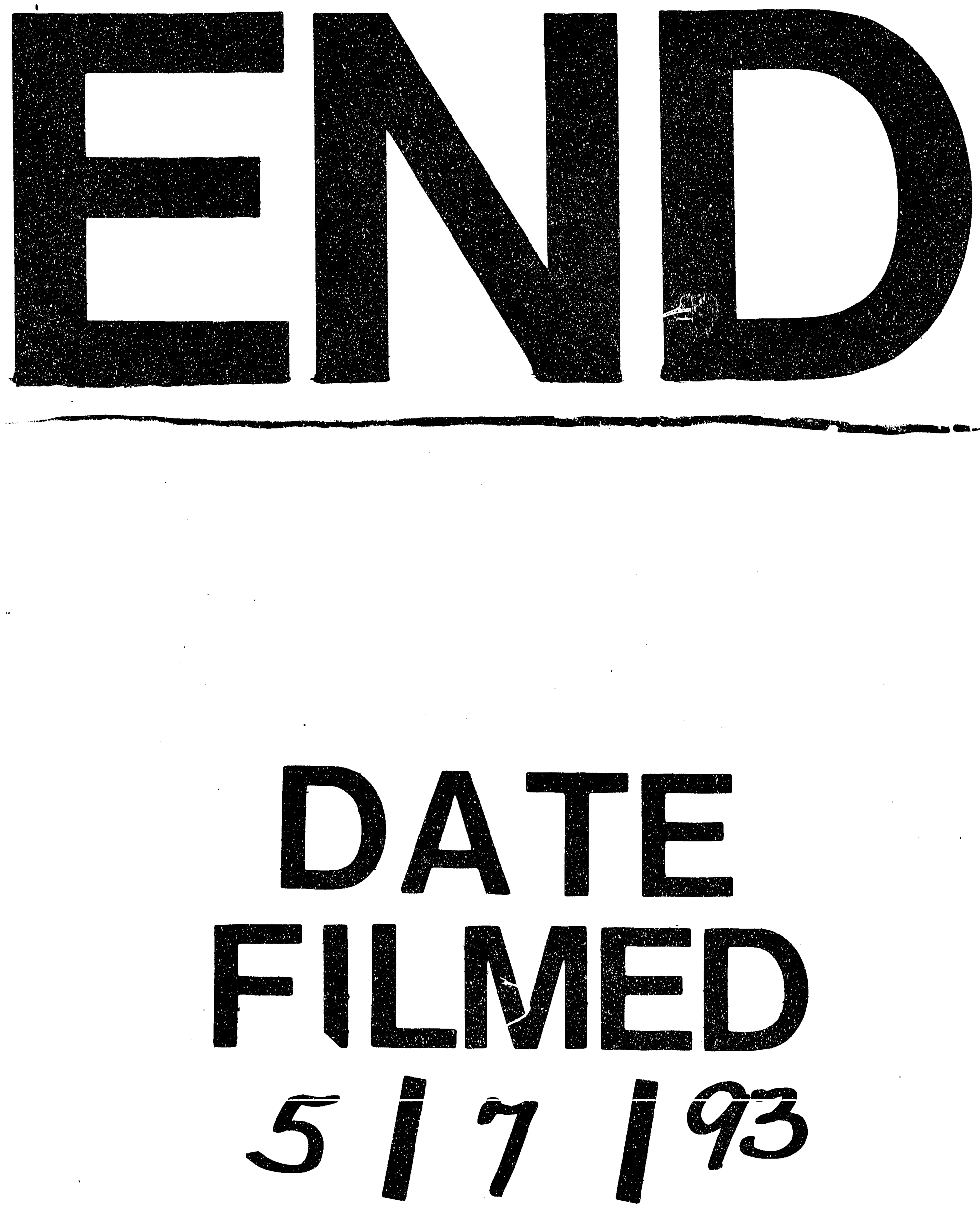


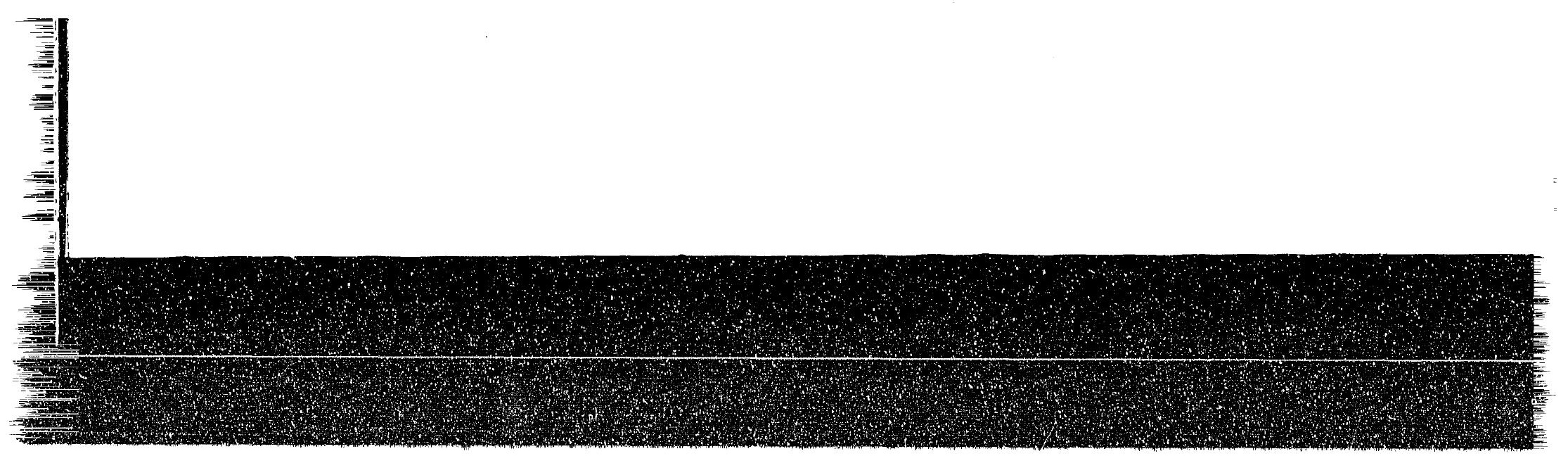

